\title{
Cardiac testing for coronary artery disease in potential kidney transplant recipients (Review)
}

Wang LW, Fahim MA, Hayen A, Mitchell RL, Baines L, Lord S, Craig JC, Webster AC

Wang LW, Fahim MA, Hayen A, Mitchell RL, Baines L, Lord S, Craig JC, Webster AC.

Cardiac testing for coronary artery disease in potential kidney transplant recipients.

Cochrane Database of Systematic Reviews 2011, Issue 12. Art. No.: CD008691.

DOI: 10.1002/14651858.CD008691.pub2.

www.cochranelibrary.com 
HEADER 1

ABSTRACT

PLAIN LANGUAGE SUMMARY

SUMMARY OF FINDINGS

BACKGROUND

OBJECTIVES

METHODS

RESULTS

Figure 1.

Figure 2.

Figure 3.

Figure 4.

Figure 5.

Figure 6.

Figure 7.

Figure 8.

Figure 9.

DISCUSSION

Figure 10.

AUTHORS' CONCLUSIONS

ACKNOWLEDGEMENTS

REFERENCES

CHARACTERISTICS OF STUDIES

DATA

Test 1. DSE.

Test 2. MPS.

Test 3. EST.

Test 4. EBCT.

Test 5. DSF.

Test 6. EV.

Test 7. CIMT.

Test 8. Echo (RWMA).

Test 9. Echo (LV).

Test 10. Echo (MAC).

Test 11. ECG.

ADDITIONAL TABLES

APPENDICES

CONTRIBUTIONS OF AUTHORS

DECLARATIONS OF INTEREST

SOURCES OF SUPPORT

DIFFERENCES BETWEEN PROTOCOL AND REVIEW

NOTES

INDEX TERMS

\section{TABLE OF CONTENTS}


[Diagnostic Test Accuracy Review]

\section{Cardiac testing for coronary artery disease in potential kidney transplant recipients}

Louis W Wang1,2, Magid A Fahim³ ${ }^{3}$ Andrew Hayen 4 , Ruth L Mitchell 5 , Laura Baines 6 , Stephen Lord7, Jonathan C Craig2,5, Angela C Webster $2,5,8$

1Department of Cardiology, St Vincent's Hospital, Darlinghurst, Australia. 2Sydney School of Public Health, University of Sydney, Sydney, Australia. ${ }^{3}$ Department of Nephrology, Princess Alexandra Hospital, Brisbane, Australia. ${ }^{4}$ Screening and Test Evaluation Program (STEP), Sydney School of Public Health, University of Sydney, Sydney, Australia. ${ }^{5}$ Cochrane Renal Group, Centre for Kidney Research, The Children's Hospital at Westmead, Westmead, Australia. ${ }^{6}$ Renal Services, Newcastle upon Tyne Hospitals NHS, Newcastle upon Tyne, UK. ${ }^{7}$ Cardiology Services, Newcastle upon Tyne Hospitals NHS, Newcastle upon Tyne, UK. ${ }^{8}$ Centre for Transplant and Renal Research, Westmead Millennium Institute, University of Sydney at Westmead, Westmead, Australia

Contact address: Louis W Wang, Department of Cardiology, St Vincent's Hospital, Darlinghurst, NSW, 2010, Australia. louis.w.wang@gmail.com.

Editorial group: Cochrane Kidney and Transplant Group.

Publication status and date: New, published in Issue 12, 2011.

Citation: Wang LW, Fahim MA, Hayen A, Mitchell RL, Baines L, Lord S, Craig JC, Webster AC. Cardiac testing for coronary artery disease in potential kidney transplant recipients. Cochrane Database of Systematic Reviews 2011, Issue 12. Art. No.: CD008691. DOI: 10.1002/14651858.CD008691.pub2.

Copyright $\odot 2011$ The Cochrane Collaboration. Published by John Wiley \& Sons, Ltd.

\section{A B S T R A C T}

\section{Background}

Patients with chronic kidney disease (CKD) are at increased risk of coronary artery disease (CAD) and adverse cardiac events. Screening for $C A D$ is therefore an important part of preoperative evaluation for kidney transplant candidates. There is significant interest in the role of non-invasive cardiac investigations and their ability to identify patients at high risk of CAD.

\section{Objectives}

We investigated the accuracy of non-invasive cardiac screening tests compared with coronary angiography to detect CAD in patients who are potential kidney transplant recipients.

\section{Search methods}

MEDLINE and EMBASE searches (inception to November 2010) were performed to identify studies that assessed the diagnostic accuracy of non-invasive screening tests, using coronary angiography as the reference standard. We also conducted citation tracking via Web of Science and handsearched reference lists of identified primary studies and review articles.

\section{Selection criteria}

We included in this review all diagnostic cross sectional, cohort and randomised studies of test accuracy that compared the results of any cardiac test with coronary angiography (the reference standard) relating to patients considered as potential candidates for kidney transplantation or kidney-pancreas transplantation at the time diagnostic tests were performed.

\section{Data collection and analysis}

We used a hierarchical modelling strategy to produce summary receiver operating characteristic (SROC) curves, and pooled estimates of sensitivity and specificity. Sensitivity analyses to determine test accuracy were performed if only studies that had full verification or applied a threshold of $\geq 70 \%$ stenosis on coronary angiography for the diagnosis of significant CAD were included. 


\section{Main results}

The following screening investigations included in the meta-analysis were: dobutamine stress echocardiography (DSE) (13 studies), myocardial perfusion scintigraphy (MPS) (nine studies), echocardiography (three studies), exercise stress electrocardiography (two studies), resting electrocardiography (three studies), and one study each of electron beam computed tomography (EBCT), exercise ventriculography, carotid intimal media thickness (CIMT) and digital subtraction fluorography (DSF). Sufficient studies were present to allow hierarchical summary receiver operating characteristic (HSROC) analysis for DSE and MPS. When including all available studies, both DSE and MPS had moderate sensitivity and specificity in detecting coronary artery stenosis in patients who are kidney transplant candidates [DSE (13 studies) - pooled sensitivity 0.79 ( $95 \% \mathrm{Cl} 0.67$ to 0.88 ), pooled specificity 0.89 ( $95 \% \mathrm{Cl} 0.81$ to 0.94 ); MPS (nine studies) pooled sensitivity $0.74(95 \% \mathrm{Cl} 0.54$ to 0.87$)$, pooled specificity $0.70(95 \% \mathrm{Cl} 0.51$ to 0.84$)]$. When limiting to studies which defined coronary artery stenosis using a reference threshold of $\geq 70 \%$ stenosis on coronary angiography, there was little change in these pooled estimates of accuracy [DSE (9 studies) - pooled sensitivity 0.76 ( $95 \% \mathrm{Cl} 0.60$ to 0.87 ), specificity 0.88 ( $95 \% \mathrm{Cl} 0.78$ to 0.94$)$; MPS (7 studies) - pooled sensitivity $0.67(95 \% \mathrm{Cl} 0.48$ to 0.82$)$, pooled specificity $0.77(95 \% \mathrm{Cl} 0.61$ to 0.88$)$ ]. There was evidence that DSE had improved accuracy over MPS ( $P=0.02)$ when all studies were included in the analysis, but this was not significant when we excluded studies which did not avoid partial verification or use a reference standard threshold of $\geq 70 \%$ stenosis $(P=0.09)$.

\section{Authors' conclusions}

DSE may perform better than MPS but additional studies directly comparing these cardiac screening tests are needed. Absence of significant CAD may not necessarily correlate with cardiac-event free survival following transplantation. Further research should focus on assessing the ability of functional tests to predict postoperative outcome.

\section{PLAIN LANGUAGESUMMARY}

\section{[Summary title]}

[Summary text] 


\section{SUMMARY OF FINDINGS}

\section{Summary of findings 1 . Summary of results}

\section{Summary of results: Results of studies on cardiac testing in kidney transplant candidates}

Review question: Comparison of non-invasive cardiac screening tests with coronary angiography for the detection of significant CAD in potential kidney transplant recipients

Patient population: Kidney transplant candidates undergoing pre-transplant cardiac evaluation

Setting: Investigations performed in hospital or in an outpatient setting

Geographical location: Studies were conducted in USA (12 studies), Brazil (4 studies), India, (3 studies) the UK (3 studies), Australia (1 study), Canada (1 study), and Spain (1 study)

Index test : Any non- or minimally invasive test used to assess risk of CAD.

\section{Reference standard: Coronary angiography}

Included studies: DSE (13 studies; 745 participants), MPS (9 studies; 582 participants), EST (2 studies; 129 participants), EBCT (1 study; 97 participants), DSF (1 study; 86 participants), exercise ventriculography (1 study; 35 participants), CIMT (1 study; 105 participants), resting wall motion abnormality on echocardiography (2 studies; 265 participants), left ventricular dysfunction on echocardiography ( 1 study; 52 participants), mitral annular calcification on echocardiography (1 study; 125 participants), resting ECG (3 studies; 263 participants).

\section{Limitations}

Only DSE and MPS were evaluated in detail, although these also had only a limited number of included comparisons with small sample sizes. No studies were found investigating cardiopulmonary exercise testing, CT coronary angiography, magnetic resonance angiography or cardiac magnetic resonance imaging. Fewer than five studies were found for each of EBCT, resting ECG, conventional echocardiography, exercise ventriculography, DSF and CIMT. Sparse directly comparative data also resulted in low power to detect important differences in accuracy between tests.

Significant heterogeneity was present among studies investigating the same screening test. Although differences in study population characteristics (e.g. prevalence of chest pain) and test application (diagnostic test threshold, criteria for positive test, choice of stress agent and stress protocol, and operator variability) likely contributed to heterogeneity, we were hindered from estimating their contributions because of relatively sparse data, which resulted in low power.

Partial verification, where not all patients who received screening tests also received coronary angiography, occurred in 5/25 comparisons. This may have affected estimates of sensitivity and specificity.

Two different reference standard thresholds ( $\geq 70 \%$ stenosis or $\geq 50 \%$ stenosis) were used in the included studies, with most studies only using one reference standard threshold or the other. An overall analysis pooling the results of all studies regardless of threshold may introduce additional heterogeneity due to a threshold effect.

\begin{tabular}{lll}
\hline Results & & MPS \\
\hline Test & DSE & 9 \\
\hline Number of studies [all studies] & 13 & 582 \\
\hline Number of participants [all studies] & 745 & $0.74(0.54$ to 0.87$)$ \\
\hline Pooled sensitivity $(95 \% \mathrm{Cl})$ [all studies] & $0.79(0.67$ to 0.88$)$ & $0.70(0.51$ to 0.84$)$ \\
\hline Pooled specificity $(95 \% \mathrm{Cl})$ [all studies] & $0.89(0.81$ to 0.94$)$ & 7 \\
\hline Number of studies [ $\geq 70 \%$ stenosis] & 9 & \\
\hline
\end{tabular}




\begin{tabular}{|c|c|c|}
\hline Number of participants [ $\geq 70 \%$ stenosis] & 668 & 517 \\
\hline Pooled sensitivity $(95 \% \mathrm{Cl})[\geq 70 \%$ stenosis $]$ & $0.76(0.60$ to 0.87$)$ & 0.67 (0.48 to 0.82$)$ \\
\hline Pooled specificity (95\% CI) [ $\geq 70 \%$ stenosis] & 0.88 (0.78 to 0.94$)$ & 0.77 (0.61 to 0.88$)$ \\
\hline $\begin{array}{l}\text { Number of false diagnoses of } \leq 70 \% \text { coronary artery stenosis in a standard } \\
\text { population of } 100 \text { patients (false negative rate) }\end{array}$ & $\begin{array}{l}24 \text { (13 to } 40) \\
\text { per } 100\end{array}$ & $\begin{array}{l}33 \text { (18 to } 52) \\
\text { per } 100\end{array}$ \\
\hline $\begin{array}{l}\text { Number of false diagnoses of } \geq 70 \% \text { coronary artery stenosis in a standard } \\
\text { population of } 1000 \text { patients (false positive rate) }\end{array}$ & $\begin{array}{l}12 \text { (6 to } 22 \text { ) } \\
\text { per } 100\end{array}$ & $\begin{array}{l}23 \text { (12 to } 39) \\
\text { per } 100\end{array}$ \\
\hline Positive likelihood ratio [ $\geq 70 \%$ stenosis] $(95 \% \mathrm{Cl})$ & $6.44(3.03$ to 13.70$)$ & 2.89 (1.39 to 5.99$)$ \\
\hline Negative likelihood ratio [ $\geq 70 \%$ stenosis] $(95 \% \mathrm{CI})$ & $0.26(0.13$ to 0.50$)$ & $0.43(0.23$ to 0.80$)$ \\
\hline $\begin{array}{l}\text { Post test probability after positive screening test result for a patient with low } \\
\text { risk ( } 10 \% \text { to } 29 \% \text { pre test probability) disease }\end{array}$ & $42 \%$ to $72 \%$ & $24 \%$ to $54 \%$ \\
\hline
\end{tabular}

Post test probability after positive screening test result for a patient with inter-
mediate risk ( $30 \%$ to $59 \%$ pre test probability) disease $90 \%$

Post test probability after positive screening test result for a patient with high $\quad 91 \%$ to $98 \%$
risk ( $60 \%$ to $90 \%$ pre test probability) disease

Post test probability after negative screening test result for a patient with low $\quad 3 \%$ to $10 \% \quad 5 \%$ to $15 \%$ risk ( $10 \%$ to $29 \%$ pre test probability) disease

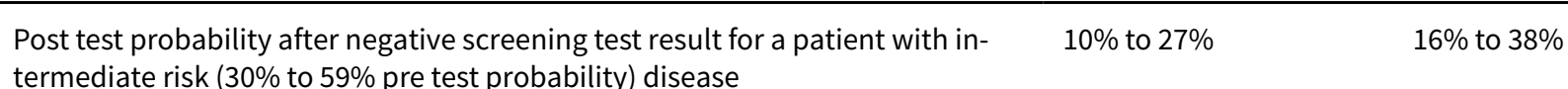
termediate risk ( $30 \%$ to $59 \%$ pre test probability) disease

Post test probability after negative screening test result for a patient with high $\quad 28 \%$ to $70 \%$
risk ( $60 \%$ to $90 \%$ pre test probability) disease

\section{Conclusions and comments}

Both tests, especially DSE, have a role as triage tests for intermediate risk transplant candidates, with negative results precluding the need for further evaluation with coronary angiography, thereby avoiding unnecessary risk to patients and potentially reducing healthcare costs.

Given the wide heterogeneity in the estimates for both DSE and MPS, there is still considerable uncertainty in the true post-test probabilities of each test.

Current evidence suggests that, where feasible, DSE should be used as the screening investigation of choice over MPS.

\section{Applicability of tests in clinical practice}

Both DSE and MPS have a role as triage tests for the intermediate risk transplant candidates, with negative results reducing the need for further evaluation with coronary angiography. In high risk patients, a positive non-invasive DSE or MPS confirms the high risk of severe CAD, but a negative result does not conclusively rule out severe CAD. In these patients, one may consider proceeding immediately to coronary angiography and avoid using functional tests.

The relatively low sensitivity and specificity of both DSE and MPS however means that they are not perfect triage tests and a significant number of patients will either have their significant CAD missed (false negatives) or be referred in vain for coronary angiography (false positive). 
Despite the shortcomings of the non-invasive tests in their role as triage tests, the very select nature of the population and the unique challenges facing cardiac investigation in this population (particularly, the need to avoid complications arising from an invasive gold standard) and the lack of an alternate better performing test means that we are forced to accept an imperfect triage test.

Functional testing may provide additional prognostic information, although an investigation into this was not included under the scope of this review.

\section{Costs}

None of the studies included a cost-effectiveness evaluation. MPS is known to be more expensive than DSE, although both are less expensive than the reference standard, coronary angiography.

CAD - coronary artery disease; $\mathrm{Cl}$ : confidence interval; CIMT: carotid intimal medial thickness; DSE: Dobutamine stress echocardiography; MPS: Myocardial perfusion scintigraphy 


\section{B A C K G R O U N D}

Kidney transplantation remains the best treatment for patients with end-stage kidney disease (ESKD) in terms of prolonging survival and improving quality of life. However, research has shown that transplantation causes significant cardiovascular stress around the time of the operation, and the incidence of myocardial infarction has been estimated to be approximately 5\% (Gunnarsson 1984; Lentine 2005). Cardiovascular disease accounts for almost half ( $40 \%$ to $55 \%$ ) of all deaths following kidney transplantation (Briggs 2001). Screening for coronary artery disease (CAD) is therefore an important part of evaluation for kidney transplantation and a key decision tool to identify which patients need specialised heart imaging tests (coronary angiography) and when. Clinical practice varies considerably in how patients are selected for testing; some centres test only those patients with significant risk factors, others test all kidney transplant candidates; and in which screening test is used (Hofmann 2008). The studies we reviewed used tests such as dobutamine stress echocardiography (DSE), myocardial perfusion scintigraphy (MPS) and stress electrocardiography (EST) versus radiographic tests such as calcium scoring, among others (Hofmann 2008).

Clinical practice guidelines from the American Society of Transplantation (Kasiske 2001), United Kingdom Renal Association (Dudley 2008) and Canadian Society of Transplantation (Knoll 2005) advise cardiac stress testing in potential transplant recipients who have symptoms or significant risk factors, but do not recommend a particular screening test. The guidelines indicate that the test should be determined by local availability and expertise. Although various screening tests for CAD are available, it remains unclear which tests perform best for patients with ESKD.

\section{Target condition being diagnosed}

The target condition was significant CAD in potential kidney transplant recipients. We defined significant $C A D$ as the presence of at least $50 \%$ stenosis in at least one epicardial coronary artery detected on coronary angiography.

\section{Index test(s)}

Any non- or minimally invasive test used to assess risk of CAD. These included:

- Stress echocardiography (using either exercise or pharmacological stress, such as DSE)

- MPS using either exercise or pharmacological stress

- EST

- Electron beam computed tomography (EBCT)

- Resting electrocardiography (ECG)

- Conventional echocardiography

- Exercise ventriculography

- Digital subtraction fluorography (DSF)

- Carotid intimal medial thickness (CIMT)

- Cardiopulmonary exercise testing

- Computed tomography (CT) coronary angiography

- Magnetic resonance angiography

- Cardiac magnetic resonance imaging.

\section{Rationale}

Severe CAD is strongly associated with the risk of myocardial infarction (MI) (Alderman 1993; Manoharan 2009). Non-invasive cardiac screening tests may enable identification of kidney transplant candidates who are at high risk of significant CAD. Such tests are therefore useful in triaging patients for coronary angiography, a test that provides confirmation of diagnosis and opportunity for timely intervention (endovascular or open surgical intervention, and aggressive risk factor modification, or both). There is significant controversy about which tests should be used in the screening process (Hofmann 2008). Although coronary angiography is the gold standard for detecting coronary artery stenosis, it is invasive, costly, and carries risk of nephrotoxicity, arrhythmia, MI, stroke and femoral artery injury. Although anatomical depiction derived from coronary angiography is a valuable diagnostic asset, the test does not provide perfusion or contractility information when the heart is under physiological stress. Non-invasive investigations such as DSE and MPS have moderate sensitivity and specificity in detecting significant CAD in the general population (Fleischmann 1998; Schinkel 2003). The applicability of these results in patients with ESKD who are potential kidney transplant recipients is however uncertain. Common comorbidities among patients with chronic kidney disease (CKD) are hypertension, cardiomyopathy, calcific vascular disease and atherosclerosis. Compared with the general population, these comorbidities may influence diagnostic test performance in people with CKD.

\section{OB JECTIVES}

We investigated the diagnostic accuracy of non-invasive cardiac screening tests versus coronary angiography in potential kidney transplant recipients. We provided summary estimates of diagnostic accuracy for individual index tests to better understand the utility and limitations of these non-invasive tests.

\section{Secondary objectives}

We compared the diagnostic accuracy among different screening tests through:

1. Direct comparison: By analysing the results of studies that assessed diagnostic accuracy of two or more tests in the same population head-to-head.

2. Indirect comparison: By comparing the pooled results of studies that assessed accuracy of screening tests in separate populations.

The ability of screening tests to detect severe coronary artery stenosis ( $\geq 70 \%$ stenosis detected on coronary angiography) was also assessed and compared among different screening tests.

\section{Investigation of sources of heterogeneity}

We also investigated if diagnostic accuracy varied among studies with different prevalence of symptomatic chest pain and analysed the effect. For this analysis, we included only studies that used a threshold of $\geq 70 \%$ stenosis on coronary angiography for the diagnosis of CAD. To avoid partial verification, we considered effects among study participants who underwent both the index test and coronary angiography. This methodology meant that we were able to avoid partial verification. 


\section{METHODS}

\section{Criteria for considering studies for this review \\ Types of studies}

We included all diagnostic cross sectional studies, cohort studies and randomised studies of test accuracy that compared cardiac test accuracy with results obtained from coronary angiography (the reference standard).

\section{Participants}

Study participants included all patients who were considered to be potential candidates for kidney transplantation or kidney-pancreas transplantation at the time the diagnostic tests were performed.

\section{Inclusion criteria}

We included studies reporting outcomes relating to patients considered to be potential candidates for kidney transplantation or kidney-pancreas transplantation at the time diagnostic tests were performed. To ensure that our review was accessible and succinct, we chose to limit the population to patients with CKD who were considered candidates for kidney transplantation, but included all possible tests used to diagnose CAD.

\section{Exclusion criteria}

Studies were excluded if they did not explicitly state that all study participants were candidates for kidney transplantation. We also excluded studies that investigated cardiac test accuracy in patients with ESKD who were not transplant candidates (i.e. they were unselected dialysis patients, not undergoing pre-transplant assessment). Patients with ESKD who are not transplantation candidates differ from patients who are transplant candidates with respect to several key prognostic variables, such as age and fitness for surgery. These differences in the key prognostic variables may result in differences in disease prevalence and test performance. We also excluded studies which investigated patients with features of acute coronary syndrome as our aim was to investigate the performance of cardiac tests in a preoperative screening context. Where it appeared that only some of the study participants were transplantation candidates, we contacted the study authors requesting separate data for only transplantation candidates.

\section{Index tests}

Any non- or minimally invasive test used to assess risk of CAD. These included:

- Stress echocardiography (using either exercise or pharmacological stress, e.g. DSE)

- MPS using either exercise or pharmacological stress

- EST

- $\mathrm{EBCT}$

- ECG

- Conventional echocardiography

- Exercise ventriculography

- DSF

- CIMT

- Cardiopulmonary exercise testing

- CT coronary angiography

- Magnetic resonance angiography

\section{- Cardiac magnetic resonance imaging.}

Information regarding the various index tests including the type of result produced, if cut-off values were present, and how differences in cut-off points were handled, is provided in Table 1.

\section{Comparator tests}

Any of the listed index tests where they were compared with each other versus the reference standard of coronary angiography.

\section{Target conditions}

Coronary artery stenosis was defined as at least 50\% narrowing in at least one epicardial coronary artery on coronary angiography. We defined severe coronary artery stenosis as $\geq 70 \%$ stenosis on coronary angiography.

\section{Reference standards}

Coronary angiography.

\section{Search methods for identification of studies}

\section{Electronic searches}

We searched the following resources.

- MEDLINE (OvidSP) 1950 - 1 November 2010

- EMBASE (OvidSP) 1980 - November 2010, Week 44

A Trials Search Co-ordinator of the Cochrane Renal Group (RM) formulated specific search strategies for the MEDLINE and EMBASE searches ( Appendix 1).

Citation tracking was performed using Web of Science. No restrictions were imposed in terms of language of publication or publication status. To maximise the sensitivity of our search, we avoided the use of methodology filters when searching for diagnostic accuracy studies because even the most sensitive filters have been found to miss relevant studies (de Vet 2008; Doust 2005).

\section{Searching other resources}

We handsearched the reference lists of all primary studies and reviews identified by the initial search.

\section{Data collection and analysis}

\section{Selection of studies}

Two authors independently reviewed the search results, first by title and abstract, and where necessary by review of full text of the study report, to determine inclusion or exclusion. Resulting sets of citations for inclusion were also compared. A third author was available to arbitrate final decisions to include or exclude.

\section{Data extraction and management}

A standardised data extraction form was used to abstract study design features and results data from each publication. For each study data were extracted independently by two authors. We extracted: year of publication, country of study, study design, clinical setting, definition of CAD (stenosis percentage on coronary angiogram), the Quality Assessment of Diagnostic Accuracy Studies (QUADAS) methodological items (Reitsma 2009), prevalence of cardiovascular risk factors in the study population (percentages of participants on haemodialysis; with ESKD, diabetes 
mellitus (DM), hypertension; who were male; with history of smoking; and symptomatic of heart disease). We also recorded the numbers of true positives, true negatives, false positives and false negatives. These data were then collated in a spreadsheet. A third author was available to adjudicate on disagreements.

\section{Assessment of methodological quality}

Methodological quality of included primary studies was assessed by two authors using a modified QUADAS tool (Smidt 2008; Whiting 2003) that included 11 of the 14 mandatory items (representative spectrum, acceptable reference standard, acceptable delay between tests, partial verification avoided, differential verification avoided, incorporation avoided, reference standard results blinded, index test results blinded, relevant clinical information, uninterpretable results explained, withdrawals explained) (Smidt 2008; Whiting 2003). The operational definitions of the QUADAS items are presented in Appendix 2.

\section{Statistical analysis and data synthesis}

Extracted data were used to create forest plots of sensitivity and specificity, to depict study-specific estimates of sensitivity and specificity in receiver operating characteristic $(\mathrm{ROC})$ space for each index test, and to investigate:

1. the diagnostic performance of each index test

2. heterogeneity in the diagnostic performance of each index test according to patient characteristics, study design, and study quality factors (identified in Table 2 where sufficient data were available)

3. the relative diagnostic performance of alternate tests based on all available studies that provided data for at least one test, and when the analysis was restricted to studies that provided data for both tests.

Hierarchical summary receiver operating curve (HSROC) models were fitted using the PROC NLMIXED procedure in SAS9. $2^{\circledR}$. We applied the HSROC model to derive inferences about diagnostic test accuracy and heterogeneity in test performance where sufficient studies $(n \geq 5)$ for tests were available. The HSROC model used study specific estimates of sensitivity and specificity to estimate the position and shape of the summary curve (Rutter 2001). The curve was defined by three parameters: threshold (the underlying test positivity rate: a proxy for the cut-point that defines a positive test); accuracy (the diagnostic log odds ratio); and shape (the dependence of accuracy on threshold). Each study provided an estimate for threshold and accuracy which were assumed to be random effects in the model. When there was no evidence of an association between accuracy and threshold, the summary curve was considered symmetric and its position defined by a constant diagnostic odds ratio (DOR). The model estimates were used to obtain summary estimates for sensitivity, specificity, positive and negative likelihood ratios, DORs and $95 \%$ confidence intervals $(\mathrm{Cl})$, and the corresponding 95\% confidence region for each index test. The corresponding area under the curve (AUC) was computed from the constant DOR as part of the analysis.

HSROC model results were used to create plots of estimated summary curves, summary points and confidence regions, superimposed on study-specific estimates of sensitivity and specificity.

We provided summary measures of diagnostic accuracy for:
1. all studies regardless of $C A D$ threshold on coronary angiography

2. studies that reported $\geq 70 \%$ stenosis threshold for diagnosis of significant $C A D$ on coronary angiography.

Pairwise comparisons of test performance among alternative index tests were performed using data from studies where comparisons between tests were made in the same study population (direct comparison) or in different study populations (indirect comparison). A covariate of test type was included in the modelling to assess if the SROC curves for tests differed in shape, or overall accuracy. When comparing the relative performance of two index tests, we initially assumed equal variances for random effects for the tests, but extended the models to accommodate unequal variances for random effects where required.

In studies reporting multiple tests in the same participants, results were expressed separately for each test component.

\section{Investigations of heterogeneity}

Factors that could influence diagnostic accuracy other than true test performance included those relating to methodological quality and study design, characteristics of the underlying population, and characteristics of the index and reference test. We detailed and compared patient inclusion criteria for each included study. We also investigated heterogeneity statistically by:

1. applying separate models to different subgroups

2. adding covariates to the hierarchical model.

Factors such as differences in study population characteristics (e.g. prevalence of chest pain, hypertension and diabetes) and test application (diagnostic test threshold, criteria for positive test, choice of stress agent and stress protocol, and operator variability) were used to explore any heterogeneity discovered in the analysis for each test separately, and to assess the impact of heterogeneity on the relative accuracy across tests.

For index tests such as ECG and echocardiography, where different definitions of an abnormal test were present, only data that had been measured using the same definitions were combined.

\section{Sensitivity analyses}

Where differences were present across studies, we controlled for heterogeneity by conducting sensitivity analyses. In particular, we investigated diagnostic accuracy in studies that:

1. aimed to provide both index tests and reference tests to their study population (studies that avoided verification bias)

2. applied a threshold of diagnosis of severe CAD of $\geq 70 \%$ stenosis on coronary angiography

3. consisted entirely of asymptomatic individuals (studies that excluded patients who had either symptoms of cardiac disease or a history of ischaemic heart disease).

\section{RE S U L T S}

\section{Results of the search}

The results of electronic database and handsearching are outlined in Figure 1. There were no disagreements between authors about either the number of studies eligible for inclusion, nor data results $(\kappa=1.0)$. We identified 26 reports of 25 studies (35 comparisons in 
total). Seven studies compared more than one test versus coronary angiography, and were interrogated to contribute data to more than one test comparison (De Lima 2003; Gang 2007; GarciaCanton 1998; Garg 2000; Sharma 2005; Sharma 2009; Vandenberg 1996). One study was reported twice (Sharma 2005), and one study (Sharples 2004) could not contribute to the meta-analysis because it reported results per coronary vessel, but not per patient. The diagnostic and treatment pathway is presented at the patient level, but including vessel-level analysis lead to inappropriate weighting in the combined analysis, and the potential for bias from clustering of patients' results. The details of all studies included in the metaanalysis are reported in Characteristics of included studies and Table 2. 
Figure 1. Flow of studies identified in literature search for systematic review of testing for coronary artery disease in potential kidney transplant recipients * Some studies investigate more than one test and so contribute to more than one test comparison CIMT: carotid intimal medial thickness; DSE: dobutamine stress echocardiography; DSF: digital subtraction fluorography; EBCT: electron beam computed tomography; ECG: resting electrocardiography; Echo/LV: echocardiography (left ventricular dysfunction or cardiomegaly); Echo/MAC: echocardiography (mitral annular calcification); Echo/RWMA: echocardiography (resting wall motion abnormality); EST: exercise stress electrocardiography; EV: exercise ventriculography; MPS: myocardial perfusion scintigraphy

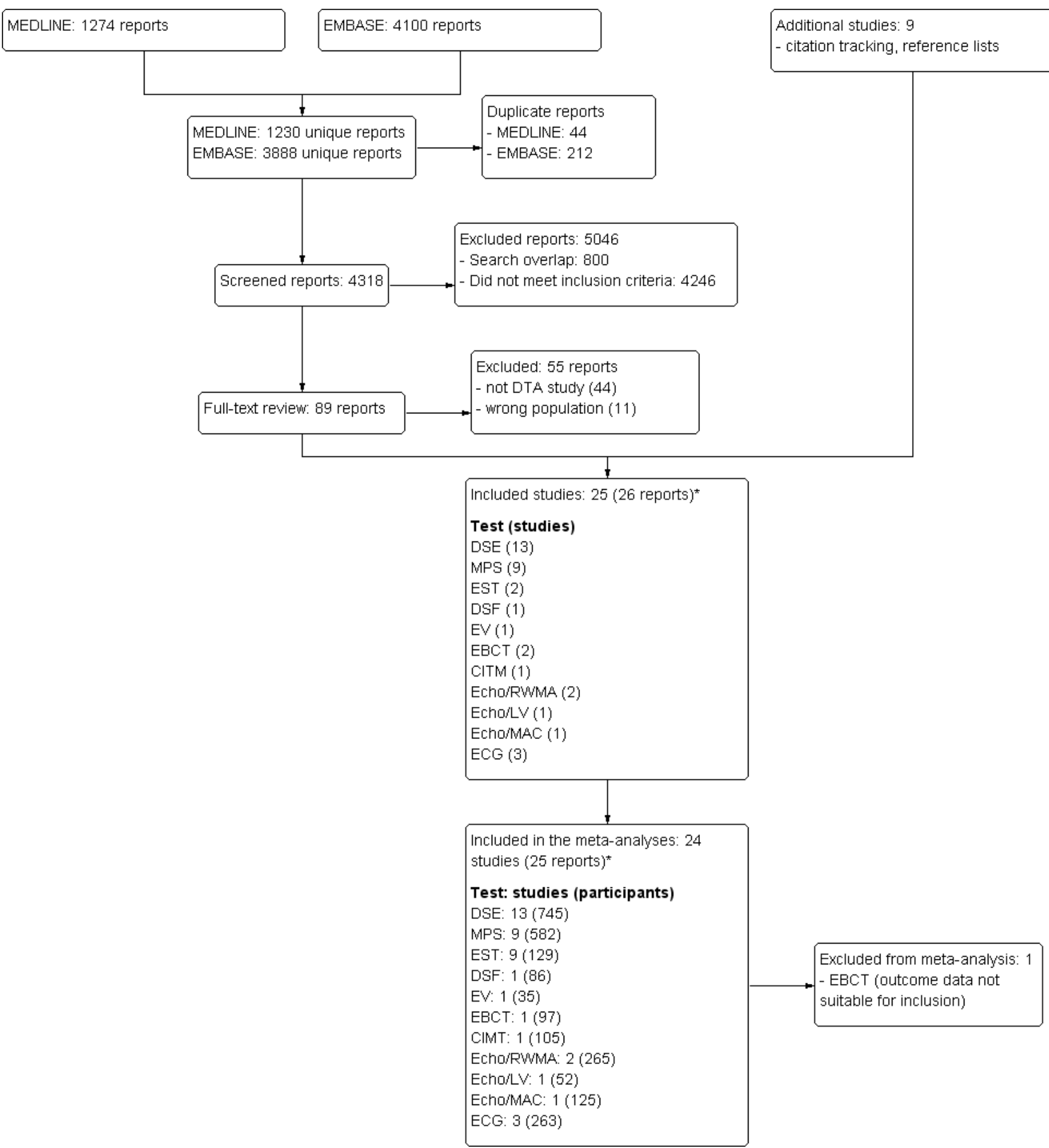

We identified a further 11 studies (Caglar 2006; Dahan 1995; Dahan 1998; Dahan 2002; De Vriese 2009; Fujimoto 2006; Fukui 2005; Nishimura 2004; Ohtake 2005; Robinson 2007; Schmidt 2001) that reported diagnostic test accuracy in patients with CKD.
However, populations in these studies did not consist entirely of patients who were being considered for kidney transplantation patients on dialysis or with CKD who were not being considered for transplantation were also represented. These studies were 
excluded from the review because we were unable to obtain separate data for potential kidney transplant recipients only from the authors of these 11 studies. We excluded a total of 55 studies from our review (see Characteristics of excluded studies).

\section{Methodological quality of included studies}

Results of the validity assessment are depicted (Figure 2; Figure 3) for the 25 included studies, including Sharples 2004, which could not contribute data. Only 10 included studies provided sufficient information to enable scoring for the 11 nominated QUADAS methodological items. Seven studies satisfied the QUADAS criteria. All included studies satisfied the QUADAS criteria of including study populations that represented the intended target population (potential kidney transplant recipients) and an acceptable reference standard (coronary angiography). Incorporation bias; which occurs when the index test is incorporated in a composite reference standard, often leading to overestimation of diagnostic test accuracy, was not present in any study. No patients were verified with a second or third reference standard because disease status (CAD) was diagnosed only by coronary angiography. Differential verification was therefore also avoided in all studies. The reference standard was not blinded to investigators in three studies that reported coronary angiography being undertaken although results of non-invasive index test were known to the investigators (Brennan 1997; De Lima 2003; Gang 2007). It was unclear if index test results were known at the time of coronary angiography in seven studies (Bennett 1978; Cai 2010; Gowdak 2010; Jassal 2007; Krawczynska 1988; Reis 1995; West 2000). In one study (De Lima 2003, author communication), coronary angiography results were known to investigators who interpreted the index test. It was also unclear if coronary angiography results were known at the time of the index test in eight studies (Bennett 1978; Cai 2010; Gang 2007; Gowdak 2010; Jassal 2007; Krawczynska 1988; Rosario 2010; West 2000). Of the 25 included studies, 20 aimed to provide coronary angiography to all patients who underwent index testing. However, only some participants who underwent index testing proceeded to the reference test in five studies (Bates 1996; Brennan 1997; Cai 2010; Krawczynska 1988; Reis 1995).

Figure 2. Methodological design and reporting quality of studies included in meta-analysis according to risk of bias in quality domains assessed using the Quality Assessment of Diagnostic Accuracy Studies tool: review authors' judgements about each methodological quality item presented as percentages across all included studies

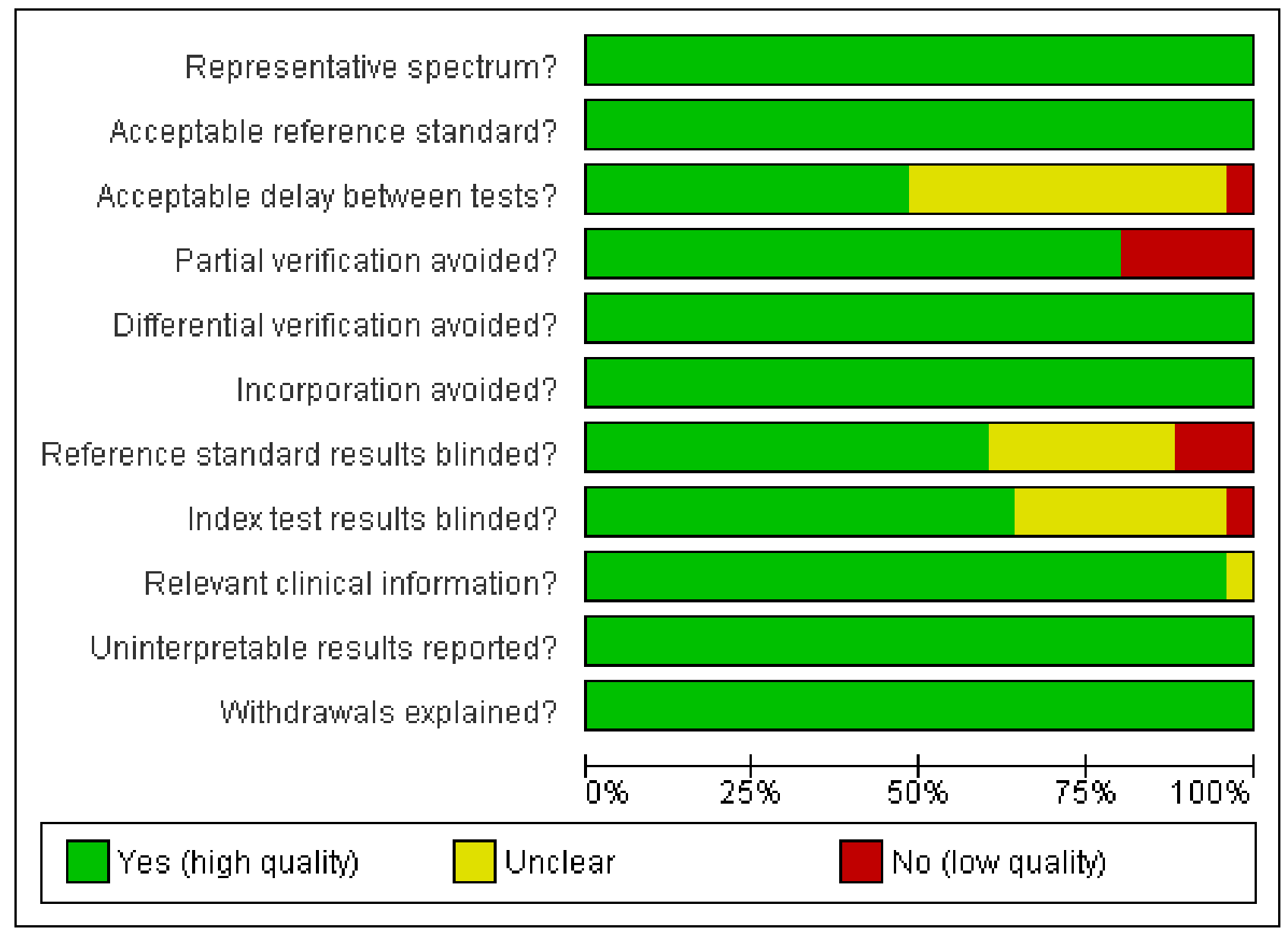


Figure 3. Methodological quality summary of studies: review authors' judgements about each methodological quality item for each included study using the Quality Assessment of Diagnostic Accuracy Studies tool

\begin{tabular}{|c|c|c|c|c|c|c|c|c|c|c|c|}
\hline & 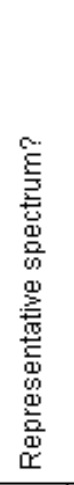 & 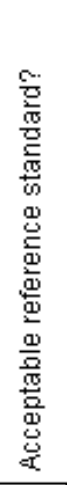 & 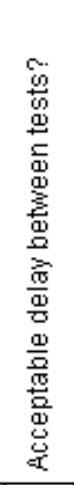 & 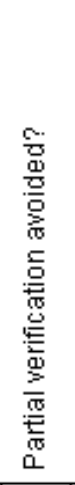 & 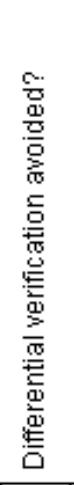 & 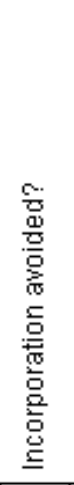 & 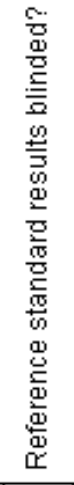 & 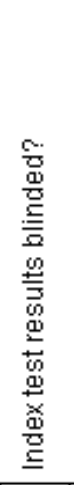 & 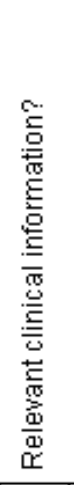 & 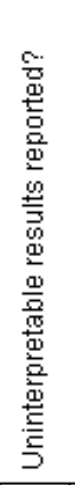 & 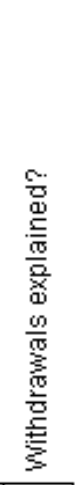 \\
\hline Bates 1996 & $\odot$ & $\odot$ & $\odot$ & 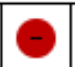 & + & + & + & + & $\odot$ & $\odot$ & + \\
\hline Bennett 1978 & + & $\odot$ & $?$ & $\odot$ & + & + & $?$ & $?$ & + & + & 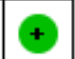 \\
\hline Boudreau 1990 & + & $\odot$ & $?$ & + & + & + & + & + & + & + & + \\
\hline Brennan 1997 & + & $\odot$ & + & $O$ & + & + & - & + & + & + & + \\
\hline Cai 2010 & $\odot$ & $\odot$ & $?$ & 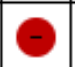 & + & + & $?$ & $?$ & + & + & + \\
\hline De Lima 2003 & + & $\odot$ & + & $\odot$ & + & + & - & $O$ & + & + & 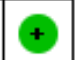 \\
\hline Ferreira 2007 & + & $\odot$ & + & $\odot$ & $\odot$ & + & + & + & + & + & 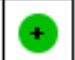 \\
\hline Gang 2007 & + & $\odot$ & $\odot$ & $\odot$ & $\odot$ & + & - & $?$ & + & + & + \\
\hline Garcia-Canton 1998 & + & $\odot$ & + & + & + & + & + & + & + & + & + \\
\hline Garg 2000 & + & $\odot$ & $?$ & $\odot$ & $\odot$ & + & 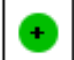 & $\odot$ & $\odot$ & $\odot$ & $\odot$ \\
\hline Gowdak 2010 & + & + & $?$ & + & + & + & $?$ & $?$ & + & + & + \\
\hline Herzog 1999 & + & $\odot$ & $\odot$ & $\odot$ & $\odot$ & $\odot$ & 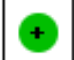 & $\odot$ & $\odot$ & + & + \\
\hline Jassal 2007 & 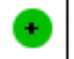 & $\odot$ & $?$ & + & + & + & $?$ & $?$ & + & + & + \\
\hline Krawczynska 1988 & + & $\odot$ & $?$ & $\odot$ & $\odot$ & + & $?$ & $?$ & $?$ & + & + \\
\hline Marwick 1989 & + & $\odot$ & + & + & + & + & + & + & + & + & + \\
\hline Marwick 1990 & + & $\odot$ & $\odot$ & $\odot$ & $\odot$ & $\odot$ & 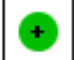 & $\odot$ & $\odot$ & + & $\odot$ \\
\hline Modi 2006 & + & $\odot$ & $?$ & 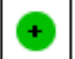 & $\odot$ & $\odot$ & $\odot$ & $\odot$ & $\odot$ & + & 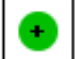 \\
\hline Reis 1995 & + & $\odot$ & $\odot$ & $\odot$ & + & + & $?$ & + & + & + & 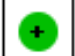 \\
\hline Rosario 2010 & + & $\odot$ & + & + & + & + & + & $?$ & + & + & + \\
\hline Sharma 2005 & + & $\odot$ & $?$ & + & $\odot$ & + & 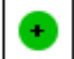 & + & + & + & + \\
\hline Sharma 2009 & + & $\odot$ & $?$ & + & + & + & + & + & + & + & + \\
\hline Sharples 2004 & + & $\odot$ & $?$ & + & + & + & + & + & + & + & + \\
\hline Vandenberg 1996 & + & $\odot$ & + & + & $\oplus$ & + & + & + & + & + & + \\
\hline West 2000 & + & + & $?$ & + & + & + & $?$ & $?$ & + & + & + \\
\hline
\end{tabular}


Figure 3. (Continued)

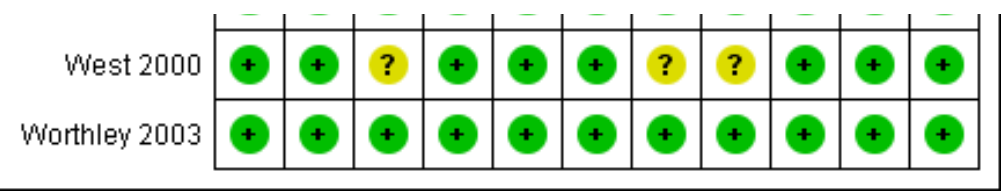

\section{Findings}

We identified 13 studies (745 participants) that evaluated DSE; nine studies (582 participants) of MPS; two exercise EST studies (129 participants), and one study investigated each of EBCT (97 participants), DSF (86 participants), exercise ventriculography (35 participants) and CIMT (105 participants). Two studies (265 participants) investigated the relationship between resting wall motion abnormality on resting transthoracic echocardiography and significant CAD. One study (125 participants) also investigated the relationship between mitral annulus calcification on echocardiography and CAD. Another study (52 participants) investigated the relationship between abnormal echocardiography (left ventricular dysfunction or cardiomegaly) and CAD. Three studies (263 participants) investigated the relationship between abnormal resting ECG and CAD. No studies of diagnostic test accuracy were identified for CT coronary angiography, cardiopulmonary exercise testing, magnetic resonance angiography, or cardiac magnetic resonance imaging.

A forest plot of the study estimates of sensitivity and specificity for each test is shown in Figure 4. Figure 5 depicts the SROC plot of sensitivity and specificity, arranged by test comparison, for all studies (with one exception) identified and included in the metaanalysis. Jassal 2007 was not included because sensitivity could not be calculated due to a lack of patients with CAD.

Figure 4. Accuracy of tests for coronary artery disease versus coronary angiography (forest plot); CIMT: carotid intimal medial thickness; DSE: dobutamine stress echocardiography; DSF: digital subtraction fluorography; EBCT: electron beam computed tomography; ECG: resting electrocardiography; Echo (LV): echocardiography (left ventricular dysfunction or cardiomegaly; Echo (MAC): echocardiography (mitral annular calcification); Echo (RWMA): echocardiography (resting wall motion abnormality); EST: exercise stress electrocardiography; EV: exercise 
ventriculography; FN: false negative; FP: false positive; MPS: myocardial perfusion scintigraphy; NS: not stated; TN: total negative; TP: total positive

DSE

$\begin{array}{lrrrrrrr}\text { Study } & \text { TP } & \text { FP } & \text { FN } & \text { TN } & \text { \%Stenosis } & \text { Sensitivity } & \text { Specificity } \\ \text { Sharma 2009 } & 36 & 5 & 4 & 95 & 70 \% \text { or higher } & 0.90[0.76,0.97] & 0.95[0.89,0.98] \\ \text { Sharma 2005 } & 32 & 5 & 4 & 84 & 70 \% \text { or higher } & 0.89[0.74,0.97] & 0.94[0.87,0.98] \\ \text { Ferreira 2007 } & 24 & 14 & 10 & 78 & 70 \% \text { or higher } & 0.71[0.53,0.85] & 0.85[0.76,0.91] \\ \text { Cai 2010 } & 15 & 2 & 8 & 13 & 70 \% \text { or higher } & 0.65[0.43,0.84] & 0.87[0.60,0.98] \\ \text { De Lima 2003 } & 15 & 7 & 19 & 48 & 70 \% \text { or higher } & 0.44[0.27,0.62] & 0.87[0.76,0.95] \\ \text { West 2000 } & 12 & 8 & 1 & 12 & 70 \% \text { or higher } & 0.92[0.64,1.00] & 0.60[0.36,0.81] \\ \text { Herrog 1999 } & 12 & 8 & 4 & 26 & 70 \% \text { or higher } & 0.75[0.48,0.93] & 0.76[0.59,0.89] \\ \text { Garcia-Canton 1998 } & 11 & 2 & 1 & 13 & 70 \% \text { or higher } & 0.92[0.62,1.00] & 0.87[0.60,0.98] \\ \text { Gang 2007 } & 9 & 1 & 10 & 20 & 70 \% \text { or higher } & 0.47[0.24,0.71] & 0.95[0.76,1.00] \\ \text { Reis 1995 } & 22 & 1 & 1 & 6 & 50 \% & 0.96[0.78,1.00] & 0.86[0.42,1.00] \\ \text { Bates 1996 } & 9 & 1 & 1 & 6 & 50 \% & 0.90[0.55,1.00] & 0.86[0.42,1.00] \\ \text { Brennan 1997 } & 4 & 1 & 2 & 5 & 50 \% & 0.67[0.22,0.96] & 0.83[0.36,1.00] \\ \text { Jassal 2007 } & 0 & 0 & 0 & 18 & 50 \% & \text { Not estimable } & 1.00[0.81,1.00]\end{array}$

MPS

Study

Gowdak 2010

Boudreau 1990

Worthley 2003

Garcia-Canton 1998

Vandenberg 1996

De Lima 2003

Marwick 1990

Krawczynska 1988

Garg 2000

\begin{abstract}
TP FP FN TN \%Stenosis Sensitivity Specificity

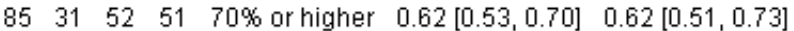

$\begin{array}{llllll}36 & 8 & 6 & 30 & 70 \% \text { or higher } 0.86[0.71,0.95] & 0.79[0.63,0.90]\end{array}$

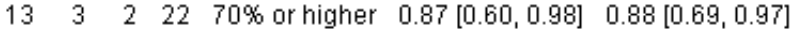

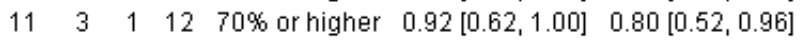

$\begin{array}{lllll}10 & 6 & 6 & 19 & 70 \% \text { or higher } \quad 0.63[0.35,0.85] \quad 0.76[0.55,0.91]\end{array}$

$\begin{array}{llllll}8 & 10 & 15 & 32 & 70 \% \text { or higher } 0.35[0.16,0.57] \quad 0.76[0.61,0.88]\end{array}$

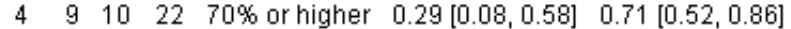

$\begin{array}{llll}20 & 18 & 0 & 8\end{array}$

$\begin{array}{llll}9 & 4 & 2 & 4\end{array}$

$50 \% \quad 1.00[0.83,1.00] \quad 0.31[0.14,0.52]$

$50 \% \quad 0.82[0.48,0.98] \quad 0.50[0.16,0.84]$
\end{abstract}

EST

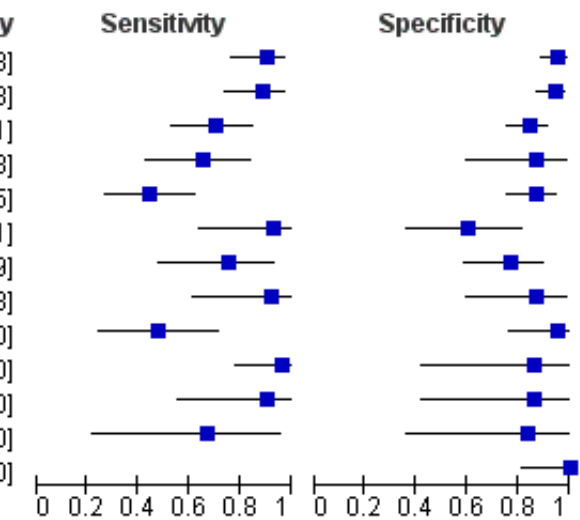

$\begin{array}{lrrrrrrr}\text { Study } & \text { TP } & \text { FP } & \text { FN } & \text { TN } & \text { \%Stenosis } & \text { Sensitivity } & \text { Specificity } \\ \text { Sharma } 2005 & 13 & 8 & 23 & 81 & 70 \% \text { or higher } & 0.36[0.21,0.54] & 0.91[0.83,0.96] \\ \text { Bennett } 1978 & 3 & 1 & 0 & 0 & 70 \% \text { or higher } & 1.00[0.29,1.00] & 0.00[0.00,0.97]\end{array}$

EBCT

Study TP FP FN TN \%Stenosis Sensitivity Specificity

Rosario $2010 \quad 16 \quad 25 \quad 9 \quad 47 \quad 70 \%$ or higher $0.64[0.43,0.82] \quad 0.65[0.53,0.76]$

DSF

Study TP FP FN TN \%Stenosis Sensitivity Specificity

Marwick $198928 \quad 17 \quad 8 \quad 33 \quad 70 \%$ or higher $0.78[0.61,0.90] \quad 0.66[0.51,0.79]$

EV

\begin{tabular}{lrrrrrrr} 
Study & TP & FP & FN & TN & $\%$ Stenosis & Sensitivity & Specificity \\
Vandenberg 1996 & 7 & 7 & 7 & 14 & $70 \%$ or higher & $0.50[0.23,0.77]$ & 0.67 \\
\hline
\end{tabular}

CIMT

Study TP FP FN TN \%Stenosis Sensitivity Specificity

Modi $2006 \quad 38 \quad 14 \quad 4 \quad 49 \quad 50 \% \quad 0.90[0.77,0.97] \quad 0.78[0.66,0.87]$

Echo (RWMA)

$\begin{array}{lllll}\text { Study } & \text { TP FP FN TN } \% \text { Stenosis Sensitivity Specificity }\end{array}$

Sharma $2009 \quad 13 \quad 5 \quad 27 \quad 95 \quad 70 \%$ or higher $0.33[0.19,0.49] \quad 0.95[0.89,0.98]$

Sharma $2005 \quad 11 \quad 4 \quad 25 \quad 85 \quad 70 \%$ or higher $0.31[0.16,0.48] \quad 0.96[0.89,0.99]$
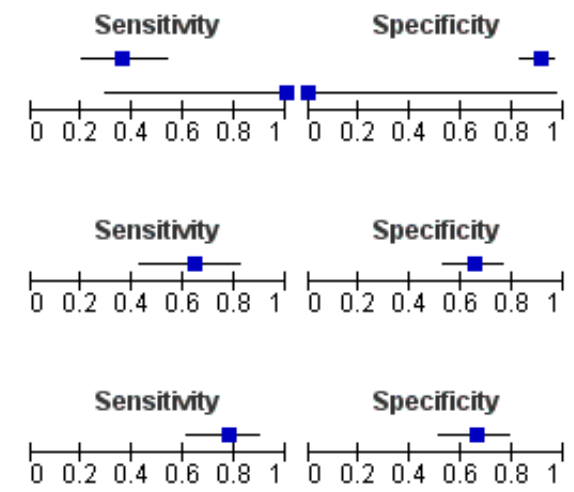

$-\cdots . .$.
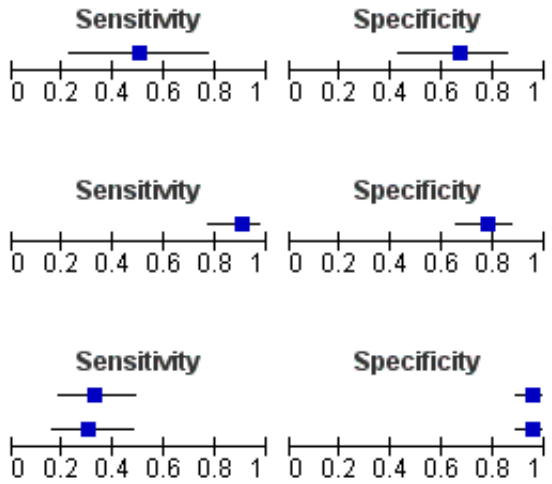


\section{Figure 4. (Continued)}

Sharma $2005 \quad 11 \quad 4 \quad 25 \quad 85 \quad 70 \%$ or higher $0.31[0.16,0.48] \quad 0.96[0.89,0.99]$ Echo (LV)

Study TP FP FN TN \%Stenosis Sensitivity Specificity

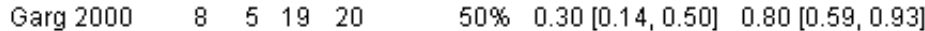

Echo (MAC)

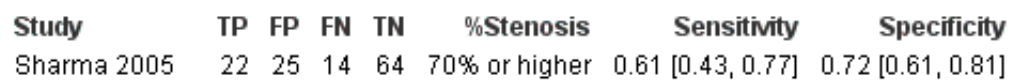

ECG

Study TP FP FN TN \%Stenosis Sensitivity Specificity

Sharma $2005 \quad 27 \quad 14 \quad 9 \quad 75 \quad 70 \%$ or higher $0.75[0.58,0.88] \quad 0.84[0.75,0.91]$

Gang $2007 \quad 9 \quad 12 \quad 10 \quad 9 \quad 70 \%$ or higher $0.47[0.24,0.71] \quad 0.43[0.22,0.66]$

$\begin{array}{lllllllll}\text { Garg } 2000 & 51 & 1 & 22 & 24 & 50 \% & 0.70[0.58,0.80] & 0.96[0.80,1.00]\end{array}$

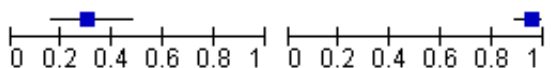
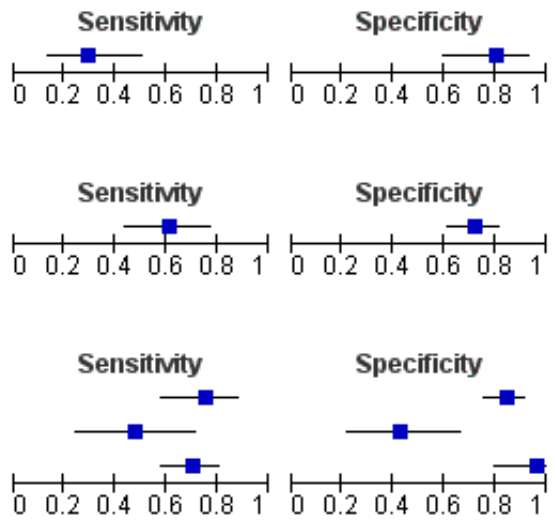
Figure 5. Summary receiver operator curve plot of sensitivity versus specificity for performance of different tests versus coronary angiography. Each symbol represents a study, with the height and width of each symbol being proportional to the inverse standard error of the sensitivity and specificity respectively CIMT: carotid intimal medial thickness; DSE: dobutamine stress echocardiography; DSF: digital subtraction fluorography; EBCT: electron beam computed tomography; ECG: resting electrocardiography; Echo (LV): echocardiography (left ventricular dysfunction or cardiomegaly); Echo (MAC): echocardiography (mitral annular calcification); Echo (RWMA): echocardiography (resting wall motion abnormality); EST: exercise stress electrocardiography; EV: exercise ventriculography; MPS: myocardial perfusion scintigraphy

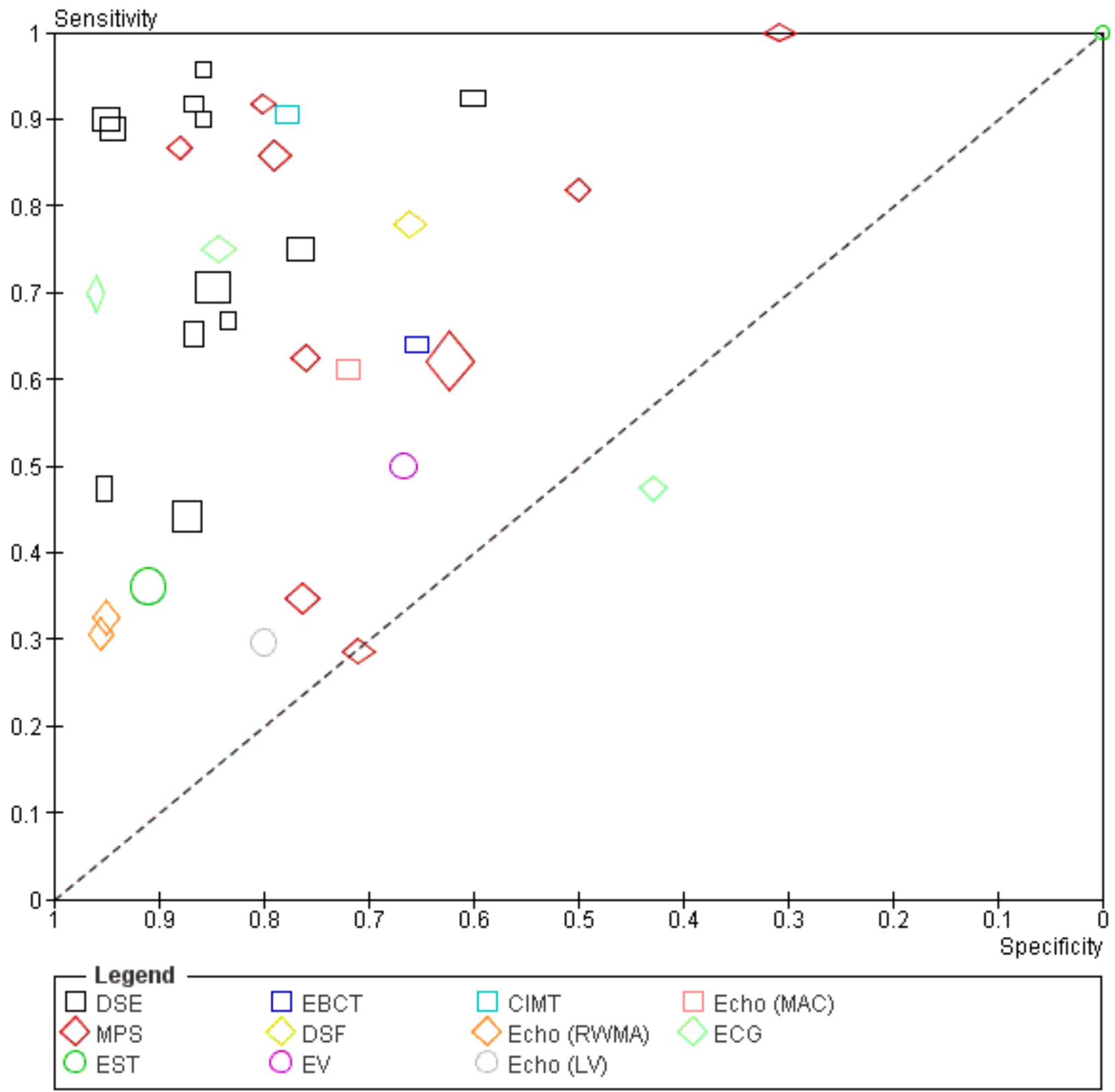

Dobutamine stress echocardiography (DSE)

DSE was compared with coronary angiography in 13 studies (745 participants) (Bates 1996; Brennan 1997; Cai 2010; De Lima 2003; Ferreira 2007; Gang 2007; Garcia-Canton 1998; Herzog 1999; Jassal 2007; Reis 1995; Sharma 2005; Sharma 2009; West 2000). Using induced wall motion abnormalities during dobutamine stress as a positive result indicating CAD, the sensitivity of DSE varied from $44 \%$ to $96 \%$ and the specificity from $60 \%$ to $100 \%$. Overall, DSE had a DOR of $29.98(95 \% \mathrm{Cl} 12.17$ to 73.89$)$ and area under the curve (AUC) of $0.91(95 \% \mathrm{Cl} 0.85$ to 0.95$)$. The pooled sensitivity was 0.79 ( $95 \% \mathrm{Cl} 0.67$ to 0.88 ), specificity 0.89 (95\% Cl 0.81 to 0.94$)$. One study also investigated the relationship between peak systolic 
velocity during DSE for CAD (Sharma 2009). This study reported that $\geq 50 \%$ elevation in peak systolic velocity with exercise during DSE was associated with $\geq 70 \%$ stenosis on coronary angiography (sensitivity $86 \%$, specificity $88 \%$ ).

Not all patients who underwent index testing proceeded to have these test results verified by the reference standard. Partial verification was made in three studies (Bates 1996; Brennan 1997; Cai 2010). Furthermore, four studies (Bates 1996; Brennan 1997; Jassal 2007; Reis 1995) used a reference test diagnostic threshold of $\geq 50 \%$ stenosis. In the nine studies that used the higher threshold of $\geq 70 \%$ stenosis, the pooled sensitivity was $0.76(95 \% \mathrm{Cl} 0.60$ to $0.87)$ and specificity $0.88(95 \% \mathrm{Cl} 0.78$ to 0.94$)$ with pooled DOR 23.01 (95\% Cl 8.08 to 65.51$)$ and AUC 0.90 . When only studies that applied a reference standard threshold of $\geq 70 \%$ stenosis and avoided partial verification were included, the pooled sensitivity was 0.78 ( $95 \% \mathrm{Cl} 0.59$ to 0.89 ), specificity 0.88 (95\% Cl 0.76 to 0.94$)$, positive likelihood ratio $6.44(95 \% \mathrm{Cl} 3.03$ to 13.70$)$ and negative likelihood ratio $0.26(95 \% \mathrm{Cl} 0.13$ to 0.50$)$ with pooled DOR 25.22 (95\% $\mathrm{Cl} 7.68$ to 82.80$)$ and AUC 0.90 .
Overall, there was very strong evidence of heterogeneity among the 13 studies (Figure 6). This remained highly statistically significant even after accounting for differences in reference standard threshold (Figure 7) and partial verification (Figure 8). The remaining studies were similar in the performance of index test and interpretation of test results, but two studies (Sharma 2005; Sharma 2009) were responsible for most of the heterogeneity. There was no statistical evidence of heterogeneity in six studies (De Lima 2003; Ferreira 2007; Gang 2007; Garcia-Canton 1998; Herzog 1999; West 2000). Sharma 2005 and Sharma 2009 differed from other studies in that they originated from a single research group and had the highest proportion of patients who were symptomatic for chest pain. Despite the hypothesis that prevalence of CAD may have accounted for heterogeneity, we could not investigate any relationship between diagnostic accuracy and prevalence of CAD more formally because of the small number of studies, lack of subgrouped patient data, and five studies (Bates 1996; Cai 2010; Garcia-Canton 1998; Jassal 2007; West 2000) did not report proportions of symptomatic patients. Two studies (Bates 1996; Gang 2007) enrolled only patients with DM, and sensitivity was found to range from $47 \%$ to $90 \%$ and specificity from $86 \%$ to $95 \%$. 
Figure 6. Summary receiver operator curve plot of sensitivity versus specificity for performance of different tests versus coronary angiography: Indirect comparison MPS versus DSE. Each symbol represents a study, with the height and width of each symbol being proportional to the inverse standard error of the sensitivity and specificity respectively. The curves represent the summary receiver operator characteristic curves for MPS and DSE. The circles represent the summary estimate of test performance and the zone outline surrounding it represents the $95 \%$ confidence region of this summary estimate DSE: dobutamine stress echocardiography; MPS: myocardial perfusion scintigraphy

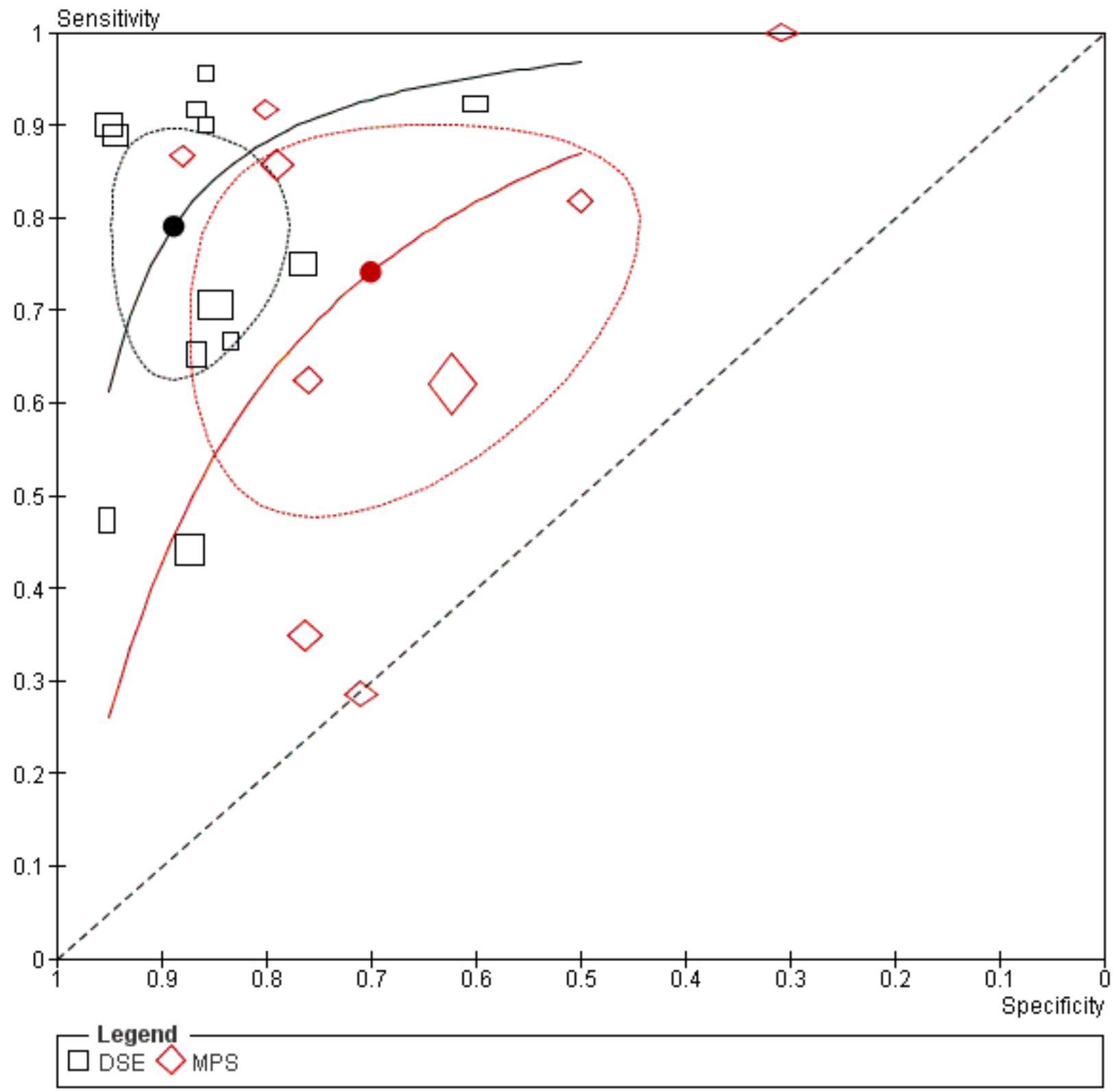


Figure 7. Summary receiver operator curve plot of sensitivity versus specificity for performance of different tests versus coronary angiography: indirect comparison MPS versus DSE, according to reference standard threshold. Each symbol represents a study, with the height and width of each symbol being proportional to the inverse standard error of the sensitivity and specificity respectively. The curves represent the summary receiver operator characteristic curves for MPS and DSE. The circles represent the summary estimate of test performance and the zone outline surrounding it represents the $95 \%$ confidence region of this summary estimate DSE: dobutamine stress echocardiography; MPS: myocardial perfusion scintigraphy

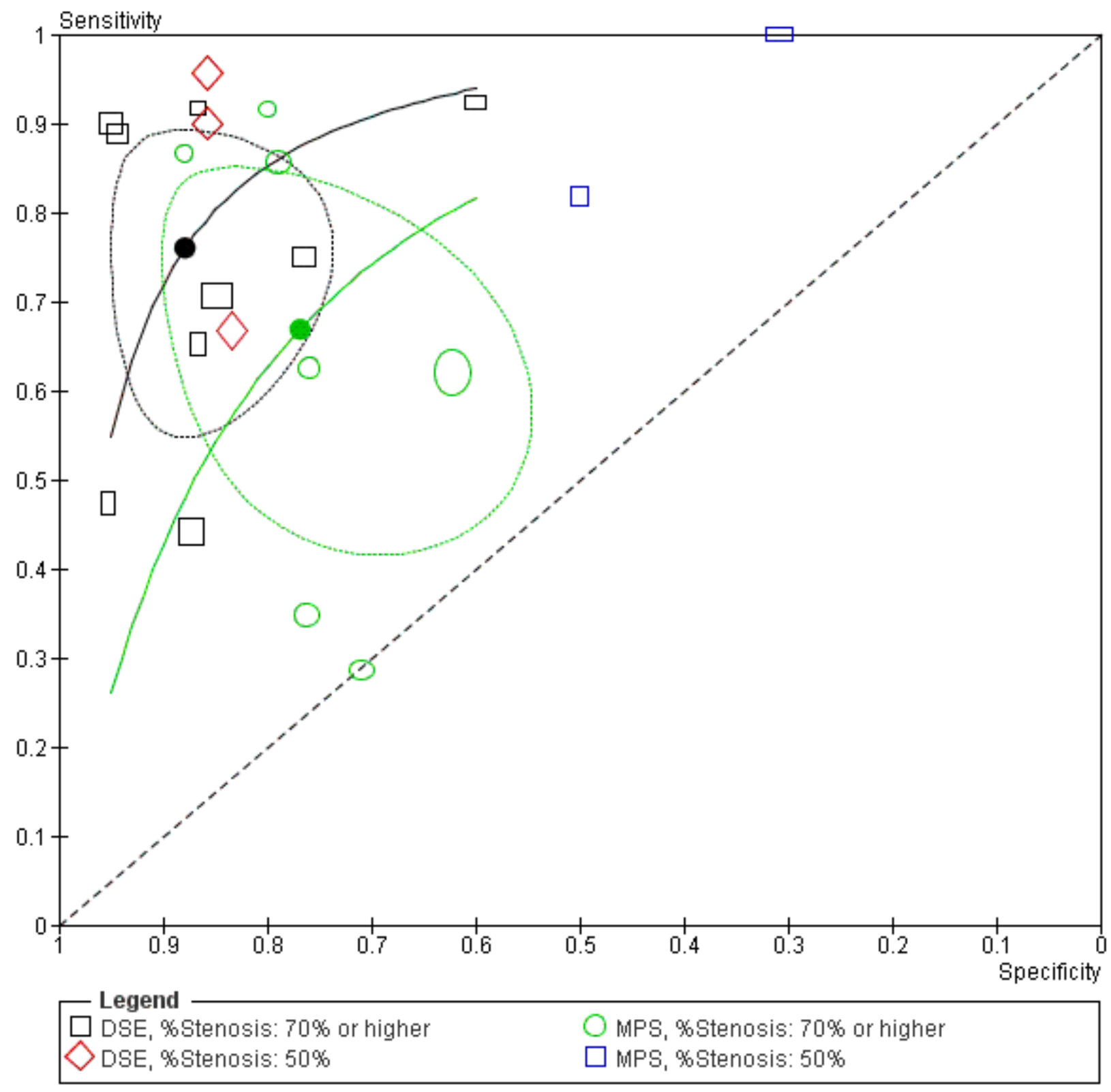


Figure 8. Summary receiver operator curve plot of sensitivity versus specificity for performance of different tests versus coronary angiography: indirect comparison MPS versus DSE, according to presence of partial verification. Each symbol represents a study, with the height and width of each symbol being proportional to the inverse standard error of the sensitivity and specificity respectively. The curves represent the summary receiver operator characteristic curves for MPS and DSE. The circles represent the summary estimate of test performance and the zone outline surrounding it represents the $95 \%$ confidence region of this summary estimate DSE: dobutamine stress echocardiography; MPS: myocardial perfusion scintigraphy.

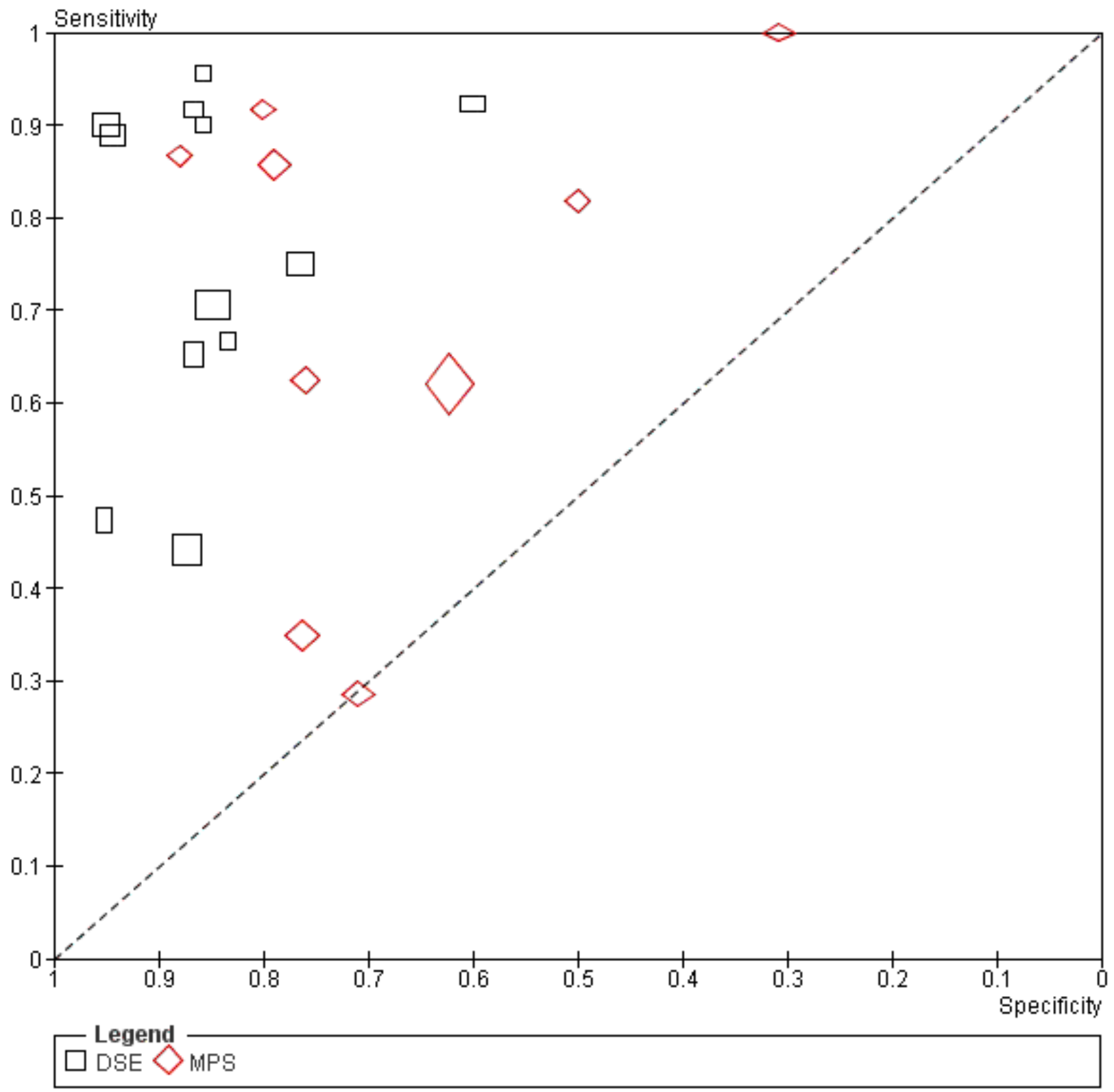

\section{Myocardial perfusion scintigraphy (MPS)}

MPS was compared with coronary angiography in nine studies (582 participants) (Boudreau 1990; De Lima 2003; Garcia-Canton 1998; Garg 2000; Gowdak 2010; Krawczynska 1988; Marwick 1990; Vandenberg 1996; Worthley 2003). Sensitivity of MPS varied from $29 \%$ to $100 \%$ and specificity from $31 \%$ to $88 \%$. The pooled summary estimates showed that MPS had a DOR $6.69(95 \% \mathrm{Cl} 2.35$ to 19.03$)$ and AUC 0.78 ( $95 \% \mathrm{Cl} 0.64$ to 0.88$)$. The pooled sensitivity was 0.74 ( $95 \% \mathrm{Cl} 0.54$ to 0.87 ), and specificity 0.70 ( $95 \% \mathrm{Cl} 0.51$ to 0.84 ).

All but one study (Krawczynska 1988) avoided partial verification bias. Two studies (Garg 2000; Krawczynska 1988) used a threshold of $\geq 50 \%$ stenosis and not the reference threshold of $\geq 70 \%$ stenosis. When these studies were removed from the analysis, DOR remained unchanged at $6.70(95 \% \mathrm{Cl} 1.84$ to 24.41$)$ and AUC 0.78. The pooled 
sensitivity was 0.67 (95\% $\mathrm{Cl} 0.48$ to 0.82$)$, specificity $0.77(95 \% \mathrm{Cl}$ 0.61 to 0.88 ), with positive and negative likelihood ratios of 2.89 $(95 \% \mathrm{Cl} 1.39$ to 5.99$)$ and $0.43(95 \% \mathrm{Cl} 0.23$ to 0.80$)$ respectively.

There was very strong evidence of heterogeneity among the nine studies (Figure 6). Heterogeneity remained even after accounting for differences in reference standard threshold (Figure 7) and partial verification (Figure 8). Of the studies that had reference standards of $\geq 70 \%$ stenosis and avoided verification bias, four (Boudreau 1990; Garg 2000; Gowdak 2010; Vandenberg 1996) enrolled only patients with DM. Heterogeneity among these four studies of patients with diabetes remained strongly significant, although heterogeneity of the other four studies (De Lima 2003; GarciaCanton 1998; Marwick 1990; Worthley 2003) decreased when they were excluded. One study (Worthley 2003) that employed tachycardia pacing in some patients to ensure diagnostic MPS had a much higher sensitivity and specificity compared with the other studies and accounted for much of the remaining heterogeneity.

Meaningful investigation into whether prevalence of angina and/or ischaemic heart disease symptoms on diagnostic test performance was not possible as four studies (Garcia-Canton 1998; Garg 2000; Gowdak 2010; Krawczynska 1988) did not provide any information regarding prevalence of angina or ischaemic heart disease symptoms in their study populations.

\section{Other tests}

- Two studies (129 participants) (Bennett 1978; Sharma 2005) compared EST with coronary angiography. In Bennett 1978, only 4/7 participants were able to achieve an adequate heart rate and had a diagnostic exercise stress test; the three remaining participants underwent non-diagnostic tests due to suboptimal stress capacity. Sensitivity for this study was 1.0 (95\% Cl 0.29 to 1.0) and specificity 0 (95\% $\mathrm{Cl} 0$ to 0.97$)$. In Sharma 2005, which enrolled 125 participants, sensitivity was $0.36(95 \% \mathrm{Cl} 0.21$ to 0.54 ) and specificity 0.91 (95\% $\mathrm{Cl} 0.83$ to 0.96$)$.

- One study (97 participants) (Rosario 2010) compared EBCT with coronary angiography. This study reported that when a calcium score threshold of 1330.72 Agatston units was used as a cut-off point, sensitivity was 0.64 ( $95 \% \mathrm{Cl} 0.43$ to 0.82$)$ and specificity 0.65 (95\% $\mathrm{Cl} 0.53$ to 0.76$)$, using a reference standard threshold of $\geq 70 \%$ stenosis to diagnose CAD.

- One study (35 participants) (Vandenberg 1996) compared exercise radionuclide ventriculography with coronary angiography showing a sensitivity of $0.50(95 \% \mathrm{Cl} 0.23$ to 0.77$)$ and a specificity of $0.67(95 \% \mathrm{Cl} 0.43$ to 0.85$)$

- One study (86 participants) (Marwick 1989) compared DSF with coronary angiography, showing a sensitivity of $0.78(95 \% \mathrm{Cl} 0.61$ to 0.90$)$ and a specificity of 0.68 ( $95 \% \mathrm{Cl} 0.51$ to 0.79$)$.

- One study (105 participants) (Modi 2006) compared CIMT with coronary angiography, showing a sensitivity of $0.90(95 \% \mathrm{Cl} 0.77$ to 0.97 ) and a specificity of 0.78 ( $95 \% \mathrm{Cl} 0.66$ to 0.87 ).

- Three studies (Garg 2000; Sharma 2005; Sharma 2009) correlated echocardiography findings with CAD. Two studies (Sharma 2005; Sharma 2009) used resting wall motion abnormality to define an abnormal index test. These studies, which were performed by the same authors on similar populations, had very similar sensitivity and specificity (Sharma 2005 reported sensitivity of $0.31(95 \% \mathrm{Cl} 0.16$ to 0.48$)$ and specificity of $0.96(95 \% \mathrm{Cl} 0.89$ to 0.99$)$; Sharma 2009 found sensitivity of $0.33(95 \% \mathrm{Cl} 0.19$ to 0.49$)$ and specificity of $0.95(95 \% \mathrm{Cl} 0.89$ to 0.98$))$. Sharma 2005 also compared mitral annular calcification and CAD and reported that this echocardiographic finding had a sensitivity of $0.61(95 \% \mathrm{Cl} 0.43$ to 0.77 ) and specificity of $0.72(95 \% \mathrm{Cl} 0.61$ to 0.81$)$. Garg 2000 used echocardiographic criteria of left ventricular dysfunction or cardiomegaly to define test positivity, and reported sensitivity of $0.30(95 \% \mathrm{Cl} 0.14$ to 0.50$)$ and specificity of $0.80(95 \% \mathrm{Cl} 0.59$ to 0.93).

- Three studies (Gang 2007; Garg 2000; Sharma 2005) investigated resting ECG for CAD diagnosis. In these studies, abnormal resting ECG was defined as the presence of pathological Q waves, left ventricular hypertrophy, ST depression $\geq 1 \mathrm{~mm}$, ST elevation $\geq 1 \mathrm{~mm}$, T wave inversion or bundle branch block. However, results differed. Gang 2007 reported sensitivity of 0.47 (95\% $\mathrm{Cl} 0.24$ to 0.71$)$ and specificity of $0.43(95 \% \mathrm{Cl} 0.22$ to 0.66$)$; Garg 2000 identified sensitivity of $0.70(95 \% \mathrm{Cl} 0.58$ to 0.80$)$ and specificity of 0.96 (95\% Cl 0.80 to 1.00$)$, and Sharma 2005 reported sensitivity of $0.75(95 \% \mathrm{Cl} 0.58$ to 0.88$)$ and specificity of $0.84(95 \% \mathrm{Cl} 0.75$ to 0.91$)$.

\section{Comparative analysis: DSE versus MPS}

Garcia-Canton 1998 and De Lima 2003 directly compared DSE and MPS (Figure 9). Both studies reported that DSE had a higher specificity and equivalent or better sensitivity compared with MPS. Each applied reference standard thresholds of $\geq 70 \%$ stenosis for diagnosing CAD, and avoided partial verification bias. 
Figure 9. Summary receiver operator curve plot of sensitivity versus specificity for performance of different tests versus coronary angiography: Direct comparison MPS versus DSE. Each symbol represents a study, with the height and width of each symbol being proportional to the inverse standard error of the sensitivity and specificity respectively. The lines connecting paired MPS and DSE studies denote studies which investigated the accuracy of MPS and DSE in the same study population (direct comparison) DSE: dobutamine stress echocardiography; MPS: myocardial perfusion scintigraphy

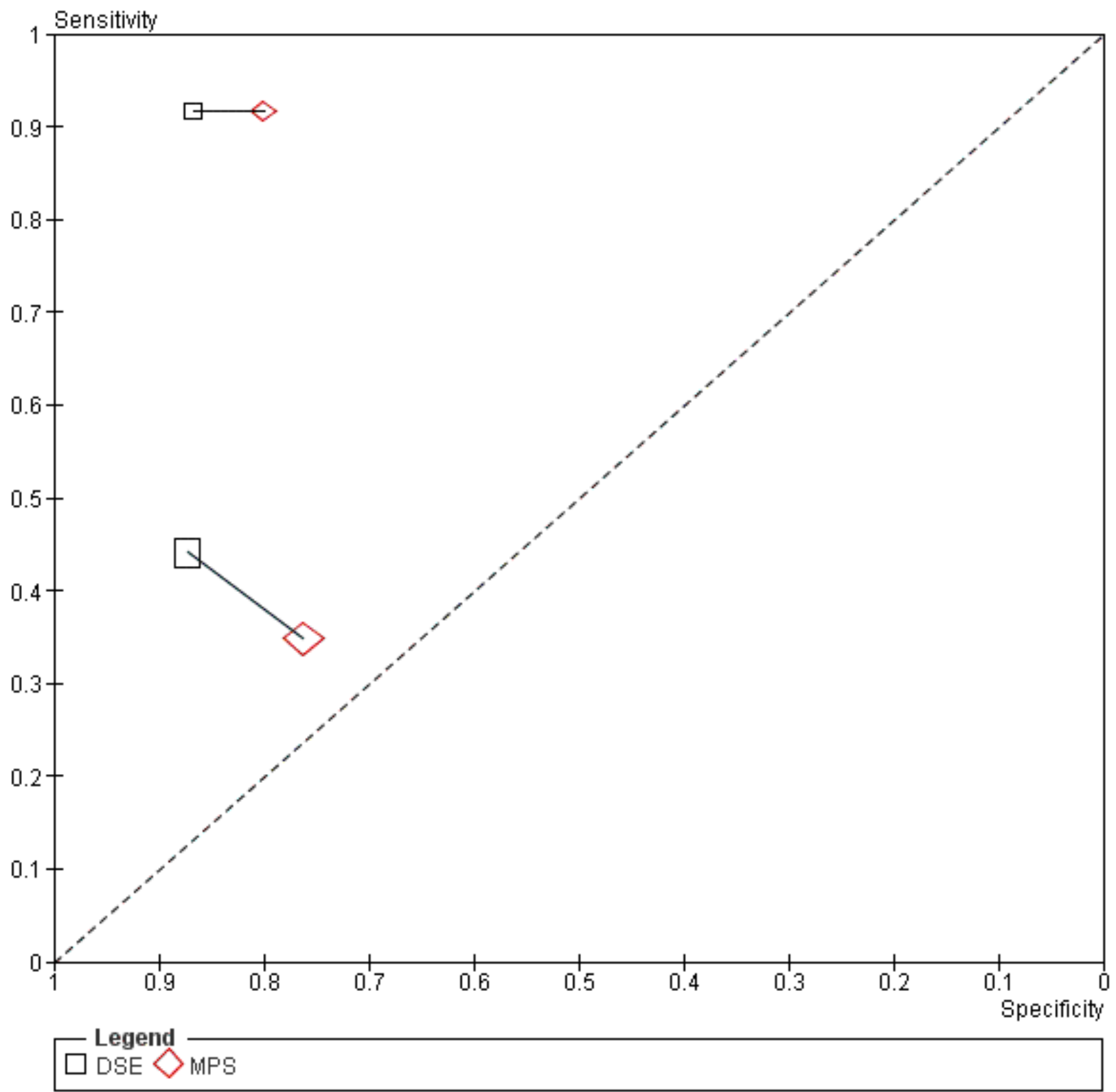

Table 3 and Figure 6 summarise indirect comparison results.

Overall, there was evidence that DSE (13 studies) had better test accuracy than MPS (9 studies) $(P=0.02)$. Using the results from the earlier analysis, DSE appeared to have a higher pooled sensitivity (DSE: 0.79 (95\% Cl 0.67 to 0.88 ) versus MPS: 0.74 (95\% $\mathrm{Cl} 0.54$ to 0.87 ) and specificity DSE: 0.89 (95\% Cl 0.81 to 0.94$)$ versus MPS: 0.70 $(95 \% \mathrm{Cl} 0.51$ to 0.84$)$. The variability in accuracy was smaller for DSE than MPS, demonstrated by the difference in size of the $95 \%$ confidence regions in HSROC space. When we included only studies that used definitions of $\geq 70 \%$ stenosis on coronary angiography to diagnose severe CAD, DSE (9 studies) had pooled sensitivity and specificity of $0.76(95 \% \mathrm{Cl} 0.60$ to 0.87$)$ and $0.88(95 \% \mathrm{Cl} 0.78$ to 0.94$)$ respectively. MPS (7 studies) had pooled sensitivity and specificity of 0.67 (95\% Cl 0.48 to 0.82 ) and 0.77 (95\% Cl 0.61 to $0.88)$ respectively. There was no statistically significant difference between tests $(P=0.09)$ (Figure 7$)$. When we included only studies where partial verification bias was avoided, DSE (10 studies) had 
pooled sensitivity and specificity of $0.80(95 \% \mathrm{Cl} 0.64$ to 0.90$)$ and 0.89 ( $95 \% \mathrm{Cl} 0.79$ to 0.95$)$ respectively. MPS (8 studies) had pooled sensitivity and specificity of $0.68(95 \% \mathrm{Cl} 0.51$ to 0.81$)$ and 0.75 (95\% Cl 0.60 to 0.86$)$ respectively. The difference in accuracy between MPS and DSE tests for these studies was statistically significant $(P=0.03)$ (Figure 8$)$. When only studies that avoided partial verification and had reference thresholds $\geq 70 \%$ stenosis on coronary angiography were included in the analysis, there was no evidence of a statistically significant difference between tests $(P=$ 0.09). DSE (8 studies) appeared to have a higher pooled sensitivity: $0.78(95 \% \mathrm{Cl} 0.59$ to 0.89$)$ than MPS $0.67(95 \% \mathrm{Cl} 0.48$ to 0.82$)$ and DSE specificity: 0.88 (95\% Cl 0.76 to 0.94$)$ versus $0.77(95 \% \mathrm{Cl}$ 0.61 to 0.88 )] compared with MPS (7 studies), as well as a higher corresponding AUC.

\section{Subgroup analyses}

Sparse data, both in terms of numbers of studies and study participants, meant that we were unable to perform meaningful subgroup analyses on the effect of DM or prevalence of angina and symptomatic ischaemic heart disease (IHD) on diagnostic test performance. Only one study (Vandenberg 1996) included a patient population who had no history of angina or IHD. Therefore, a sensitivity analysis of diagnostic accuracy in studies that enrolled only patients who had no symptoms of cardiac disease or history of IHD could not be conducted.

\section{DISCUSSION}

\section{Summary of main results}

Preliminary findings of comparisons of DSE and MPS versus coronary angiography have been published by our review team (Wang 2011), but this systematic review represents more index tests and several studies that were since identified. Of the many screening tests available, most studies investigated the accuracy of DSE and MPS. Two systematic reviews were conducted that compared DSE and MPS in the general population. These reviews reported that MPS was more sensitive in detecting CAD, but exercise stress echocardiography had higher specificity (Fleischmann 1998; Schinkel 2003). Findings from our review indicate that DSE and MPS have moderate levels of sensitivity and specificity to detect severe coronary artery stenosis.

Our key findings are presented in Summary of findings 1 . On direct analysis, DSE had a higher point estimate of sensitivity and specificity compared with MPS. This was statistically significant for both the overall indirect comparison analysis $(P=0.02)$ and the sensitivity analysis which included only studies that avoided partial verification $(P=0.03)$. There was no statistical evidence that DSE had higher diagnostic accuracy in the sensitivity analysis which included only studies that avoided partial verification and had reference standard thresholds $\geq 70 \%$ stenosis $(P=0.09$ ). However, because results from studies that applied this common threshold were similar to the overall analysis, the lack of statistical significance may have resulted from a reduction of power due to the smaller number of included studies. Although there were few direct comparisons, in two studies that compared DSE and MPS in the same population, DSE had a higher specificity and equivalent or better sensitivity than MPS.

That DSE had a higher specificity than MPS is consistent with the principle that reversible systolic dysfunction (detected by DSE) usually occurs after reversible perfusion abnormalities (detected by MPS). In the general population, MPS should have higher sensitivity but lower specificity than stress echocardiography because systolic dysfunction often occurs only when severe CAD is present. Patients with ESKD often have hypertension, left ventricular hypertrophy and decreased coronary flow reserve, all of which could account for reduced specificity of MPS in kidney transplant candidates (Houghton 1990).

Causes of false negative results in MPS in the general population include balanced triple vessel disease and submaximal heart rate during stress. Although the reason for lower sensitivity in kidney transplant candidates compared with the general population remains unclear, differences in the effect of the stress agent drug among patients with CKD and the general population offers a possible physiological reason for the difference in sensitivity. Dipyridamole, the drug routinely used in MPS, causes vasodilation of coronary blood vessels by promoting accumulation of adenosine, an endogenous vasodilator. Dipyridamole infusion leads to vasodilation of normal coronary arteries, which is interpreted as an appropriate normal increase in cardiac perfusion. The decreased perfusion resulting from reduced vasodilator response of diseased vessels is interpreted as reversible ischaemia. A corresponding rise in heart rate also generally occurs during dipyridamole infusion and is thought to be secondary to vasodilatation, mediated in part by the cardiac nerves. Heart transplant recipients have been shown to have limited vasodilator response to dipyridamole, which has been attributed to increased resting myocardial blood flow in the transplanted heart resulting from increased cardiac workload and cardiac de-innervation (Rechavia 1992). Similarly, patients with CKD (particularly those who have diabetes) may also experience a degree of functional de-innervation as part of an autonomic neuropathy, which would potentially reduce the relative efficacy of dipyridamole. CKD is also invariably associated with arterial calcification and reduced coronary artery flow reserve (Niizuma 2008; Sezer 2007). This may also potentially lead to a decrease in responsiveness to the vasodilating properties of dipyridamole. On the other hand, dobutamine which is commonly used in stress echocardiography, has direct inotropic effects on the cardiac myocyte and potentially may be less affected by the mechanism described.

There was also more variability in the spread of the MPS test results in SROC space compared with DSE. This is probably because MPS is a more subjective test. Several studies of MPS demonstrated considerable inter- and intra-patient result variability, which may limit its diagnostic utility (Akesson 2004; Burkhoff 2001). Variability was also observed in the DSE results, which may be due to unevenness in local expertise to interpret test results across different studies.

Significant heterogeneity was present, which could not be explained by differences in reference threshold and partial verification. Clearly, other factors may have contributed to the clinical heterogeneity in the results. These include differences in study population characteristics (such as prevalence of chest pain, prevalence of diabetes) and test application (diagnostic test threshold, criteria for positive test, choice of stress agent and stress protocol, and operator variability). Limited data from the small numbers of studies and participants meant that we were unable to perform subgroup analyses of the effect of DM and prevalence of angina and IHD on diagnostic performance. Other differences 
across studies may also have played a role. One possible factor was sex of the participants. One study (Gowdak 2010) showed that among patients with diabetes, MPS test performance was influenced by the sex of participants; sensitivity was lower in women (females 56\%; males 65\%). Accuracy data based on sex was not reported in any of the included studies. Hence, we were unable to determine if the sex of the participant influenced diagnostic accuracy.

Generally, methodological quality was poorly reported. Methodological quality scoring was based on published reports and additional data provided from correspondence with study authors. Unclear reporting of certain methodological issues may not necessarily indicate poor study design; restrictions imposed by journal word limits, or editing, may have precluded reporting all QUADAS items. Several methodological quality items were reported less frequently than others. These included blinding of reference tests $(7 / 25$ not reported), blinding of index tests $(8 / 25$ not reported), and acceptable delay between tests (12/25 not reported). In addition to the studies where blinding of reference and index tests was uncertain, $3 / 25$ studies reported no blinding of the reference standard; one study reported no blinding of the index test. Therefore, lack of blinding may have affected our results; the overall effect of unblinded reporting of reference and index tests is generally leads to overestimation of diagnostic accuracy (Leeflang 2006).

We did not find any studies that investigated cardiopulmonary exercise testing, CT coronary angiography, magnetic resonance angiography or cardiac magnetic resonance imaging. Fewer than five studies were found for each of EBCT, ECG, conventional echocardiography, exercise ventriculography, DSF and CIMT. This precluded any further meaningful comparisons other than that between DSE and MPS. DSF and exercise ventriculography are seldom used for CAD screening. Nevertheless, results from studies identified for this review (DSF: sensitivity $78 \%$, specificity $66 \%$; exercise ventriculography: sensitivity $50 \%$, specificity $67 \%$ ) suggest that neither DSF nor exercise ventriculography were likely to be superior to DSE or MPS. EST appeared to have offer high specificity $(91 \%)$ but poor sensitivity $(36 \%)$ in the one study that included a sufficient number of participants (Sharma 2005). Resting wall motion abnormality detected on traditional resting transthoracic echocardiography was also found to offer high specificity (95\% to $96 \%$ ) but low sensitivity (31\% to 33\%). Mitral annular calcification on echocardiography was studied in the same population (Sharma $2005)$ and this had higher sensitivity $(61 \%)$ at the expense of lower specificity $(72 \%)$. The marked variability in sensitivity and specificity of resting ECG confirms that it has no role in triaging patients for CAD. Notwithstanding the limitations posed by few numbers of studies and participants presented, EBCT and calcium scoring methods also appeared to have limited utility in evaluating the cardiac health of potential kidney transplant recipients. This is reflected in the fact that the optimal test performance of EBCT in the only study identified (Rosario 2010) was a calcium score of 1330.72, which is higher than the usual threshold used in the general population. There is also a theoretical disadvantage of calcium scoring methods in potential kidney transplant recipients due to the increased prevalence of arterial calcification in patients with CKD, arising from metabolic bone disease. Although published studies were not identified in this review, other tests that might be expected to have limited application in the pre-transplant setting for patients with CKD include CT coronary angiography (exposure to nephrotoxic IV contrast that could adversely affect any residual kidney function) and magnetic resonance imaging (MRI) or angiography (risk of gadolinium induced nephrogenic systemic fibrosis).

\section{Strengths and weaknesses of the review}

A strength of this review was the sensitive electronic search strategy developed that identified both published and unpublished studies. Our search strategy excluded search filters for diagnostic terms because they have limited utility (Leeflang 2006; Ritchie 2007). Other strengths included our analytic approach of combining results from studies with similar methodological characteristics and applying the HSROC model to conduct our analysis. The hierarchical modelling strategy accounted for sampling variability in estimates of sensitivity and specificity (and their correlations) in each study when estimating the random effects. This resulted in accuracy estimates that provided better assessments of underlying common log odds ratios (Macaskill 2003). To ensure that findings were generalisable, we included only studies that investigated only potential kidney transplant recipients. We excluded studies that enrolled participants with ESKD because it could be reasonably anticipated that inclusion of unselected dialysis patients would modify expected differences in underlying prevalence of CAD, and the presence and severity of other comorbidities, as well as differences in clinical rationales for testing. By concentrating on potential transplant candidates our findings may not be generalisable to dialysis or CKD patients who would not benefit from transplantation. Our vigilance in contacting authors to obtain data missing or not reported in studies was rewarded by a satisfying number of responses.

Significant heterogeneity was present among studies that investigated the same screening test. Given that underlying prevalence of disease in a population has potential to alter diagnostic performance (Leeflang 2009), knowledge of the effect of clinical characteristics such as angina or diabetes on diagnostic performance would enable better informed decisions about screening and interpretation of results. Although differences in study population characteristics, such as prevalence of chest pain, and test application (diagnostic test threshold, criteria for positive test, choice of stress agent and stress protocol, and operator variability) were likely to have contributed to heterogeneity, we were hindered in estimating their contributions because of data paucity, which resulted in low power. Consequently, we were unable to derive summary measures of diagnostic performance for specific patient subgroups. Data that were directly comparative were limited and also resulted in low power to detect important differences in accuracy among tests. Incomplete reporting of baseline characteristics and study design features that are necessary for scoring methodological quality was a further limitation that was resolved by contacting study authors to obtain additional data.

\section{Applicability of findings to the review question}

Current guidelines for preoperative cardiac evaluation of transplant candidates are unclear about the optimal method of assessment for potential kidney transplant recipients. Patients are often referred for coronary angiography as a result of a positive noninvasive screening test or deemed to be at high risk of CAD. Noninvasive functional tests, such as DSE or MPS, have been used in the general population as a method of triaging patients for coronary 
angiography. Results from our review provide a base to inform clinical decision making that were derived from studies conducted in relevant populations. Table 4 summarises test performance for transplant candidates relative to the general population.

Figure 10 illustrates the applicability of our findings to clinical practice. Patients in the general population who present with stable chest pain for assessment are typically assigned pre-test probabilities of significant CAD of $10 \%$ to $29 \%$ (low risk), $30 \%$ to $59 \%$ (intermediate risk) or $60 \%$ to $90 \%$ (high risk) determined using risk tables (NICE Clinical Guideline 1995). Given the wide heterogeneity in the estimates for both DSE and MPS, there is considerable uncertainty in the true post-test probabilities of each test. However, using the summary estimates in this review, both DSE and MPS may prove useful in ruling out CAD in patients considered to be at low risk for the condition. Patients with positive stress test results warrant additional investigation with coronary angiography. However, the true discriminating value of both tests (especially DSE) is in detecting CAD in intermediate risk patients - a category that includes many potential kidney transplant recipients. Both tests help to classify patients at intermediate risk into either high or low risk categories. When DSE was used, patients at intermediate risk of CAD who tested positive had posttest probability of $73 \%$ to $90 \%$ (high risk) and those who tested negative were downgraded to low risk (10\% to $27 \%$ ). Both tests, but especially DSE, have roles as triage tests for intermediate risk transplant candidates; negative results can reduce the need for further evaluation with coronary angiography. In high risk patients, a positive non-invasive DSE or MPS test result confirms the high risk of severe CAD, but a negative result does not conclusively rule out severe CAD. These patients can be managed by being referred for coronary angiography, thus avoiding functional tests. Nevertheless, functional testing may provide additional prognostic information, or help to prioritise patients waiting to be referred for coronary angiography in resource-limited areas. 
Figure 10. †Based on the positive and negative likelihood ratios calculated from the systematic review in studies which avoided partial verification and used a reference standard threshold of $\geq 70 \%$ stenosis. DSE had a positive likelihood ratio of $6.44(95 \% \mathrm{Cl} 3.03$ to 13.70$)$ and negative likelihood ratio of $0.26(95 \% \mathrm{Cl} 0.13$ to 0.50$)$. MPS had a positive likelihood ratio of 2.89 (95\% Cl 1.39 to 5.99) and negative likelihood ratio of $0.43(95 \% \mathrm{Cl} 0.23$ to 0.80$)$.

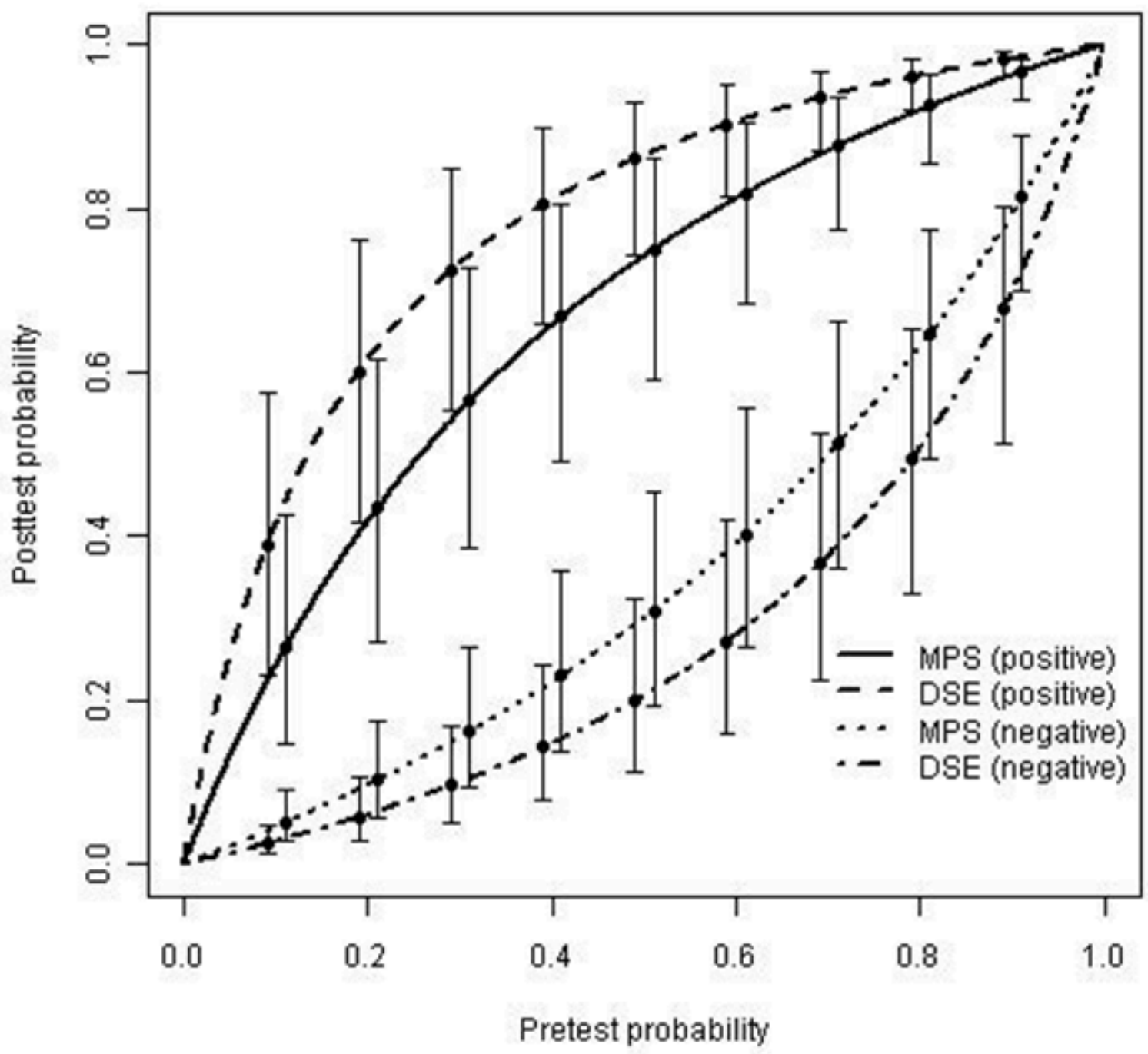

\begin{tabular}{|l|l|c|c|}
\hline \multicolumn{1}{|c|}{ Test } & \multicolumn{1}{|c|}{$\begin{array}{c}\text { Pre-test probability of } \\
\text { coronary artery disease }\end{array}$} & $\begin{array}{c}\text { Post-test Probability (\%) } \\
\text { after positive result }\end{array}$ & $\begin{array}{c}\text { Post-test Probability (\%) } \\
\text { after negative result }\end{array}$ \\
\hline \multirow{2}{*}{$\begin{array}{l}\text { Dobutamine stress } \\
\text { echocardiography (DSE) }\end{array}$} & Low risk (10-29\%) & $42-72 \%$ & $3-10 \%$ \\
\cline { 2 - 4 } & Intermediate risk (30-59\%) & $73-90 \%$ & $10-27 \%$ \\
\cline { 2 - 4 } $\begin{array}{l}\text { Myocardial perfusion } \\
\text { scintigraphy (MPS) }\end{array}$ & Low risk (10-29\%) & $91-98 \%$ & $28-70 \%$ \\
\cline { 2 - 4 } & Intermediate risk (30-59\%) & $24-54 \%$ & $5-15 \%$ \\
\cline { 2 - 4 } & High risk (60-90\%) & $55-81 \%$ & $16-38 \%$ \\
\hline
\end{tabular}

DSE and MPS are not perfect triage tests and a significant number of patients will either have their significant CAD missed (false negatives) or be referred unnecessarily for coronary angiography (false positives). Furthermore, the imprecision of the likelihood ratios resulting from significant between-study heterogeneity produces significant uncertainty in the post-test probabilities for both positive and negative tests. A negative DSE test would still, in a low risk population, yield a post-test probability of $10 \%$ to $27 \%$. However, both the desire to avoid complications arising from routine referral of such patients to an invasive gold standard investigations, and the lack of a more accurate alternative method of screening may or may not convince clinicians to consider such posterior test probabilities to be sufficiently low to 
excuse an asymptomatic individual from having further invasive investigation.

Our results need to be considered together with the real world limitations of practising medicine. Despite the apparent superiority of DSE over MPS to detect severe CAD, the interaction of many clinical factors often result in different transplant centres preferring one screening test over another. These factors may be institutional, arising from practicalities such as availability and or expertise of one screening modality, but not both, in a transplant centre; or patient-related issues such as lack of cardiorespiratory fitness or mobility for exercise stress testing. DSE requires IV infusion and is not available in all cardiology departments. Many cardiology practices offer exercise stress echocardiography, but we were unable to identify any studies of exercise stress echocardiography in potential kidney transplant recipients. The diagnostic accuracy of exercise stress echocardiography is likely to be similar to DSE, although there is a higher chance of submaximal, and therefore uninterpretable, stress test results in patients who undergo this test. The patient factors that affect physician choice of screening test are less likely to be an issue in a population of potential kidney transplant recipients compared with people who are not transplantation candidates, given that transplantation candidates represent a selected healthier subpopulation of those with CKD. MPS requires the presence of a nuclear medicine department. Although these departments are found in tertiary referral hospitals, they may not be present in smaller hospitals or resource-poor settings.

For this review, we defined coronary artery stenosis as $\geq$ $50 \%$ stenosis, and severe coronary artery stenosis as $\geq 70 \%$ stenosis. Although asymptomatic patients with certain high risk coronary lesions (e.g. left main or equivalent disease, and triple vessel CAD, particularly with left ventricular dysfunction) benefit from revascularisation regardless of symptoms (Eagle 2004), the benefit of preoperative revascularisation before transplant surgery remains questionable. Two RCTs (CARP (McFalls 2004) and DECREASE-V (Poldermans 2007)) did not demonstrate any revascularisation benefit in asymptomatic CAD before major vascular surgery. Nevertheless, the diagnosis of angiographicallyproven significant CAD in kidney transplant candidates imposes further implications on patient management. These include consideration of need for perioperative beta blockade, antiplatelet agents and anticoagulation. A recent registry study (De Lima 2010) confirmed that in patients with CKD and significant CAD, medical therapy results in adequate long-term event-free survival. However, in this study, a greater cardiac event rate occurred in patients who fulfilled criteria for revascularisation but declined intervention. Nevertheless, the lack of RCTs specifically addressing this question in kidney transplant settings means that uncertainty remains about if failure to perform coronary intervention when necessary results in an accentuated increased risk of adverse events and death.

\section{AUTHORS' CONCLUSIONS}

\section{Implications for practice}

Of the non-invasive screening tests available to detect CAD in potential kidney transplant candidates, MPS and DSE have been studied in detail. Both tests, especially DSE, have roles as triage tests for transplant candidates with intermediate of CAD. Negative DSE results preclude need for further evaluation using coronary angiography, avoiding unnecessary risk to patients and potentially reducing healthcare costs. Given the wide heterogeneity in the estimates for both DSE and MPS, considerable uncertainty remains concerning the true post-test probabilities of each test. Current evidence suggests that where feasible DSE should be used as the screening investigation of choice.

\section{Implications for research}

The ability to identify patients at high risk of CAD may not necessarily enable clinicians to predict cardiac event-free survival following transplantation. In the postoperative period, other factors such as inflammation, sympathetic nervous system activation, hypercoagulability and hypoxia contribute to increased cardiac morbidity and mortality (Yao 2004). Patients with kidney disease have abnormal coronary microcirculation and reduced coronary flow reserve, which may result in cardiac ischaemic events, even in the absence of macrovascular stenoses (Caliskan 2008; Niizuma 2008; Sezer 2007). Future research examining the ability of functional tests to predict postoperative outcome is urgently needed.

\section{ACKN OWLEDGEMENTS}

The authors would especially like to thank Petra Macaskill for her assistance in designing the statistical methodology for this review and providing invaluable statistical support. We also thank Professors Les Irwig and Stephen Chadban for their kind comments and assistance in reviewing an earlier version of this review; Narelle Willis, Managing Editor of the Cochrane Renal Group, and Leslee Edwards, the Administrative Officer of the Cochrane Renal Group, for their assistance in managing the editorial aspects of this review.

We would also like to thank the many study authors who provided additional information regarding their research, especially: Daniel Brennan, Maria Dolores Checa, José Jayme Galvão de Lima, An de Vriese, Cesar Garcia-Canton, Sishir Gang, Thomas Marwick, Gert Mayer, Gilmar Reis, Sylvia Rosas, Alice Schmidt, Jamshid Shirani, Nakul Sinha and Matthew Worthley.

This research was supported, in part, by the Jacquot Research Establishment Award administered by The Royal Australasian College of Physicians and the Australian and New Zealand Society of Nephrology. Dr Andrew Hayen has also received financial support from the Australian National Health and Medical Research Council Program (Grant Number 402764). 


\section{R E F E R E N C E S}

\section{References to studies included in this review}

Bates 1996 \{published data only\}

* Bates JR, Sawada SG, Segar DS, Spaedy AJ, Petrovic O, Fineberg NS, et al. Evaluation using dobutamine stress echocardiography in patients with insulin-dependent diabetes mellitus before kidney and/or pancreas transplantation. American Journal of Cardiology 1996;77(2):175-9. [MEDLINE: 8546087]

\section{Bennett 1978 \{published data only\}}

* Bennett WM, Kloster F, Rosch J, Barry J, Porter GA. Natural history of asymptomatic coronary arteriographic lesions in diabetic patients with end-stage renal disease. American Journal of Medicine 1978;65(5):779-84. [MEDLINE: 360837]

\section{Boudreau 1990 \{published data only\}}

* Boudreau RJ, Strony JT, DuCret RP, Kuni CC, Wang Y, Wilson R, F, et al. Perfusion thallium imaging of type I diabetes patients with end stage renal disease: Comparison of oral and intravenous dipyridamole administration. Radiology 1990;175(1):103-5. [MEDLINE: 2315467]

\section{Brennan 1997 \{published and unpublished data\}}

* Brennan DC, Vedala G, Miller SB, Anstey ME, Singer GG, Kovacs, $A$, et al. Pretransplant dobutamine stress echocardiography is useful and cost-effective in renal transplant candidates. Transplantation Proceedings 1997;29(1-2):233-4. [MEDLINE: 9122976]

Cai 2010 \{published data only (unpublished sought but not used)\}

* Cai Q, Serrano R, Kalyanasundaram A, Shirani J. A preoperative echocardiographic predictive model for assessment of cardiovascular outcome after renal transplantation. Journal of the American Society of Echocardiography 2010;23(5):560-6. [MEDLINE: 20381999]

De Lima 2003 \{published and unpublished data\}

* De Lima JJG, Sabbaga E, Vieira MLC, De Paula FJ, Ianhez LE, Krieger EM, et al. Coronary angiography is the best predictor of events in renal transplant candidates compared with noninvasive testing. Hypertension 2003;42(3):263-8. [MEDLINE: 12913060]

\section{Ferreira 2007 \{published data only\}}

* Ferreira PAM, De Lima VC, Campos FO, Gil MA, Cordovil A, Machado, CV, et al. Feasibility, safety and accuracy of dobutamine/atropine stress echocardiography for the detection of coronary artery disease in renal transplant candidates. Arquivos Brasileiros de Cardiologia 2007;88(1):41-7. [MEDLINE: 17364118]

\section{Gang 2007 \{published and unpublished data\}}

* Gang S, Dabhi M, Rajapurkar MM. Ischaemia imaging in type 2 diabetic kidney transplant candidates - is coronary angiography essential?. Nephrology Dialysis Transplantation 2007;22(8):2334-8. [MEDLINE: 17550928]
Garcia-Canton 1998 \{published and unpublished data\}

* Garcia-Canton C, Culebras C, Hernandez-Briz MJ, Palomar R, Moreno A, Toledo A, et al. Dobutamine stress echocardiography and stress 99M-Technetium methoxyisobutylisonitrile SPECT in the assessment of coronary artery disease in kidney transplant candidates [abstract]. Journal of the American Society of Nephrology 1998;9(September, Program and Abstracts):708.

Garg 2000 \{published and unpublished data\}

* Garg N, Kapoor A, Umesan CV, Sharma RK, Sinha N. Role of pretransplant arteriography in diabetic end-stage renal disease. Asian Cardiovascular and Thoracic Annals 2000;8(2):150-4. [EMBASE: 2000282610]

Gowdak 2010 \{published data only (unpublished sought but not used)\}

* Gowdak LH, De Paula FJ, De Oliveira AL, Arantes RL, Cesar LA, Ramires JA, et al. Non-invasive screening for coronary artery disease in renal transplant candidates with diabetes is influenced by gender. European Society of Cardiology Congress; 2010 Aug 28-Sep 01; Stockholm, Sweden. http:// spo.escardio.org/AbstractDetails.aspx?id=91377 (last accessed 04 Oct 2011). 2010

Herzog 1999 \{published data only\}

* Herzog CA, Marwick TH, Pheley AM, White CW, Rao VK, Dick CD. Dobutamine stress echocardiography for the detection of significant coronary artery disease in renal transplant candidates. American Journal of Kidney Diseases 1999;33(6):1080-90. [MEDLINE: 10352196]

\section{Jassal 2007 \{published data only\}}

* Jassal DS, Neilan TG, Picard MH, Wood MJ. Stress echocardiography: Abnormal response of tissue Dopplerderived indices to dobutamine in the absence of obstructive coronary artery disease in patients with chronic renal failure. Echocardiography 2007;24(6):580-6. [MEDLINE: 17584197]

Krawczynska 1988 \{published data only\}

* Krawczynska EG, DePuey EG, Whelchel JD. Tl-201 cardiac SPECT to evaluate pre-renal transplant patients [abstract]. Journal of Nuclear Medicine 1988;29(5 Suppl):950.

Marwick 1989 \{published and unpublished data\}

* Marwick T, Hobbs R, Vanderlaan RL, Steinmuller D, Braun W. Use of digital subtraction fluorography in screening for coronary artery disease in patients with chronic renal failure. American Journal of Kidney Diseases 1989;14(2):105-9. [MEDLINE: 2667345]

\section{Marwick 1990 \{published and unpublished data\}}

* Marwick TH, Steinmuller DR, Underwood DA, Hobbs RE, Go RT, Swift C, et al. Ineffectiveness of dipyridamole SPECT thallium imaging as a screening technique for coronary artery disease in patients with end-stage renal failure. Transplantation 1990;49(1):100-3. [MEDLINE: 2300998] 
Modi 2006 \{published data only\}

* Modi N, Kapoor A, Kumar S, Tewari S, Garg N, Sinha N. Utility of carotid intimal medial thickness as a screening tool for evaluation of coronary artery disease in pre-transplant end stage renal disease. Journal of Postgraduate Medicine 2006;52(4):266-70. [MEDLINE: 17102544]

Reis 1995 \{published and unpublished data\}

* Reis G, Marcovitz PA, Leichtman AB, Merion RM, Fay WP, Werns SW, et al. Usefulness of dobutamine stress echocardiography in detecting coronary artery disease in end-stage renal disease. American Journal of Cardiology 1995;75(10):707-10. [MEDLINE: 7900665]

\section{Rosario 2010 \{published data only\}}

* Rosario MA, de Lima JJ, Parga JR, Avila LF, Gowdak LH, Lemos PA, et al. Coronary calcium score as predictor of stenosis and events in pretransplant renal chronic failure. Arquivos Brasileiros de Cardiologia 2010;94(2):239-43. [MEDLINE: 20428622]

\section{Sharma 2005 \{published data only\}}

* Sharma R, Pellerin D, Gaze DC, Gregson H, Streather CP, Collinson PO, et al. Dobutamine stress echocardiography and the resting but not exercise electrocardiograph predict severe coronary artery disease in renal transplant candidates. Nephrology Dialysis Transplantation 2005;20(10):2207-14. [MEDLINE: 16030034]

Sharma R, Pellerin D, Gaze DC, Shah JS, Streather CP, Collinson PO, et al. Dobutamine stress echocardiography and cardiac troponin $\mathrm{T}$ for the detection of significant coronary artery disease and predicting outcome in renal transplant candidates. European Journal of Echocardiography 2005;6(5):327-35. [MEDLINE: 15985387]

\section{Sharma 2009 \{published data only\}}

* Sharma R, Mehta RL, Brecker SJD, Gaze DC, Gregson H, Streather $\mathrm{CP}$, et al. The diagnostic and prognostic value of tissue Doppler imaging during dobutamine stress echocardiography in end-stage renal disease. Coronary Artery Disease 2009;20(3):230-7. [MEDLINE: 19387250]

\section{Sharples 2004 \{published data only\}}

* Sharples EJ, Pereira D, Summers S, Cunningham J, Rubens M, Goldsmith $\mathrm{D}$, et al. Coronary artery calcification measured with electron-beam computerized tomography correlates poorly with coronary artery angiography in dialysis patients. American Journal of Kidney Diseases 2004;43(2):313-9. [MEDLINE: 14750097]

\section{Vandenberg 1996 \{published and unpublished data\}}

* Vandenberg BF, Rossen JD, Grover-Mckay M, Shammas NW, Burns TL, Rezai K. Evaluation of diabetic patients for renal and pancreas transplantation: Noninvasive screening for coronary artery disease using radionuclide methods. Transplantation 1996;62(9):1230-5. [MEDLINE: 8932262]

\section{West 2000 \{published data only\}}

* West JC, Napoliello DA, Costello JM, Nassef LA, Butcher RJ, Hartle JE, et al. Preoperative dobutamine stress echocardiography versus cardiac arteriography for risk assessment prior to renal transplantation. Transplant International 2000;13(Suppl 1):S27-30. [MEDLINE: 11111956]

Worthley 2003 \{published and unpublished data\}

* Worthley MI, Unger SA, Mathew TH, Russ GR, Horowitz JD. Usefulness of tachycardic-stress perfusion imaging to predict coronary artery disease in high-risk patients with chronic renal failure. American Journal of Cardiology 2003;92(11):1318-20. [MEDLINE: 14636911]

\section{References to studies excluded from this review}

\section{Ali 2004 \{published data only\}}

* Ali M, Giblin L, Farhad K, O'Kelly P, Hickey D, Little D, et al. Pretransplant cardiac investigations in the Irish renal transplant population--the effectiveness of our current screening techniques in predicting cardiac events. Renal Failure 2004;26(4):375-80. [MEDLINE: 15462104]

\section{Arantes 2010 \{published data only\}}

* Arantes RL, Gowdak LH, Paula FJ, lanhez LE, Ramires JAF, Krieger EM, et al. Myocardial scintigraphy and clinical stratification as predictors of events in renal transplant candidates. Journal of Nephrology 2010;23(3):314-20. [MEDLINE: 20349410]

\section{Braun 1984 \{published data only\}}

* Braun WE, Phillips DF, Vidt DG, Novick AC, Nakamoto S, Popowniak KL, et al. Coronary artery disease in 100 diabetics with end-stage renal failure. Transplantation Proceedings 1984;16(3):603-7. [MEDLINE: 6375027]

Brown 1989 \{published data only\}

* Brown KA, Rimmer J, Haisch C. Noninvasive cardiac risk stratification of diabetic and nondiabetic uremic renal allograft candidates using dipyridamole-thallium-201 imaging and radionuclide ventriculography. American Journal of Cardiology 1989;64(16):1017-21. [MEDLINE: 2816731]

Caglar 2006 \{published data only\}

* Caglar M, Mahmoudian B, Aytemir K, Kahraman S, Arici M, Kabakci G, et al. Value of 99mTc-methoxyisobutylisonitrile (99mTc-MIBI) gated SPECT for the detection of silent myocardial ischemia in hemodialysis patients: clinical variables associated with abnormal test results. Nuclear Medicine Communications 2006;27(1):61-9. [MEDLINE: 16340725]

Camp 1990 \{published data only\}

* Camp AD, Garvin PJ, Hoff J, Marsh J, Byers SL, Chaitman BR. Prognostic value of intravenous dipyridamole thallium imaging in patients with diabetes mellitus considered for renal transplantation. American Journal of Cardiology 1990;65(22):1459-63. [MEDLINE: 2353652]

Cortigiani 2005 \{published data only\}

* Cortigiani L, Desideri A, Gigli G, Vallebona A, Terlizzi R, Giusti R, et al. Clinical, resting echo and dipyridamole stress echocardiography findings for the screening of renal transplant candidates. International Journal of Cardiology 2005;103(2):168-74. [MEDLINE: 16080976] 
Cottier 1990 \{published data only\}

* Cottier C, Pfisterer M, Muller-Brand J, Thiel G, Burkart F. Cardiac evaluation of candidates for kidney transplantation: value of exercise radionuclide angiocardiography. European Heart Journal 1990;11(9):832-8. [MEDLINE: 2226509]

\section{Cross 1996 \{published data only\}}

* Cross DS, Alagarsamy SH, Adams M, Esquivel-Avila JG, Carson R, Ahmad M. Dobutamine stress echocardiography for risk stratification in patients for renal transplantation [abstract no: 3967]. Circulation 1996;94.

Dahan 1995 \{published data only\}

* Dahan M, Legallicier B, Himbert D, Faraggi M, Aubry N, Siohan P, et al. [Diagnostic value of myocardial thallium stress scintigraphy in the detection of coronary artery disease in patients undergoing chronic hemodialysis] [Valeur diagnostique de la scintigraphie myocardique au thallium sous stimulation dans la detection de la maladie coronarienne chez l'hemodialyse chronique]. Archives des Maladies du Coeur et des Vaisseaux 1995;88(8):1121-3. [MEDLINE: 8572857]

\section{Dahan 1998 \{published data only\}}

* Dahan M, Viron BM, Faraggi M, Himbert DL, Legallicier BJ, Kolta AM, et al. Diagnostic accuracy and prognostic value of combined dipyridamole- exercise thallium imaging in hemodialysis patients. Kidney International 1998;54(1):255-62. [MEDLINE: 9648086]

\section{Dahan 2002 \{published data only\}}

* Dahan M, Viron BM, Poiseau E, Kolta AM, Aubry N, Paillole C, et al. Combined dipyridamole-exercise stress echocardiography for detection of myocardial ischemia in hemodialysis patients: An alternative to stress nuclear imaging. American Journal of Kidney Diseases 2002;40(4):737-44. [MEDLINE: 12324908]

De Vriese 2009 \{published data only (unpublished sought but not used)\}

* De Vriese AS, De Bacquer DA, Verbeke FH, De Winter O, Franken PR, De Sutter JH, et al. Comparison of the prognostic value of dipyridamole and dobutamine myocardial perfusion scintigraphy in hemodialysis patients. Kidney International 2009;76(4):428-36. [MEDLINE: 19494798]

Derfler 1991 \{published data only\}

* Derfler K, Kletter K, Balcke P, Heinz G, Dudczak R. Predictive value of thallium-201-dipyridamole myocardial stress scintigraphy in chronic hemodialysis patients and transplant recipients. Clinical Nephrology 1991;36(4):192-202. [MEDLINE: 1959245]

\section{Dussol 2004 \{published data only\}}

* Dussol B, Bonnet J-L, Sampol J, Savin B, De La Forte C, Mundler $\mathrm{O}$, et al. Prognostic value of inducible myocardial ischemia in predicting cardiovascular events after renal transplantation. Kidney International 2004;66(4):1633-9. [MEDLINE: 15458460]

\section{Eschertzhuber 2005 \{published data only\}}

* Eschertzhuber S, Hohlrieder M, Boesmueller C, Pomaroli A, Steurer W, Junker T, et al. Incidence of coronary heart disease and cardiac events in patients undergoing kidney and pancreatic transplantation. Transplantation Proceedings 2005;37(2):1297-300. [MEDLINE: 15848702]

Feola 2002 \{published data only\}

* Feola M, Biggi A, Ribichini F, Rovere A, Vado A, Camuzzini G, et al. Predicting cardiac events with TL201 dipyridamole myocardial scintigraphy in renal transplant recipients. Journal of Nephrology 2002;15(1):48-53. [MEDLINE: 11936426]

Fossati 2004 \{published data only\}

* Fossati N, Meacci L, Amorese G, Bellissima G, Pieri M, Nardi S et al. Cardiac evaluation for simultaneous pancreas-kidney transplantation and incidence of cardiac perioperative complications: Preliminary study. Transplantation Proceedings 2004;36(3):582-5. [MEDLINE: 15110601]

Fujimoto 2006 \{published data only\}

* Fujimoto N, Iseki K, Tokuyama K, Tamashiro M, Takishita S. Significance of coronary artery calcification score (CACS) for the detection of coronary artery disease (CAD) in chronic dialysis patients. Clinica Chimica Acta 2006;367(1-2):98-102. [MEDLINE: 16413522]

\section{Fukui 2005 \{published data only\}}

* Fukui M, Mori Y, Takehana K, Masaki H, Motohiro M, Sakamoto N, et al. Assessment of coronary artery disease in hemodialysis patients with delayed systolic blood pressure response after exercise testing. Blood Purification 2005;23(6):466-72. [MEDLINE: 16282683]

\section{Fuster 2000 \{published data only\}}

* Fuster D, Magrina J, Ricart MJ, Pascual J, Laterza C, Setoain FJ, et al. Noninvasive assessment of cardiac risk in type I diabetic patients being evaluated for combined pancreas-kidney transplantation using dipyridamole-MIBI perfusion tomographic scintigraphy. Transplant International 2000;13(5):327-32. [MEDLINE: 11052267]

Holley 1991 \{published data only\}

* Holley JL, Fenton RA, Arthur RS. Thallium stress testing does not predict cardiovascular risk in diabetic patients with endstage renal disease undergoing cadaveric renal transplantation. American Journal of Medicine 1991;90(5):563-70. [MEDLINE: 2029013]

Iqbal 1991 \{published data only\}

* Iqbal A, Gibbons RJ, McGoon MD, Sterioff S, Frohnert PP, Velosa JA. Noninvasive assessment of cardiac risk in insulindependent diabetic patients being evaluated for pancreatic transplantation using thallium-201 myocardial perfusion scintigraphy. Clinical Transplantation 1991;5(1):13-9. [MEDLINE: 10147633]

Jeloka 2007 \{published data only\}

* Jeloka TK, Ross H, Smith R, Huang M, Fenton S, Cattran D, et al. Renal transplant outcome in high-cardiovascular risk recipients. Clinical Transplantation 2007;21(5):609-14. [MEDLINE: 17845634] 
Krotin 2007 \{published data only\}

* Krotin M, Vukovic D, Stojanovic O, Milovanovic B, Celeketic D, Blagojevic R. Prognostic value of dobutamine stress echocardiography in patients with terminal renal insufficiency undergoing hemodialysis - a 5-year follow up. Medicinski Pregled 2007;60(7-8):333-7. [MEDLINE: 17990798]

Langford 1997 \{published data only\}

* Langford EJ, De Belder AJ, Cairns H, Hendry BM, Wainwright RJ. Non-invasive cardiac investigations in patients awaiting renal transplantation. Journal of the Royal Society of Medicine 1997;90(3):136-7. [MEDLINE: 9135610]

\section{Le 1994 \{published data only\}}

* Le A, Wilson R, Douek K, Pulliam L, Tolzman D, Norman D, et al. Prospective risk stratification in renal transplant candidates for cardiac death. American Journal of Kidney Diseases 1994;24(1):65-71. [MEDLINE: 8023826]

\section{Leonardi 2009 \{published data only\}}

* Leonardi G, Tamagnone M, Ferro M, Tognarelli G, Messina M, Giraudi R, et al. Assessment of cardiovascular risk in waitinglisted renal transplant patients: a single center experience in 558 cases. Clinical Transplantation 2009;23(5):653-9. [MEDLINE: 19563485]

\section{Lewis 2002 \{published data only\}}

* Lewis MS, Wilson RA, Walker KW, Wilson DJ, Norman DJ, Barry JM, et al. Validation of an algorithm for predicting cardiac events in renal transplant candidates. American Journal of Cardiology 2002;89(7):847-50. [MEDLINE: 11909572]

\section{Lin 2001 \{published data only\}}

* Lin K, Stewart D, Cooper S, Davis CL. Pre-transplant cardiac testing for kidney-pancreas transplant candidates and association with cardiac outcomes. Clinical Transplantation 2001;15(4):269-75. [MEDLINE: 11683822]

\section{Ma 2006 \{published data only\}}

* Ma IW, Valantine HA, Shibata A, Waskerwitz J, Dafoe DC, Alfrey EJ, et al. Validation of a screening protocol for identifying low-risk candidates with type 1 diabetes mellitus for kidney with or without pancreas transplantation. Clinical Transplantation 2006;20(2):139-46. [MEDLINE: 16640517]

\section{Manske 1997 \{published data only\}}

* Manske CL, Wilson RF, Wang Y, Thomas W. Atherosclerotic vascular complications in diabetic transplant candidates. American Journal of Kidney Diseases 1997;29(4):601-7. [MEDLINE: 9100051]

\section{Mao 2010 \{published data only\}}

* Mao J, Karthikeyan V, Poopat C, Song T, Pantelic M, Chattahi J, et al. Coronary computed tomography angiography in dialysis patients undergoing pre-renal transplantation cardiac risk stratification. Cardiology Journal 2010;17(4):349-61. [MEDLINE: 20690090]

\section{Mistry 1998 \{published data only\}}

* Mistry BM, Bastani B, Solomon H, Hoff J, Aridge DL, Lindsey LM, et al. Prognostic value of dipyridamole thallium-201 screening to minimize perioperative cardiac complications in diabetics undergoing kidney or kidney-pancreas transplantation. Clinical Transplantation 1998;12(2):130-5. [MEDLINE: 9575401]

\section{Morrow 1983 \{published data only\}}

* Morrow CE, Schwartz JS, Sutherland DE, Simmons RL, Ferguson RM, Kjellstrand CM, et al. Predictive value of thallium stress testing for coronary and cardiovascular events in uremic diabetic patients before renal transplantation. American Journal of Surgery 1983;146(3):331-5. [MEDLINE: 6351648]

Nguyen 2007 \{published data only\}

* Nguyen PT, Coche E, Goffin E, Beguin C, Vlassenbroek A, Devuyst $O$, et al. Prevalence and determinants of coronary and aortic calcifications assessed by chest CT in renal transplant recipients. American Journal of Nephrology 2007;27(4):329-35. [MEDLINE: 17505133]

\section{Nishimura 2004 \{published data only\}}

* Nishimura M, Hashimoto T, Kobayashi H, Fukuda T, Okino K, Yamamoto N, et al. Myocardial scintigraphy using a fatty acid analogue detects coronary artery disease in hemodialysis patients. Kidney International 2004;66(2):811-9. [MEDLINE: 15253738]

\section{Ohtake 2005 \{published data only\}}

* Ohtake T, Kobayashi S, Moriya H, Negishi K, Okamoto K, Maesato K, et al. High prevalence of occult coronary artery stenosis in patients with chronic kidney disease at the initiation of renal replacement therapy: an angiographic examination. Journal of the American Society of Nephrology 2005;16(4):1141-8. [MEDLINE: 15743997]

Oliveira 2005 \{published data only\}

* Oliveira DC, Filho GG, Nakamoto A, Souza FL, De Sa JR, Pestana JO, et al. Prevalence of coronary artery disease in type I diabetic candidates for double transplantation (kidney and pancreas). Arquivos Brasileiros de Cardiologia 2005;84(2):108-110. [MEDLINE: 15761631]

Patel 2003 \{published data only\}

* Patel AD, Abo-Auda WS, Davis JM, Zoghbi GJ, Deierhoi MH, Heo J, et al. Prognostic value of myocardial perfusion imaging in predicting outcome after renal transplantation. American Journal of Cardiology 2003;92(2):146-51. [MEDLINE: 12860215]

Patel 2008 \{published data only\}

* Patel RK, Mark PB, Johnston N, McGeoch R, Lindsay M, Kingsmore DB, et al. Prognostic value of cardiovascular screening in potential renal transplant recipients: a singlecenter prospective observational study. American Journal of Transplantation 2008;8(8):1673-83. [MEDLINE: 18510627]

\section{Philipson 1986 \{published data only\}}

* Philipson JD, Carpenter BJ, Itzkoff J, Hakala TR, Rosenthal JT, Taylor RJ, et al. Evaluation of cardiovascular risk for renal transplantation in diabetic patients. American Journal of Medicine 1986;81(4):630-4. [MEDLINE: 3532789] 
Porter 2003 \{published data only\}

* Porter GA, Norton TL, Lindsley J, Stevens JS, Phillips DS, Bennett WM. Relationship between elevated serum troponin values in end-stage renal disease patients and abnormal isotopic cardiac scans following stress. Renal Failure 2003;25(1):55-65. [MEDLINE: 12617333]

\section{Rakhit 2006 \{published data only\}}

* Rakhit DJ, Armstrong KA, Beller E, Isbel NM, Marwick TH. Risk stratification of patients with chronic kidney disease: Results of screening strategies incorporating clinical risk scoring and dobutamine stress echocardiography. American Heart Journal 2006;152(2):363-70. [MEDLINE: 16875924]

\section{Robinson 2007 \{published data only\}}

* Robinson J, Tan AU, Wilensky RL, Matthai W, Munoz M, Rosas SE. Electron-beam computerized tomography correlates with coronary angiogram in chronic kidney disease patients. American Journal of Nephrology 2007;27(3):247-52. [MEDLINE: 17389785]

\section{Russell 1993 \{published data only\}}

* Russell JD, Stanton EB, Lambert K, et al. Risk stratification for cardiovascular disease in renal transplant candidates: The role of dipyridamole thallium scintigraphy [abstract]. Journal of the American Society of Nephrology. 1993; Vol. 4, issue 3:960.

Schmidt 2001 \{published data only (unpublished sought but not used)\}

* Schmidt A, Stefenelli T, Schuster E, Mayer G. Informational contribution of noninvasive screening tests for coronary artery disease in patients on chronic renal replacement therapy. American Journal of Kidney Diseases 2001;37(1):56-63. [MEDLINE: 11136168]

\section{Sharma 2007 \{published data only\}}

* Sharma R, Chemla E, Tome M, Mehta RL, Gregson H, Brecker SJ, et al. Echocardiography-based score to predict outcome after renal transplantation. Heart 2007;93(4):464-9. [MEDLINE: 16980518]

Tita 2008 \{published data only\}

* Tita C, Karthikeyan V, Stroe A, Jacobsen G, Ananthasubramaniam K. Stress echocardiography for risk stratification in patients with end-stage renal disease undergoing renal transplantation. Journal of the American Society of Echocardiography 2008;21(4):321-6. [MEDLINE: 17681725]

\section{Trochu 1991 \{published data only\}}

* Trochu JN, Cantarovich D, Renaudeau J, Patra O, du Roscoat P, Helias J. Assessment of coronary artery disease by thallium scan in type-1 diabetic uremic patients awaiting combined pancreas and renal transplantation. Angiology 1991;42(4):302-7. [MEDLINE: 2014921]

\section{Venkataraman 2008 \{published data only\}}

* Venkataraman R, Hage FG, Dorfman T, Heo J, Aqel RA, de Mattos AM, et al. Role of myocardial perfusion imaging in patients with end-stage renal disease undergoing coronary angiography. American Journal of Cardiology 2008;102(11):1451-6. [MEDLINE: 19026294]

Weinrauch 1978 \{published data only\}

* Weinrauch L, D'Elia JA, Healy RW, Gleason RE, Christleib AR, Leland OS. Asymptomatic coronary artery disease: angiographic assessment of diabetics evaluated for renal transplantation. Circulation 1978;58(6):1184-90. [MEDLINE: 361277]

Weinrauch 1992 \{published data only\}

* Weinrauch LA, D'Elia JA, Monaco AP, Gleason RE, Welty F, Nishan PC, et al. Preoperative evaluation for diabetic renal transplantation: Impact of clinical, laboratory, and echocardiographic parameters on patient and allograft survival. American Journal of Medicine 1992;93(1):19-28. [MEDLINE: 1626568]

Witczak 2006 \{published data only\}

* Witczak BJ, Hartmann A, Jenssen T, Foss A, Endresen K. Routine coronary angiography in diabetic nephropathy patients before transplantation. American Journal of Transplantation 2006;6(10):2403-8. [MEDLINE: 16952302]

Wong 2008 \{published data only\}

* Wong CF, Little MA, Vinjamuri S, Hammad A, Harper JM. Technetium myocardial perfusion scanning in prerenal transplant evaluation in the United Kingdom. Transplantation Proceedings 2008;40(5):1324-28. [MEDLINE: 18589097]

\section{Additional references}

\section{Akesson 2004}

Akesson L, Svensson A, Edenbrandt L. Operator dependent variability in quantitative analysis of myocardial perfusion images. Clinical Physiology and Functional Imaging 2004;24(6):374-9. [MEDLINE: 15522047]

\section{Alderman 1993}

Alderman EL, Corley SD, Fisher LD, Chaitman BR, Faxon DP, Foster ED, et al. Five-year angiographic follow-up of factors associated with progression of coronary artery disease in the Coronary Artery Surgery Study (CASS). CASS Participating Investigators and Staff. Journal of the American College of Cardiology 1993;22(4):1141-54. [MEDLINE: 8409054]

\section{Briggs 2001}

Briggs JD. Causes of death after renal transplantation. Nephrology Dialysis Transplantation 2001;16(8):1545-9. [MEDLINE: 11477152]

\section{Burkhoff 2001}

Burkhoff D, Jones JW, Becker LC. Variability of myocardial perfusion defects assessed by thallium-201 scintigraphy in patients with coronary artery disease not amenable to angioplasty or bypass surgery. Journal of the American College of Cardiology 2001;38(4):1033-9. [MEDLINE: 1583878]

\section{Caliskan 2008}

Caliskan Y, Oflaz H, Demirturk M, Yazici H, Turkmen A, Cimen A, et al. Coronary flow reserve dysfunction in hemodialysis 
and kidney transplant patients. Clinical Transplantation 2008;22(6):785-93. [MEDLINE: 19040561]

\section{De Lima 2010}

de Lima JJG, Gowdak LHW, de Paula FJ, Arantes RL, de Oliveira ALV, Ramires JAF, et al. Treatment of coronary artery disease in hemodialysis patients evaluated for transplant-A registry study. Transplantation 2010;89(7):845-50. [MEDLINE: 20019646]

\section{de Vet 2008}

de Vet HCW, Eisinga A, Riphagen II, Aertgeerts B, Pewsner D. Chapter 7: Searching for Studies. Cochrane Handbook for Systematic Reviews of Diagnostic Test Accuracy. Version 0.4 [updated September 2008]. The Cochrane Collaboration, 2008.

\section{Doust 2005}

Doust JA, Pietrzak E, Sanders S, Glasziou PP. Identifying studies for systematic reviews of diagnostic tests was difficult due to the poor sensitivity and precision of methodologic filters and the lack of information in the abstract. Journal of Clinical Epidemiology 2005;58(5):444-9. [MEDLINE: 15845330]

\section{Dudley 2008}

Dudley C, Harden P. Assessment for renal transplantation, 4th edition. UK Renal Association. http://www.renal.org/guidelines (accessed 17 January 2010) 2008.

\section{Eagle 2004}

Eagle KA, Guyton RA, Davidoff R, Edwards FH, Ewy GA, Gardner TJ, et al. ACC/AHA 2004 guideline update for coronary artery bypass graft surgery: a report of the American College of Cardiology/American Heart Association Task Force on Practice Guidelines (Committee to Update the 1999 Guidelines for Coronary Artery Bypass Graft Surgery). Circulation 2004;110(9):1168-1176. [DOI: 10.1161/01.CIR.0000138790.14877.7D]

\section{Fleischmann 1998}

Fleischmann KE, Hunink MGM, Kuntz KM, Douglas PS. Exercise echocardiography or exercise SPECT imaging? A meta-analysis of diagnostic test performance. JAMA 1998;280(10):913-20. [MEDLINE: 9739977]

\section{Gunnarsson 1984}

Gunnarsson R, Lofmark R, Nondlander R, Nyquist O, Groth CG. Acute myocardial infarction in renal transplant recipients: incidence and prognosis. European Heart Journal 1984;5(3):218-21. [MEDLINE: 6373265]

\section{Hofmann 2008}

Hofmann RM. Pretransplant cardiac evaluation: does it really prevent cardiovascular complications?. American Journal of Transplantation 2008;8(8):1575-7. [MEDLINE: 18694471]

\section{Houghton 1990}

Houghton JL, Frank MJ, Carr AA, von Dohlen TW, Prisant LM. Relations among impaired coronary flow reserve, left ventricular hypertrophy and thallium perfusion defects in hypertensive patients without obstructive coronary artery disease. Journal of the American College of Cardiology 1990;15(1):43-51. [MEDLINE: 2136877]

\section{Kasiske 2001}

Kasiske BL, Cangro CB, Hariharan S, Hricik DE, Kerman RH, Roth $\mathrm{D}$, et al. The evaluation of renal transplantation candidates: clinical practice guidelines. American Journal of Transplantation 2001;1(Suppl 2):3-95. [MEDLINE: 12108435]

\section{Knoll 2005}

Knoll G, Cockfield S, Blydt-Hansen T, Baran D, Kiberd B, Landsberg D, et al. Canadian Society of Transplantation: consensus guidelines on eligibility for kidney transplantation. CMAJ Canadian Medical Association Journal 2005;173(10):S1-25. [MEDLINE: 16275956]

\section{Leeflang 2006}

Leeflang MMG, Scholten RJPM, Rutjes AWS, Reitsma JB, Bossuyt PMM. Use of methodological search filters to identify diagnostic accuracy studies can lead to the omission of relevant studies. Journal of Clinical Epidemiology 2006;59(3):234-40. [MEDLINE: 16488353]

\section{Leeflang 2009}

Leeflang MMG, Bossuyt PMM, Irwig L. Diagnostic test accuracy may vary with prevalence: implications for evidence-based diagnosis. Journal of Clinical Epidemiology 2009;62(1):5-12. [MEDLINE: 18778913]

\section{Lentine 2005}

Lentine KL, Brennan DC, Schnitzler MA. Incidence and predictors of myocardial infarction after kidney transplantation. Journal of the American Society of Nephrology 2005;16(2):496-506. [MEDLINE: 15615820]

\section{Macaskill 2003}

Macaskill P. Empirical bayes estimates generated in a hierarchical summary ROC analysis agreed closely with those of a full Bayesian analysis. Journal of Clinical Epidemiology 2004;57:925-32. [MEDLINE: 15504635]

\section{Manoharan 2009}

Manoharan G, Ntalianis A, Muller O, Hamilos M, Sarno G, Melikian N, et al. Severity of coronary arterial stenoses responsible for acute coronary syndromes. American Journal of Cardiology 2009;103(9):1183-8. [MEDLINE: 19406256]

\section{McFalls 2004}

McFalls EO, Ward HB, Moritz TE, Goldman S, Krupski WC, Littooy F, et al. Coronary-artery revascularization before elective major vascular surgery. New England Journal of Medicine 2004;351:2795-804. [MEDLINE: 15625331]

\section{NICE Clinical Guideline 1995}

National Clinical Guideline Centre for Acute and Chronic Conditions. National Clinical Guideline 95. Chest pain of recent onset: Assessment and diagnosis of recent onset chest pain or discomfort of suspected cardiac origin. NHS National Institute for Health and Clinical Excellence. http://www.nice.org.uk/ guidance/CG95. (accessed June 9 2010) March 2010. 


\section{Niizuma 2008}

Niizuma S, Takiuchi S, Okada S, Horio T, Kamide K, Nakata H, et al. Decreased coronary flow reserve in haemodialysis patients. Nephrology Dialysis Transplantation 2008;23(7):2324-8. [MEDLINE: 18234846]

\section{Poldermans 2007}

Poldermans D, Schouten O, Vidakovic R, Bax JJ. Thomson IR. Hoeks SE, et al. A clinical randomized trial to evaluate the safety of a noninvasive approach in high-risk patients undergoing major vascular surgery: the DECREASE-V pilot study. Journal of the American College of Cardiology 2007;49(17):1763-9. [MEDLINE: 17466225]

\section{Rechavia 1992}

Rechavia E, Araujo LI, De Silva R, Kushwaha SS, Lammertsma AA, Jones T, et al. Dipyridamole vasodilator response after human orthotopic heart transplantation: quantification by oxygen-15-labeled water and positron emission tomography. Journal of the American College of Cardiology 1992;19(1):100-6. [MEDLINE: 1729318]

\section{Reitsma 2009}

Reitsma JB, Rutjes AWS, Whiting P, Vlassov VV, Leeflang MMG, Deeks JJ. Chapter 9: Assessing methodological quality. In: Deeks JJ, Bossuyt PM, Gatsonis C (editors), Cochrane Handbook for Systematic Reviews of Diagnostic Test Accuracy Version 1.0.0. The Cochrane Collaboration, 2009. Available from: http:// srdta.cochrane.org.

\section{Ritchie 2007}

Ritchie G, Glanville J, Lefebvre C. Do published search filters to identify diagnostic test accuracy studies perform adequately?. Health Information and Libraries Journal 2007;24(3):188-92. [MEDLINE: 17714173]

\section{Rutter 2001}

Rutter CM, Gatsonis CA. A hierarchical regression approach to meta-analysis of diagnostic test accuracy evaluations. Statistics in Medicine 2001;20(19):2865-84. [MEDLINE: 11568945]

\section{SAS9. $2^{\circledR}$ [Computer program]}

Copyright SAS Institute Inc. SAS. Version 9.2. Cary, NC, USA: Copyright SAS Institute Inc.

\section{CHARACTERISTICS OF STUDIES}

Characteristics of included studies [ordered by study ID]

\section{Schinkel 2003}

Schinkel AFL, Bax JJ, Geleijnse ML, Boersma E, Elhendy A, Roelandt JR, et al. Noninvasive evaluation of ischaemic heart disease: myocardial perfusion imaging or stress echocardiography?. European Heart Journal. 2003;24(9):789-800. [MEDLINE: 12727146]

\section{Sezer 2007}

Sezer M, Ozcan M, Okcular I, Elitok A. Umman S. Umman B, et al. A potential evidence to explain the reason behind the devastating prognosis of coronary artery disease in uraemic patients: Renal insufficiency is associated with poor coronary collateral vessel development. International journal of cardiology 2007;115(3):366-72. [MEDLINE: 16793151]

\section{Smidt 2008}

Smidt N, Deeks J, Moore T (editors). Chapter 4: Guide to the contents of a Cochrane review and protocol. http:// srdta.cochrane.org/sites/srdta.cochrane.org/files/uploads/ Handbook1CC_Chapter04_101.pdf (accessed 25 May 2010).

\section{Wang 2011}

Wang LW, Fahim MA, Hayen A, Mitchell RL, Baines L, Lord S, et al. Cardiac testing for coronary artery disease in potential kidney transplant recipients: a systematic review of test accuracy studies. American Journal of Kidney Diseases. 2011;57(3):476-87. [DOI: 10.1053/j.ajkd.2010.11.018; MEDLINE: 21257239]

\section{Whiting 2003}

Whiting P, Rutjes AW, Reitsma JB, Bossuyt PM, Kleijnen J. The development of QUADAS: a tool for the quality assessment of studies of diagnostic accuracy included in systematic reviews. BMC Medical Research Methodology 2003;3:25. [MEDLINE: 14606960]

\section{Yao 2004}

Yao Q, Pecoits-Filho R, Lindholm B, Stenvinkel P. Traditional and non-traditional risk factors as contributors to atherosclerotic cardiovascular disease in end-stage renal disease. Scandinavian Journal of Urology and Nephrology 2004;38(5):405-16. [MEDLINE: 15764253]

* Indicates the major publication for the study

Bates 1996

Clinical features and settings

\section{Clinical features}

- Adult patients who developed insulin dependent DM aged $\leq 25$ years and underwent DSE before planned kidney or kidney-pancreas transplantation between January 1989 and July 1993.

\section{Setting}

- University Hospital, Indianapolis, Indiana, USA. 
Bates 1996 (Continued)

- DM: $100 \%$

- Angina pectoris: Not reported

- Hypertension: $98 \%$

- Sex: $64 \%$ male

\begin{tabular}{ll}
\hline Study design & Prospective, cohort study \\
\hline $\begin{array}{l}\text { Target condition and ref- } \\
\text { erence standard(s) }\end{array}$ & CAD on coronary angiography \\
\hline $\begin{array}{l}\text { Index and comparator } \\
\text { tests }\end{array}$ & defined by $\geq 50 \%$ stenosis \\
& - $\begin{array}{l}\text { Regional wall motion was graded as normal, hypokinetic, akinetic, or dyskinetic using a 16-segment } \\
\text { model at rest, low dose, peak dose, and recovery stages, and assigned a coronary vascular distrib- } \\
\text { ution. A study was considered abnormal if a wall motion abnormality involving } \geq 2 \text { segments was } \\
\text { present at rest or developed during stress. }\end{array}$
\end{tabular}

Follow-up

Patients were followed-up for a mean of $498 \pm 425$ days (range 2 to 1269 ) after transplantation.

\section{Notes}

\section{Table of Methodological Quality}

\begin{tabular}{|c|c|c|}
\hline Item & Authors' judgement & Description \\
\hline $\begin{array}{l}\text { Representative spectrum? } \\
\text { All tests }\end{array}$ & Yes & $\begin{array}{l}\text { Adult patients with insulin-dependent DM being considered for kidney and/or } \\
\text { kidney-pancreas transplantation. }\end{array}$ \\
\hline $\begin{array}{l}\text { Acceptable reference stan- } \\
\text { dard? } \\
\text { All tests }\end{array}$ & Yes & Coronary angiography with a reference standard threshold $\geq 50 \%$ stenosis. \\
\hline $\begin{array}{l}\text { Acceptable delay between } \\
\text { tests? } \\
\text { All tests }\end{array}$ & No & $\begin{array}{l}18 \text { patients underwent cardiac catheterisation within } 101 \pm 263 \text { days (range }= \\
200 \text { days before to } 557 \text { days after) of DSE. Interval progression of CAD is possi- } \\
\text { ble. }\end{array}$ \\
\hline $\begin{array}{l}\text { Partial verification avoid- } \\
\text { ed? } \\
\text { All tests }\end{array}$ & No & $18 / 53$ patients underwent coronary angiography. \\
\hline $\begin{array}{l}\text { Differential verification } \\
\text { avoided? } \\
\text { All tests }\end{array}$ & Yes & Disease status (CAD) diagnosed by coronary angiography. \\
\hline $\begin{array}{l}\text { Incorporation avoided? } \\
\text { All tests }\end{array}$ & Yes & Disease status (CAD) diagnosed by coronary angiography. \\
\hline $\begin{array}{l}\text { Reference standard results } \\
\text { blinded? } \\
\text { All tests }\end{array}$ & Yes & $\begin{array}{l}\text { All available catheterisation studies were interpreted by a blinded, experi- } \\
\text { enced angiographer using digital callipers. }\end{array}$ \\
\hline $\begin{array}{l}\text { Index test results blinded? } \\
\text { All tests }\end{array}$ & Yes & $\begin{array}{l}\text { All studies were interpreted by an experienced echocardiographer blinded to } \\
\text { the clinical and stress electrocardiogram data. }\end{array}$ \\
\hline $\begin{array}{l}\text { Relevant clinical informa- } \\
\text { tion? } \\
\text { All tests }\end{array}$ & Yes & $\begin{array}{l}\text { Relevant clinical information was provided regarding the performance and } \\
\text { analysis of both the index and reference tests. }\end{array}$ \\
\hline
\end{tabular}


Bates 1996 (Continued)

Uninterpretable results re- Yes No results were reported to be uninterpretable.

ported?

No results were reported to be uninterpretable.

All tests

Withdrawals explained? Yes All patients missing from the final analysis were accounted for.
All tests

\section{Bennett 1978}

Clinical features and settings

\section{Clinical features}

- Patients with juvenile insulin-dependent DM and ESKD who presented for kidney transplant cardiac evaluation. Eleven patients with evidence of arteriosclerotic heart disease gave their informed consent for coronary arteriogram and left ventricular angiogram. Seven patients had EST.

\section{Setting}

- University of Oregon Health Sciences Center, Oregon, USA

\begin{tabular}{ll}
\hline Participants & Number: 4 participants \\
& - DM: $100 \%$ \\
& - Angina pectoris: percentage of patients with angina not reported \\
& - Sex: $36 \%$ male \\
\hline Study design & Cohort study
\end{tabular}

\section{Target condition and ref- Coronary artery stenosis measured by coronary angiography erence standard(s)}

- Absolute degree of stenosis recorded for each patient.

\begin{tabular}{ll}
\hline $\begin{array}{l}\text { Index and comparator } \\
\text { tests }\end{array}$ & EST \\
\hline Follow-up & $30-38$ months, unless death occurred earlier. \\
\hline Notes & $\begin{array}{l}\text { Three of the seven patients had a non-diagnostic stress test due to inadequate rate as a result of fa- } \\
\text { tigue. }\end{array}$ \\
\hline
\end{tabular}

\section{Table of Methodological Quality}

\begin{tabular}{|c|c|c|}
\hline Item & Authors' judgement & Description \\
\hline $\begin{array}{l}\text { Representative spectrum? } \\
\text { All tests }\end{array}$ & Yes & $\begin{array}{l}\text { Patients with juvenile insulin-dependent DM and ESKD who presented for kid- } \\
\text { ney transplant cardiac evaluation. }\end{array}$ \\
\hline $\begin{array}{l}\text { Acceptable reference stan- } \\
\text { dard? } \\
\text { All tests }\end{array}$ & Yes & $\begin{array}{l}\text { Coronary artery stenosis measured by coronary angiography. Absolute degree } \\
\text { of stenosis recorded for each patient. }\end{array}$ \\
\hline $\begin{array}{l}\text { Acceptable delay between } \\
\text { tests? } \\
\text { All tests }\end{array}$ & Unclear & Unclear, but likely to be only short delay between tests. \\
\hline
\end{tabular}

Partial verification avoid- Yes $\quad$ All patients received angiography.
ed?
ed? 
Bennett 1978 (Continued)

All tests

\begin{tabular}{|c|c|c|}
\hline $\begin{array}{l}\text { Differential verification } \\
\text { avoided? }\end{array}$ & Yes & $\begin{array}{l}\text { This was not an issue in this study. Disease status (CAD) is diagnosed only } \\
\text { through coronary angiography. }\end{array}$ \\
\hline
\end{tabular}

This was not an issue in this study. Disease status (CAD) is diagnosed only through coronary angiography.

$\begin{array}{ll}\text { Incorporation avoided? } \quad \text { Yes } & \begin{array}{l}\text { This was not an issue in this study. Disease status (CAD) is diagnosed only } \\ \text { through coronary angiography. }\end{array} \\ \text { All tests } & \end{array}$

Reference standard results Unclear Not reported.

blinded?

All tests

\begin{tabular}{lll}
\hline $\begin{array}{l}\text { Index test results blinded? } \\
\text { All tests }\end{array}$ & Unclear & Not reported. \\
\hline $\begin{array}{l}\text { Relevant clinical informa- } \\
\text { tion? }\end{array}$ & Yes & $\begin{array}{l}\text { Relevant clinical information was provided regarding the performance and } \\
\text { analysis of both the index and reference tests. }\end{array}$ \\
$\begin{array}{l}\text { All tests } \\
\begin{array}{l}\text { Uninterpretable results re- } \\
\text { ported? } \\
\text { All tests }\end{array}\end{array}$ & Yes & No results were reported to be uninterpretable. \\
\hline $\begin{array}{l}\text { Withdrawals explained? } \\
\text { All tests }\end{array}$ & Yes & All patients missing from the final analysis were accounted for. \\
\hline
\end{tabular}

\section{Boudreau 1990}

$\begin{array}{ll}\begin{array}{l}\text { Clinical features and set- } \\ \text { tings }\end{array} & \text { Clinical features } \\ & \text { - Patients with DM type } 1 \text { and ESKD who presented for kidney transplant evaluation }\end{array}$

\section{Setting}

- University of Minnesota Hospital and Clinics, Minnesota, USA

\begin{tabular}{ll}
\hline Participants & Number: 80 \\
& - DM type $1: 100 \%$ \\
& - Angina pectoris: $12.5 \%$ patients had history of myocardial infarction \\
& - Sex: $64 \%$ male \\
\hline Study design & Cross sectional study.
\end{tabular}

\section{Target condition and ref- Coronary artery stenosis measured by coronary angiography} erence standard(s)

- Coronary angiograms were analysed by a blinded observer who was unaware of thallium scan results or the patient's history. Quantitative analysis sought to determine the percentage of cross sectional narrowing and absolute cross sectional diameter. The criterion for positive test results was $\geq 70 \%$ reduction in cross sectional area.

$\begin{aligned} & \text { Index and comparator } \\ & \text { tests }\end{aligned}$
$\begin{aligned} & \text { Dipyridamole-Tl-201 scintigraphy MPS (40 oral, } \mathbf{4 0} \text { IV dipyridamole) } \\ & \text { Scans interpreted by consensus of three experienced radiologists who were unaware of angiography } \\ & \text { results or patient history. Each view was subdivided into five segments, and the stress views (first set } \\ & \text { of images) examined for areas of reduced activity. Categorisation as 'indeterminate' was not permit- }\end{aligned}$


ted. Stress segments classified as abnormal were examined for definite, possible, or absent redistribution. Other categories were 'positive' and 'fixed defect'. Mixed defects were defined as areas of partial redistribution in a fixed defect or fixed defects in association with reversible defects. Quantitative analysis, including count profiles and washout rates, was also performed. However, only qualitative results were used to reach the final diagnosis, since normal quantitative values are unavailable for this test in this patient population.

\begin{tabular}{ll}
\hline Follow-up & None. \\
\hline Notes & $\begin{array}{l}\text { Patients were reported as being followed-up long-term to assess the risk factors (including the thallium } \\
\text { scan) for cardiac events after kidney transplantation, although no published data were available. }\end{array}$
\end{tabular}

\section{Table of Methodological Quality}

\begin{tabular}{lll}
\hline Item & Authors' judgement & Description \\
\hline $\begin{array}{l}\text { Representative spectrum? } \\
\text { All tests }\end{array}$ & Yes & $\begin{array}{l}\text { Patients with type 1 DM and ESKD who presented for kidney transplant evalua- } \\
\text { tion. }\end{array}$ \\
\hline $\begin{array}{l}\text { Acceptable reference stan- } \\
\text { dard? }\end{array}$ & Yes & Coronary angiography with a reference standard threshold of $\geq 70 \%$ stenosis. \\
All tests & &
\end{tabular}

\begin{tabular}{lll}
\hline $\begin{array}{l}\text { Acceptable delay between } \\
\text { tests? }\end{array}$ & Unclear & Likely to be a short delay between tests. \\
All tests & \\
\hline $\begin{array}{l}\text { Partial verification avoid- } \\
\text { ed? }\end{array}$ & Yes & $\begin{array}{l}\text { All participants who underwent the index test also received the reference stan- } \\
\text { dard test. }\end{array}$ \\
All tests &
\end{tabular}

Differential verification $\quad$ Yes Disease status (CAD) diagnosed by coronary angiography.
avoided?
All tests

\begin{tabular}{lll}
\hline $\begin{array}{l}\text { Incorporation avoided? } \\
\text { All tests }\end{array}$ & Yes & Disease status (CAD) diagnosed by coronary angiography. \\
\hline $\begin{array}{l}\text { Reference standard results } \\
\text { blinded? }\end{array}$ & Yes & $\begin{array}{l}\text { Coronary angiograms were analysed by a blinded observer (not the person } \\
\text { who performed the angiography) who was unaware of the Tl-201 scan results } \\
\text { oll tests }\end{array}$
\end{tabular}

\begin{tabular}{ll}
\hline Index test results blinded? Yes & The scans were interpreted by consensus of three experienced radiologists \\
All tests & who were unaware of the angiography results or patient history.
\end{tabular}

\begin{tabular}{|c|c|c|}
\hline $\begin{array}{l}\text { Relevant clinical informa- } \\
\text { tion? } \\
\text { All tests }\end{array}$ & Yes & $\begin{array}{l}\text { Relevant clinical information was provided regarding the performance and } \\
\text { analysis of both the index and reference tests. }\end{array}$ \\
\hline
\end{tabular}

\begin{tabular}{lll}
\hline $\begin{array}{l}\text { Uninterpretable results re- } \\
\text { ported? }\end{array}$ & Yes & \\
All tests & & \\
\hline $\begin{array}{l}\text { Withdrawals explained? } \\
\text { All tests }\end{array}$ & Yes & No missing patients. \\
\hline
\end{tabular}




\section{Clinical features and set- tings}

\section{Clinical features}

- Patients with ESKD at risk of CAD who presented for kidney transplant cardiac evaluation

\section{Setting}

- Washington University and Barnes-Jewish Hospital, St. Louis, Missouri, USA

\begin{tabular}{ll}
\hline Participants & Number: 47 \\
& - DM: $56 \%$ \\
- Hypertension: $90 \%$ \\
- Mean age: 51 years \\
- History of smoking: $61 \%$ \\
- Hypercholesterolaemia: $15 \%$ \\
- Coronary heart failure: $2 \%$ \\
- Clinical evidence CAD: $21 \%$ \\
\hline Study design & Cohort study \\
\hline
\end{tabular}

\section{Target condition and ref- Coronary artery stenosis measured by coronary angiography}

erence standard(s)

- The criterion for positive test results was $\geq 50 \%$ reduction in cross sectional area.

Index and comparator DSE

tests

\section{DSE}

- Two-dimensional echocardiography as part of pretransplant evaluation. Graded infusions of dobutamine were administered ( 5 to $40 \mathrm{mg} / \mathrm{kg} / \mathrm{min}$ ) until the maximum predicted heart rate was achieved. If needed, IV atropine ( 0.4 to $2.0 \mathrm{mg}$ ) was given to increase heart rate to $85 \%$ of the maximum predicted heart rate. The test was terminated if patients developed: significant arrhythmia, severe hypertension or hypotension, or had new or worsening baseline segmental wall motion abnormalities in $\geq 2$ major coronary perfusion regions. Segmental wall motion was scored according to American Society of Echocardiography recommendations, using lh-segment model. Each segment was graded using a semi-quantitative scoring system (normal or hyperdynamic (1); hypokinesis (2); akinesis (3); dyskinesis (4)). The wall motion score index was derived as an average of the 16 segments. All studies were reviewed independently by 2 experienced echocardiographers who were blinded to the clinical data.

Notes

Of the 47 patients who underwent DSE, all 5 patients who tested positive received coronary angiography. Seven other patients who had negative DSE received coronary angiography. The decision about providing coronary angiography for those who were index test negative was not made on grounds of clinical or high pre-test suspicion (author correspondence).

Table of Methodological Quality

\begin{tabular}{lll}
\hline Item & Authors' judgement & Description \\
\hline $\begin{array}{l}\text { Representative spectrum? } \\
\text { All tests }\end{array}$ & Yes & $\begin{array}{l}\text { Patients with ESKD at risk of CAD who presented for kidney transplant cardiac } \\
\text { evaluation. }\end{array}$ \\
\hline
\end{tabular}

Acceptable reference stan- Yes Coronary angiography with a reference standard threshold of $\geq 50 \%$ stenosis. dard?

All tests

\begin{tabular}{|c|c|c|}
\hline $\begin{array}{l}\text { Acceptable delay between } \\
\text { tests? } \\
\text { All tests }\end{array}$ & Yes & $\begin{array}{l}\text { Average time from DSE to coronary angiography }<9 \text { months (author corre- } \\
\text { spondence). }\end{array}$ \\
\hline
\end{tabular}


Brennan 1997 (Continued)

Partial verification avoid- $\quad$ No ed?

All tests
Of the 47 patients who underwent DSE, 5 who tested positive underwent coronary angiography, and 7 others who had negative DSE results also underwent coronary angiography. The reason that patients who were index test negative underwent coronary angiography was for other than clinical or high pre-test suspicion (author correspondence)

Differential verification $\quad$ Yes Disease status (CAD) diagnosed by coronary angiography.
avoided?
All tests

Incorporation avoided? Yes Disease status (CAD) diagnosed by coronary angiography.

All tests

$\begin{array}{ll}\begin{array}{l}\text { Reference standard results } \\ \text { blinded? }\end{array} & \text { No } \\ \begin{array}{ll}\text { All tests } & \text { aware of the DSE result. However, because later coronary angiograms were } \\ \text { performed by an outside institution, this was not necessarily the case (author } \\ \text { correspondence). }\end{array}\end{array}$

\begin{tabular}{lll}
\hline $\begin{array}{l}\text { Index test results blinded? } \\
\text { All tests }\end{array}$ & Yes & $\begin{array}{l}\text { All studies were reviewed independently by two experienced echocardiogra- } \\
\text { phers who were blinded to the clinical data. }\end{array}$ \\
\hline $\begin{array}{l}\text { Relevant clinical informa- } \\
\text { tion? }\end{array}$ & Yes & $\begin{array}{l}\text { Relevant clinical information was provided regarding the performance and } \\
\text { analysis of both the index and reference tests. }\end{array}$ \\
All tests & &
\end{tabular}

Uninterpretable results re- Yes No results were reported to be uninterpretable.
ported?
All tests

Withdrawals explained? Yes All patients missing from the final analysis were accounted for.
All tests

\section{Cai 2010}

\section{Clinical features and set- Clinical features} tings

- Patients with ESKD and intermediate to high risk of CAD awaiting kidney transplantation. CAD defined as presence of at least 1 of: age $>50$ years, DM, previous MI or stroke, or extracardiac atherosclerosis

\section{Setting}

- Geisinger Medical Center, Danville, Pennsylvania, USA

Participants
$\begin{aligned} & \text { Patients at intermediate to high risk of CAD u } \\ & \text { kidney transplantation }\end{aligned}$
- Number: 38
- Angina pectoris: percentage not reported
- Hypertension: $86 \%$
- Sex: $64 \%$ male

Study design Retrospective cohort study.

Target condition and ref-

Coronary artery stenosis measured by coronary angiography erence standard(s) 
Cai 2010 (Continued)

- The criterion for positive test results was $\geq 70 \%$ reduction in cross sectional area.

Index and comparator tests

\section{DSE}

- Performed according to a standard dobutamine-atropine protocol and included complete resting echo-Doppler cardiography. Incremental doses of dobutamine ( 5 to $50 \mathrm{mg} / \mathrm{kg} / \mathrm{min}$ ) infused at 3 minute intervals. If the target ( $85 \%$ predicted maximum for age) heart rate was not reached, and in the absence of inducible ischaemia, $0.25 \mathrm{mg}$ IV atropine administered up to a maximum dose of $1 \mathrm{mg}$. Echocardiographic images were obtained in the standardised parasternal long- and short-axes (midventricular and apical), and in apical 2-, 3-, 4-, and 5-chamber views at each stage, and were stored digitally. DSE end points were defined as development of new or worsening wall motion abnormality (ischaemia), achievement of $>85 \%$ of the predicted maximum heart rate for age, severe symptoms of angina or dyspnoea, SBP $<85 \mathrm{~mm} \mathrm{Hg}$ or $>220 \mathrm{~mm} \mathrm{Hg}$ or a decrease in SBP $>20 \mathrm{~mm} \mathrm{Hg}$ from one stage to the next, > $2 \mathrm{mV}$ ST segment depression in at least 2 consecutive leads, or significant arrhythmias (non-sustained/sustained ventricular/supraventricular tachycardia or high-grade atrioventricular block).

Follow-up

Patients were followed up for a mean of 60 months (range 3 to 145 months) after DSE. The time from kidney transplant to follow-up was 1 to 135 months (median 49 months).

Notes

For the purpose of the analysis, only inducible wall motion abnormalities were counted as positive DSE.

\section{Table of Methodological Quality}

\begin{tabular}{lll}
\hline Item & Authors' judgement & Description \\
\hline $\begin{array}{l}\text { Representative spectrum? } \\
\text { All tests }\end{array}$ & Yes & $\begin{array}{l}\text { Patients with ESKD and intermediate to high risk of CAD awaiting kidney trans- } \\
\text { plantation. }\end{array}$ \\
\hline $\begin{array}{l}\text { Acceptable reference stan- } \\
\text { dard? }\end{array}$ & Yes & Coronary angiography with a reference standard threshold of $\geq 70 \%$ stenosis. \\
All tests & & \\
\hline
\end{tabular}

\begin{tabular}{|c|c|c|}
\hline $\begin{array}{l}\text { Acceptable delay between } \\
\text { tests? } \\
\text { All tests }\end{array}$ & Unclear & Likely to be short delay between tests. \\
\hline $\begin{array}{l}\text { Partial verification avoid- } \\
\text { ed? } \\
\text { All tests }\end{array}$ & No & $\begin{array}{l}38 \text { patients ( } 23 \text { with and } 15 \text { without inducible ischaemia on DSE) underwent } \\
\text { coronary angiography after DSE. }\end{array}$ \\
\hline
\end{tabular}

Differential verification $\quad$ Yes Disease status (CAD) diagnosed by coronary angiography.
avoided?
All tests

\begin{tabular}{l}
\hline $\begin{array}{l}\text { Incorporation avoided? } \\
\text { All tests }\end{array}$ \\
\hline
\end{tabular}

\begin{tabular}{lll}
\hline $\begin{array}{l}\text { Reference standard results } \\
\text { blinded? }\end{array}$ & Unclear & \\
All tests & Not reported. \\
\hline $\begin{array}{l}\text { Index test results blinded? } \\
\text { All tests }\end{array}$ & Unclear & $\begin{array}{l}\text { Relevant clinical information was provided regarding the performance and } \\
\text { analysis of both the index and reference tests. }\end{array}$ \\
\hline $\begin{array}{l}\text { Relevant clinical informa- } \\
\text { tion? }\end{array}$ & Yes &
\end{tabular}


Cai 2010 (Continued)

Uninterpretable results re- Yes No results were reported to be uninterpretable. ported?

All tests

Withdrawals explained? Yes All patients missing from the final analysis were accounted for.
All tests

\section{De Lima 2003}

Clinical features and settings

\section{Clinical features}

- Patients presenting for pre-transplant cardiac evaluation based on the presence of at least one of the following characteristics: age > 50 years, DM, angina, previous MI or stroke, left ventricular dysfunction, and extracardiac atherosclerosis. Subjects without these characteristics were not studied because they have a low frequency of coronary events.

\section{Setting}

- Hospital das Clínicas, University of São Paulo Medical School, Brazil
- Number: 150 (data from 24 participants excluded: lost to follow-up (5); declined to continue (19))

- DM: $30 \%$

- Angina pectoris: $25 \%$

- Hypertension: $95 \%$

- Sex: $77 \%$ male

Study design $\quad$ Cohort study.

\section{Target condition and ref- erence standard(s)}

\section{Coronary artery stenosis measured by coronary angiography}

- The criterion for positive test results was $\geq 70 \%$ reduction in cross sectional area. Invasive and noninvasive testing were analysed independently by 2 experts in the respective methods without previous knowledge of the experimental hypothesis. Disagreement was arbitrated by a third expert.

\footnotetext{
Index and comparator DSE tests

- Stepwise infusion of dobutamine was started at $5 \mu \mathrm{g} / \mathrm{kg} / \mathrm{min}$ and increased to $40 \mu \mathrm{g} / \mathrm{kg} / \mathrm{min}$ in 3 minute stages. Inducible ischaemia was defined as hypokinesis or as accentuation of the degree of baseline hypokinesis during the infusion. The test was interrupted if SBP or DBP surpassed $220 \mathrm{~mm}$ $\mathrm{Hg}$ and $120 \mathrm{~mm} \mathrm{Hg}$, respectively, or when SBP fell below $90 \mathrm{~mm} \mathrm{Hg}$.

- Dipyridamole stress testing (single photon emission-computed tomography with technecium-99m methoxyisobutylisonitrite)

* Stress was induced by dipyridamole $(0.5 \mathrm{mg} / \mathrm{kg}$ IV). Fixed perfusion defects were interpreted as evidence of fibrosis; transient hypoperfusion was interpreted as ischaemia.
}

Follow-up

Five participants were lost to follow-up. Minimum and mean follow-up periods were 6 and 26 months, respectively. The outcome measure was cardiac events, predefined as sudden death, MI, life-threatening arrhythmia, heart failure, pulmonary oedema, unstable angina, and myocardial revascularisation.

Notes

\section{Table of Methodological Quality}

\begin{tabular}{lll}
\hline Item & Authors' judgement & Description \\
\hline Representative spectrum? & Yes & Kidney transplantation candidates as part of cardiac evaluation.
\end{tabular}


De Lima 2003 (Continued)

All tests

Acceptable reference stan- Yes dard?

Coronary angiography with a reference standard threshold of $\geq 70 \%$ stenosis.

All tests

Acceptable delay between Yes Interval between tests was 2 to 6 weeks (author correspondence).
tests?

All tests

\begin{tabular}{ll}
\hline $\begin{array}{l}\text { Partial verification avoid- } \\
\text { ed? }\end{array}$ & Yes \\
All participants who underwent an index test also received the reference stan- \\
dard test.
\end{tabular}

All tests

Differential verification $\quad$ Yes Disease status (CAD) diagnosed by coronary angiography.
avoided?
All tests

\begin{tabular}{lll}
\hline $\begin{array}{l}\text { Incorporation avoided? } \\
\text { All tests }\end{array}$ & Yes & \\
\hline $\begin{array}{l}\text { Reference standard results } \\
\text { blinded? }\end{array}$ & No & No blinding for outcomes assessment. \\
All tests & & \\
\hline
\end{tabular}

Index test results blinded? No No blinding for outcomes assessment.
All tests

\begin{tabular}{|c|c|c|}
\hline $\begin{array}{l}\text { Relevant clinical informa- } \\
\text { tion? } \\
\text { All tests }\end{array}$ & Yes & $\begin{array}{l}\text { Relevant clinical information was provided regarding the performance and } \\
\text { analysis of both the index and reference tests. }\end{array}$ \\
\hline
\end{tabular}

Uninterpretable results re- Yes The number of tests that were submaximal were reported.
ported?
All tests

All tests
Withdrawals explained? Yes All patients missing from the final analysis were accounted for.
All tests

\section{Ferreira 2007}

$\begin{array}{ll}\begin{array}{l}\text { Clinical features and set- } \\ \text { tings }\end{array} & \text { Clinical features } \\ & \begin{array}{l}\text { Kidney transplant candidates with diabetic kidney disease or other causes of CKD or ESKD undergoing } \\ \text { cardiac evaluation. Examinations performed one day after haemodialysis. }\end{array}\end{array}$

\section{Setting}

- Universidade Federal de São Paulo, Escola Paulista de Medicina, Hospital do Rim e Hipertensão e Hospital São Paulo, Brazil

- Aged $>40$ years, who presented with $\geq 2$ risk factors
- Number: 126 participants
- DM: $27 \%$
- Angina pectoris: $12 \%$
- Hypertension: not reported


Ferreira 2007 (Continued)

- Sex: $69 \%$ male

\section{Exclusion criteria}

- Previous history of MI or surgical or percutaneous myocardial revascularization; unstable angina; decompensated CHF; significant aortic stenosis; pulmonary HTN; hypertrophic cardiomyopathy; inadequate echocardiographic window; atropine use restrictions (glaucoma and obstructive uropathy); irregular dialysis regimen.

Study design Cross sectional study.

\section{Target condition and ref- Coronary artery stenosis measured by coronary angiography} erence standard(s)

- The criterion for positive test results was $\geq 70 \%$ reduction in cross-sectional area.

Index and comparator tests

\section{Dobutamine/atropine stress echocardiography}

- Progressive doses of dobutamine 5, 10, 20, 30 and $40 \mu \mathrm{g} / \mathrm{kg} / \mathrm{min}$, with an increment every 3 minutes. In cases when the final objective of the evaluation had not been reached, $0.25 \mathrm{mg} / \mathrm{min}$ atropine was added simultaneously after the third minute of the infusion of $40 \mu \mathrm{g} / \mathrm{kg} / \mathrm{min}$ of dobutamine, up to a total maximum cumulative dose of $1 \mathrm{mg}$. The test was considered diagnostic when either $85 \%$ of the maximum for age or echocardiographic signs of myocardial ischaemia was reached. The test was considered non-diagnostic when there were inadequate images for the analysis (lack of definition on $\geq$ 2 myocardial segments); inability to reach target stress, and premature test withdrawal due to limiting side effects without attaining one of the test aims.

- Definitions guiding interpretation were: Normal result defined as uniform increase of systolic movement and thickening of the left ventricular wall and consequent reduction of its final systolic volume (global hyperdynamic response); a positive result for myocardial ischaemia was defined as a new alteration of the reversible segmental contractility or worsening of a pre-existing segmental alteration, in $\geq 2$ contiguous myocardial segments.

Follow-up

\section{Notes}

Table of Methodological Quality

\begin{tabular}{|c|c|c|}
\hline Item & Authors' judgement & Description \\
\hline $\begin{array}{l}\text { Representative spectrum? } \\
\text { All tests }\end{array}$ & Yes & $\begin{array}{l}\text { Patients with ESKD who were kidney transplant candidates undergoing car- } \\
\text { diac evaluation. Examinations performed one day after haemodialysis. }\end{array}$ \\
\hline $\begin{array}{l}\text { Acceptable reference stan- } \\
\text { dard? } \\
\text { All tests }\end{array}$ & Yes & Coronary angiography with a reference standard threshold of $\geq 70 \%$ stenosis. \\
\hline $\begin{array}{l}\text { Acceptable delay between } \\
\text { tests? } \\
\text { All tests }\end{array}$ & Yes & Not longer than 2 months. \\
\hline $\begin{array}{l}\text { Partial verification avoid- } \\
\text { ed? } \\
\text { All tests }\end{array}$ & Yes & $\begin{array}{l}\text { All participants who underwent an index test also received the reference stan- } \\
\text { dard test. }\end{array}$ \\
\hline $\begin{array}{l}\text { Differential verification } \\
\text { avoided? } \\
\text { All tests }\end{array}$ & Yes & $\begin{array}{l}\text { This was not an issue in this study. Disease status (CAD) is diagnosed only } \\
\text { through coronary angiography. }\end{array}$ \\
\hline
\end{tabular}


Ferreira 2007 (Continued)

$\begin{array}{ll}\text { Incorporation avoided? } \quad \text { Yes } & \text { This was not an issue in this study. Disease status (CAD) is diagnosed only } \\ \text { All tests } & \text { through coronary angiography. }\end{array}$

Reference standard results Yes

blinded?

The measurement bias was controlled through the "blind" interpretation of

All tests

the test regarding the coronary angiography, which was considered the refer-

ence standard.

Index test results blinded? Yes

All tests

The recorded images were later interpreted by two members who were blinded to the patients' clinical data, as independent observers. The discordance was solved by consensus between the two observers.

$\begin{array}{ll}\text { Relevant clinical informa- } \quad \text { Yes } & \text { Relevant clinical information was provided regarding the performance and } \\ \text { tion? } & \text { analysis of both the index and reference tests. }\end{array}$

All tests

Uninterpretable results re- Yes

ported?

Of 148 patients submitted to the test, 135 finished the protocol, which corresponds to a feasibility of $91 \%$. The reasons that led to test interruption were:

All tests attaining $85 \%$ of maximum CF for age: $121(81 \%)$; limiting side effects: $13(9 \%)$; echocardiographic signs of ischaemia: $10(7 \%)$ and end of the protocol: $4(3 \%)$.

Withdrawals explained? Yes

All tests

Thirteen patients presented an early withdrawal of the protocol due to limiting side effects: $12(8.5 \%)$ due to hypertensive response and $1(0.5 \%)$ due to severe angina.

\section{Gang 2007}

$\begin{array}{ll}\begin{array}{l}\text { Clinical features and set- } \\ \text { tings }\end{array} & \text { Clinical features } \\ & \text { - Patients with DM and ESKD who presented for kidney transplant cardiac evaluation }\end{array}$

\section{Setting}

- Muljibhai Patel Urological Hospital, Gujarat, India

\begin{tabular}{|c|c|}
\hline Participants & $\begin{array}{l}\text { - Number: } 40 \\
\text { - Type } 2 \text { DM: } 100 \% \\
\text { - ESKD: } 100 \% \\
\text { - Angina pectoris: } 5 \% \\
\text { - Hypertension: } 92 \% \\
\text { - Sex: } 90 \% \text { male }\end{array}$ \\
\hline Study design & Cross sectional study. \\
\hline $\begin{array}{l}\text { Target condition and ref- } \\
\text { erence standard(s) }\end{array}$ & $\begin{array}{l}\text { Coronary artery stenosis measured by coronary angiography } \\
\text { - Criterion for positive test results was } \geq 70 \% \text { reduction in cross sectional area }\end{array}$ \\
\hline $\begin{array}{l}\text { Index and comparator } \\
\text { tests }\end{array}$ & $\begin{array}{l}\text { DSE } \\
\text { - DSE was performed by recording images in standard parasternal long- and short-axis and apical } 4 \\
\text { chamber and } 2 \text { chamber views at baseline, and during stepwise infusion of dobutamine in } 3 \text { minute } \\
\text { stages at } 5,10,20,30 \text { and } 40 \mu \mathrm{g} / \mathrm{kg} / \mathrm{min} \text {. Atropine was administered as needed. DSE end points } \\
\text { were target heart rate achieved ([220-age } \times 0.85) \text {, maximum drug dose, intolerable angina, new in- } \\
\text { ducible regional wall motion abnormalities in } \geq 2 \text { coronary vascular territories, ventricular tachycar- } \\
\text { dia, supraventricular tachycardia, hypotension and SBP }>240 \mathrm{~mm} \mathrm{Hg} \text {. }\end{array}$ \\
\hline
\end{tabular}

\section{Resting ECG}


Gang 2007 (Continued)

- Abnormal ECG findings included evidence of left ventricular hypertrophy by voltage criteria (8 patients), evidence of underlying ischaemia, or left bundle branch block.

\begin{tabular}{ll}
\hline Follow-up & None \\
\hline Notes & Patients underwent DSE followed by coronary angiography as a part of kidney transplant evaluation. \\
- & Resting ECG was discounted from the analysis as "abnormal ECG". This was a heterogeneous concept \\
that was suggestive of both ischaemic and non-ischaemic (such as left ventricular hypertrophy) re- \\
sults. $12 / 40$ patients (30\%) had baseline ECG evidence of left ventricular hypertrophy by voltage crite- \\
ria, 8 (20\%) patients had evidence of underlying ischaemia; one patient (4\%) had left bundle branch \\
block. 19 patients had normal ECGs. 9/21 patients whose ECGs were abnormal had significant CAD on \\
angiography.
\end{tabular}

Table of Methodological Quality

\begin{tabular}{|c|c|c|}
\hline Item & Authors' judgement & Description \\
\hline $\begin{array}{l}\text { Representative spectrum? } \\
\text { All tests }\end{array}$ & Yes & $\begin{array}{l}\text { Patients with DM and ESKD who presented for kidney transplant cardiac evalu- } \\
\text { ation. }\end{array}$ \\
\hline $\begin{array}{l}\text { Acceptable reference stan- } \\
\text { dard? } \\
\text { All tests }\end{array}$ & Yes & Coronary angiography with a reference standard threshold of $\geq 70 \%$ stenosis. \\
\hline $\begin{array}{l}\text { Acceptable delay between } \\
\text { tests? } \\
\text { All tests }\end{array}$ & Yes & $\begin{array}{l}\text { DSE and coronary angiography were performed within the same week (author } \\
\text { correspondence). }\end{array}$ \\
\hline $\begin{array}{l}\text { Partial verification avoid- } \\
\text { ed? } \\
\text { All tests }\end{array}$ & Yes & $\begin{array}{l}\text { All participants who underwent an index test also received the reference stan- } \\
\text { dard test. }\end{array}$ \\
\hline
\end{tabular}

Differential verification $\quad$ Yes Disease status (CAD) diagnosed by coronary angiography.
avoided?
All tests

Incorporation avoided? Yes Disease status (CAD) diagnosed by coronary angiography.
All tests

\begin{tabular}{|c|c|c|}
\hline $\begin{array}{l}\text { Reference standard results } \\
\text { blinded? } \\
\text { All tests }\end{array}$ & No & $\begin{array}{l}\text { The person who interpreted the coronary angiogram reports was not blinded } \\
\text { to DSE results (author correspondence). }\end{array}$ \\
\hline $\begin{array}{l}\text { Index test results blinded? } \\
\text { All tests }\end{array}$ & Unclear & $\begin{array}{l}\text { All coronary angiograms were performed after DSE, so index tests were likely } \\
\text { to be performed without influence from the reference standard. }\end{array}$ \\
\hline $\begin{array}{l}\text { Relevant clinical informa- } \\
\text { tion? } \\
\text { All tests }\end{array}$ & Yes & $\begin{array}{l}\text { Relevant clinical information was provided regarding the performance and } \\
\text { analysis of both the index and reference tests. }\end{array}$ \\
\hline $\begin{array}{l}\text { Uninterpretable results re- } \\
\text { ported? } \\
\text { All tests }\end{array}$ & Yes & No results were reported to be uninterpretable. \\
\hline $\begin{array}{l}\text { Withdrawals explained? } \\
\text { All tests }\end{array}$ & Yes & No withdrawals reported. \\
\hline
\end{tabular}


Garcia-Canton 1998

$\begin{array}{ll}\begin{array}{l}\text { Clinical features and set- } \\ \text { tings }\end{array} & \text { Clinical features } \\ & \begin{array}{l}\text { Patients who presented for cardiac evaluation before kidney transplantation underwent DSE and MPS } \\ \text { followed by coronary angiography }\end{array}\end{array}$

\section{Setting}

- Hospital Universitario Insular de Gran Canaria, Spain

\begin{tabular}{ll}
\hline Participants & - Number: 27 \\
& - EM: percentage not reported \\
& - Angina pectoris: percentage not reported \\
& - Hypertension: percentage not reported \\
& - Sex: $67 \%$ male \\
\hline Study design & Cross sectional study
\end{tabular}

\section{Target condition and ref- Coronary artery stenosis measured by coronary angiography} erence standard(s)

- Criterion for positive test results was $\geq 70 \%$ reduction in cross sectional area.

\begin{tabular}{ll}
\hline $\begin{array}{l}\text { Index and comparator } \\
\text { tests }\end{array}$ & DSE \\
\hline Follow-up & Stress 99M-Technetium methoxyisobutylisonitrile SPECT \\
\hline Notes & Cone reported. \\
& Concence presentation. Unpublished as a study. Additional information obtained from correspon-
\end{tabular}

\section{Table of Methodological Quality}

\begin{tabular}{|c|c|c|}
\hline Item & Authors' judgement & Description \\
\hline $\begin{array}{l}\text { Representative spectrum? } \\
\text { All tests }\end{array}$ & Yes & Patients who presented for cardiac evaluation before kidney transplantation. \\
\hline $\begin{array}{l}\text { Acceptable reference stan- } \\
\text { dard? } \\
\text { All tests }\end{array}$ & Yes & Coronary angiography with a reference standard threshold of $\geq 70 \%$ stenosis. \\
\hline $\begin{array}{l}\text { Acceptable delay between } \\
\text { tests? } \\
\text { All tests }\end{array}$ & Yes & $\begin{array}{l}\text { All coronary angiography was performed from two weeks to three months af- } \\
\text { ter the other tests (author correspondence). }\end{array}$ \\
\hline $\begin{array}{l}\text { Partial verification avoid- } \\
\text { ed? } \\
\text { All tests }\end{array}$ & Yes & $\begin{array}{l}\text { All participants who underwent the index test also had the reference standard } \\
\text { test. }\end{array}$ \\
\hline $\begin{array}{l}\text { Differential verification } \\
\text { avoided? } \\
\text { All tests }\end{array}$ & Yes & Disease status (CAD) diagnosed by coronary angiography. \\
\hline $\begin{array}{l}\text { Incorporation avoided? } \\
\text { All tests }\end{array}$ & Yes & Disease status (CAD) diagnosed by coronary angiography. \\
\hline
\end{tabular}




\section{Garcia-Canton 1998 (Continued)}

Reference standard results Yes blinded?

Coronary angiography result was reported by a cardiology team member who All tests

was unaware of other test results (author correspondence).
MIBI scan and DSE results were interpreted by clinical and technical experts without knowledge of the other. Both were conducted before coronary angiography.

Relevant clinical information was provided concerning the performance and analysis of both the index and reference tests (author correspondence).
Relevant clinical informa- Yes

tion?

All tests
There were no uninterpretable results.

Uninterpretable results re- Yes

ported?

Yes

All tests

Withdrawals explained? Yes There were no withdrawals reported.
All tests

\section{Clinical features and set- Clinical features tings \\ - Patients with DM who were candidates for kidney transplant}

\section{Setting}

- Sanjay Gandhi Post-Graduate Institute of Medical Sciences, Lucknow, India

\begin{tabular}{ll}
\hline Participants & Number: 52 \\
& - DM: $100 \%$ \\
- Angina pectoris: not reported \\
- Hex: $88 \%$ male \\
- Age (Mean \pm SD): $46 \pm 6$ years \\
\hline Study design & Cohort study.
\end{tabular}

\section{Target condition and ref- Coronary artery stenosis measured by coronary angiography} erence standard(s)

- Criterion for positive test results was $\geq 50$ reduction in cross sectional area. Each angiogram was independently reviewed by two experienced cardiologists who were blinded to the clinical data and uninvolved in patient management.

Index and comparator tests

\section{DSTS}

- Patients received $400 \mathrm{mg}$ oral dipyridamole and $1.5 \mathrm{mCi}$ TL-201 injected IV one hour after DSTS. Studies were interpreted qualitatively and quantitatively. Planar thallium was performed in all cases. Normal test results were characterised by: the patient had no chest pain, no significant ST depression in the ECG during stress, and no significant perfusion defect. The test was considered positive if significant defects that were either fixed or reversible were revealed on delayed imaging, based on circumferential count profile analysis.

\section{Echocardiography}

- Resting wall motion abnormality 
Garg 2000 (Continued)

\section{Resting ECG}

- ECGs evaluated for evidence of MI, abnormal ST-T changes, and left ventricular hypertrophy. Evidence of MI was regarded as positive if significant $Q$ waves were present in more than one lead. ST-T segment abnormality was noted as present if ST-segment depression or elevation of at least $1 \mathrm{~mm}$; or inverted T wave in any lead where the QRS complex had a net positive deflection were detected in the absence of bundle branch block and left ventricular hypertrophy.

\begin{tabular}{ll}
\hline Follow-up & Survival data are available. \\
\hline Notes & $\begin{array}{l}\text { All patients underwent coronary angiography, echocardiography and resting ECG. } 19 \text { patients under- } \\
\text { went dipyridamole MPS. }\end{array}$
\end{tabular}

\section{Table of Methodological Quality}

\begin{tabular}{lll}
\hline Item & Authors' judgement & Description \\
\hline $\begin{array}{l}\text { Representative spectrum? } \\
\text { All tests }\end{array}$ & Yes & Patients with DM who were candidates for kidney transplant. \\
\hline $\begin{array}{l}\text { Acceptable reference stan- } \\
\text { dard? }\end{array}$ & Yes & Coronary angiography with a reference standard threshold of $\geq 50 \%$ stenosis. \\
All tests & & \\
\hline
\end{tabular}

\begin{tabular}{lll}
$\begin{array}{l}\text { Acceptable delay between } \\
\text { tests? }\end{array}$ & Unclear & \\
All tests & \\
\hline $\begin{array}{l}\text { Partial verification avoid- } \\
\text { ed? }\end{array}$ & Yes & $\begin{array}{l}\text { All participants who underwent an index test received the reference standard } \\
\text { All tests }\end{array}$
\end{tabular}

\begin{tabular}{|c|c|c|}
\hline $\begin{array}{l}\text { Differential verification } \\
\text { avoided? } \\
\text { All tests }\end{array}$ & Yes & Disease status (CAD) diagnosed by coronary angiography. \\
\hline $\begin{array}{l}\text { Incorporation avoided? } \\
\text { All tests }\end{array}$ & Yes & Disease status (CAD) diagnosed by coronary angiography. \\
\hline $\begin{array}{l}\text { Reference standard results } \\
\text { blinded? } \\
\text { All tests }\end{array}$ & Yes & $\begin{array}{l}\text { Each angiogram was independently reviewed by two experienced cardiolo- } \\
\text { gists who were blinded to the clinical data and uninvolved in patient manage- } \\
\text { ment. }\end{array}$ \\
\hline $\begin{array}{l}\text { Index test results blinded? } \\
\text { All tests }\end{array}$ & Yes & Studies were interpreted qualitatively and quantitatively. \\
\hline $\begin{array}{l}\text { Relevant clinical informa- } \\
\text { tion? } \\
\text { All tests }\end{array}$ & Yes & $\begin{array}{l}\text { Relevant clinical information was provided regarding the performance and } \\
\text { analysis of both the index and reference tests. }\end{array}$ \\
\hline $\begin{array}{l}\text { Uninterpretable results re- } \\
\text { ported? } \\
\text { All tests }\end{array}$ & Yes & No results were reported to be uninterpretable. \\
\hline $\begin{array}{l}\text { Withdrawals explained? } \\
\text { All tests }\end{array}$ & Yes & All patients missing from the final analysis were accounted for. \\
\hline
\end{tabular}


Gowdak 2010

\begin{tabular}{|c|c|}
\hline $\begin{array}{l}\text { Clinical features and set- } \\
\text { tings }\end{array}$ & $\begin{array}{l}\text { Clinical features } \\
\text { - Patients with DM on dialysis who were candidates for kidney transplant } \\
\text { Setting } \\
\text { - University of São Paulo Medical School, Brazil }\end{array}$ \\
\hline Participants & $\begin{array}{l}\text { - Number: } 219 \\
\text { - DM: } 100 \% \\
\text { - Angina pectoris: not reported } \\
\text { - Hypertension: } 92 \% \\
\text { - Sex: } 67 \% \text { male } \\
\text { - Mean age: } 57 \text { years } \\
\text { - Mean duration on dialysis: } 36 \text { months }\end{array}$ \\
\hline Study design & Cross sectional study. \\
\hline $\begin{array}{l}\text { Target condition and ref- } \\
\text { erence standard(s) }\end{array}$ & $\begin{array}{l}\text { Coronary artery stenosis measured by coronary angiography } \\
\text { - Criterion for positive test results was } \geq 70 \% \text { reduction in cross sectional area. }\end{array}$ \\
\hline $\begin{array}{l}\text { Index and comparator } \\
\text { tests }\end{array}$ & $\begin{array}{l}\text { SPECT+ Sestamibi cardiac scintigraphy } \\
\text { - Pharmacological stress induced by dipyridamole. }\end{array}$ \\
\hline Follow-up & Data not available. \\
\hline Notes & $\begin{array}{l}\text { Data obtained from poster presented at the European Society of Cardiology conference in } 2010 \text { http:// } \\
\text { spo.escardio.org/AbstractDetails.aspx?id=91377 }\end{array}$ \\
\hline
\end{tabular}

\section{Table of Methodological Quality}

\begin{tabular}{|c|c|c|}
\hline Item & Authors' judgement & Description \\
\hline $\begin{array}{l}\text { Representative spectrum? } \\
\text { All tests }\end{array}$ & Yes & Patients with DM who were candidates for kidney transplant. \\
\hline $\begin{array}{l}\text { Acceptable reference stan- } \\
\text { dard? } \\
\text { All tests }\end{array}$ & Yes & Coronary angiography with a reference standard threshold of $\geq 70 \%$ stenosis. \\
\hline $\begin{array}{l}\text { Acceptable delay between } \\
\text { tests? } \\
\text { All tests }\end{array}$ & Unclear & Not reported. \\
\hline $\begin{array}{l}\text { Partial verification avoid- } \\
\text { ed? } \\
\text { All tests }\end{array}$ & Yes & All patients underwent coronary angiography. \\
\hline $\begin{array}{l}\text { Differential verification } \\
\text { avoided? } \\
\text { All tests }\end{array}$ & Yes & Disease status (CAD) diagnosed by coronary angiography. \\
\hline $\begin{array}{l}\text { Incorporation avoided? } \\
\text { All tests }\end{array}$ & Yes & Disease status (CAD) diagnosed by coronary angiography. \\
\hline
\end{tabular}


Gowdak 2010 (Continued)

Reference standard results Unclear Not reported.

blinded?

All tests

Index test results blinded? Unclear Not reported.
All tests

\begin{tabular}{|c|c|c|}
\hline $\begin{array}{l}\text { Relevant clinical informa- } \\
\text { tion? }\end{array}$ & Yes & $\begin{array}{l}\text { Relevant clinical information was provided regarding the performance and } \\
\text { analysis of both the index and reference tests. }\end{array}$ \\
\hline
\end{tabular}

All tests

Uninterpretable results re- Yes No uninterpretable results present.

ported?

All tests

Withdrawals explained? Yes No withdrawals reported.

All tests

Herzog 1999

$\begin{array}{ll}\begin{array}{l}\text { Clinical features and set- } \\ \text { tings }\end{array} & \text { Clinical features } \\ & \text { Patients referred for kidney transplantation evaluation from June } 1992 \text { to January } 1995 \\ & \text { ESKD from diabetic kidney disease or other causes } \\ \text { - unable to perform treadmill exercise } & \geq 2 \text { CAD risk factors: male; HTN; hypercholesterolaemia (total cholesterol level } 240 \mathrm{mg} / \mathrm{dL} \text { or low-den- } \\ & \text { sity lipoprotein cholesterol level } 160 \mathrm{mg} / \mathrm{dL} \text { ); history of smoking; family history or any evidence sug- } \\ & \text { gestive of IHD (angina, effort dyspnoea, previous MI by history or ECG, or abnormal global or regional } \\ & \text { left ventricular function) }\end{array}$

\section{Setting}

- Hennepin County Medical Center, Minneapolis, Minnesota, USA

\begin{tabular}{ll}
\hline Participants & Patients were predominantly middle-aged white men. Nearly all patients (92\%) were undergoing \\
& chronic haemodialysis \\
- & Number: 50 \\
- DM: $82 \%$ \\
- Angina pectoris: $16 \%$ \\
- Hypertension: $94 \%$ \\
- Sex: $60 \%$ male
\end{tabular}

\section{Exclusion criteria}

- Significant aortic stenosis; unstable angina; inability to obtain informed consent; previous coronary angiography

\begin{tabular}{ll}
\hline Study design & Cohort study \\
\hline $\begin{array}{l}\text { Target condition and ref- } \\
\text { erence standard(s) }\end{array}$ & $\begin{array}{l}\text { Coronary artery stenosis measured by coronary angiography } \\
\text { - Criterion for positive test result was } \geq 70 \% \text { reduction in cross sectional area by quantitative coronary } \\
\text { angiography. }\end{array}$ \\
\hline
\end{tabular}

Index and comparator DSE
tests

Cardiac testing for coronary artery disease in potential kidney transplant recipients (Review) 
- End points for stopping drug infusion were: new inducible wall motion abnormalities involving $\geq$ 2 coronary artery vascular territories, intolerable patient discomfort, angina with $\geq 2 \mathrm{~mm}$ ST segment depression or elevation in a previously normal ECG lead, significant tachyarrhythmia (sustained supraventricular tachycardia or $\geq 3$-beat run of ventricular tachycardia), symptomatic severe hypotension, $\mathrm{SBP} \geq 240 \mathrm{~mm} \mathrm{Hg}$ or $\mathrm{DBP} \geq 120 \mathrm{~mm} \mathrm{Hg}$, attaining target heart rate ([220 - age $] \times 0.85)$, or reaching the maximum dose of dobutamine and atropine.

- DSE studies were analysed in digital format independently by three echocardiographers blinded to angiographic data. DSE study was defined as positive for inducible ischaemia when $\geq 1$ normal segments developed absolute or relative hypokinesis with stress compared with other segments or an abnormal segment at rest had deterioration of regional systolic thickening with stress. DSE study result was normal if all segments were hyperdynamic with stress. If a resting baseline regional wall motion abnormality was unchanged with stress and all other segments became hyperdynamic, the DSE result was classified as a baseline regional wall motion abnormality with no inducible ischaemia.

Notes

Table of Methodological Quality

\begin{tabular}{|c|c|c|}
\hline Item & Authors' judgement & Description \\
\hline $\begin{array}{l}\text { Representative spectrum? } \\
\text { All tests }\end{array}$ & Yes & Patients referred for kidney transplantation evaluation. \\
\hline $\begin{array}{l}\text { Acceptable reference stan- } \\
\text { dard? } \\
\text { All tests }\end{array}$ & Yes & Coronary angiography with a reference standard threshold of $\geq 70 \%$ stenosis. \\
\hline $\begin{array}{l}\text { Acceptable delay between } \\
\text { tests? } \\
\text { All tests }\end{array}$ & Yes & $\begin{array}{l}47 \text { patients had angiography within } 2 \text { weeks after DSE (median, } 2 \text { days; mean, } \\
12.4 \pm 41 \text { days); three patients had angiographic studies at } 69,85 \text {, and } 280 \\
\text { days after DSE (angiography was delayed wound infection ( } 1 \text { patient) and psy- } \\
\text { chosocial reasons ( } 2 \text { patients). }\end{array}$ \\
\hline $\begin{array}{l}\text { Partial verification avoid- } \\
\text { ed? } \\
\text { All tests }\end{array}$ & Yes & $\begin{array}{l}\text { All participants who underwent the index test received the reference standard } \\
\text { test. }\end{array}$ \\
\hline
\end{tabular}

Differential verification $\quad$ Yes Disease status (CAD) diagnosed by coronary angiography.
avoided?
All tests

\begin{tabular}{l}
\hline $\begin{array}{l}\text { Incorporation avoided? } \\
\text { All tests }\end{array}$ \\
\hline
\end{tabular}

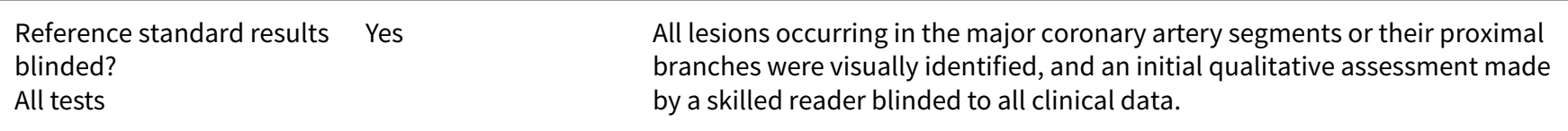

\begin{tabular}{lll}
\hline $\begin{array}{l}\text { Index test results blinded? } \\
\text { All tests }\end{array}$ & Yes & $\begin{array}{l}\text { All DSE studies were analysed in digital format independently by three } \\
\text { echocardiographers blinded to angiographic data. }\end{array}$ \\
\hline $\begin{array}{l}\text { Relevant clinical informa- } \\
\text { tion? }\end{array}$ & Yes & $\begin{array}{l}\text { Relevant clinical information was provided regarding the performance and } \\
\text { analysis of both the index and reference tests. }\end{array}$ \\
All tests & &
\end{tabular}

Uninterpretable results re- Yes No uninterpretable results were present.
ported?
ported? 
Herzog 1999 (Continued)

All tests

Withdrawals explained? Yes

All tests
55 eligible patients participated; 2 were excluded for unstable angina before scheduled testing; 3 underwent DSE and subsequently declined coronary angiography; 50 patients completed the research protocol. 39/50 patients qualified for DSE by the prespecified inclusion criterion of ESKD secondary to diabetic nephropathy (regardless of exercise capacity). The remaining 11 patients were unable to perform treadmill exercise because of peripheral vascular disease (4 patients), musculoskeletal disease (4 patients), lung disease (1 patient), and generalised fatigue (2 patients).

Jassal 2007

\begin{abstract}
Clinical features and settings

\section{Clinical features}

- Between 2004 and 2006, 30 patients were prospectively evaluated who underwent both DSE and coronary angiography. This population included 12 patients ( 5 male, mean age $59 \pm 13$ years) referred to rule out CAD with normal kidney function $(\mathrm{Cr}<2.0 \mathrm{mg} / \mathrm{dL}$ ) and 18 patients (8 male, mean age $55 \pm 12$ years) with $\mathrm{CKD}(\mathrm{Cr}>2.0 \mathrm{mg} / \mathrm{dL})$ on haemodialysis referred for pre-renal transplant workup.
\end{abstract}

\title{
Setting
}

- Boniface General Hospital, Manitoba, Canada

\begin{tabular}{ll}
\hline Participants & Number: 18 \\
- DM: $38 \%$ \\
- Angina pectoris: percentage not reported \\
- Hypertension: $77 \%$ \\
- Sex: $44 \%$ male
\end{tabular}

\begin{tabular}{l} 
Study design \\
\hline $\begin{array}{l}\text { Target condition and ref- } \\
\text { erence standard(s) }\end{array}$
\end{tabular}

Cross sectional study

erence standard(s)

\section{Coronary artery stenosis measured by coronary angiography}

- Criterion for positive test results was $\geq 50 \%$ reduction in cross sectional area.

Index and comparator tests

\section{DSE}

- Beta-adrenergic blocking agents were withdrawn for 24 hours before the study.

- Dobutamine was infused at doses of $5,10,20,30$, and $40 \mathrm{mg} / \mathrm{kg} / \mathrm{min}$ for 3 minutes each. Images were analysed using the standard16-segment model

\begin{tabular}{ll}
\hline Follow-up & None reported \\
\hline Notes & $\begin{array}{l}\text { Only data for the } 18 \text { patients referred for pre-renal transplant workup were considered. Sufficient data } \\
\text { in published report to create } 2 \times 2 \text { table }\end{array}$
\end{tabular}

\section{Table of Methodological Quality}

\begin{tabular}{lll}
\hline Item & Authors' judgement & Description \\
\hline $\begin{array}{l}\text { Representative spectrum? } \\
\text { All tests }\end{array}$ & Yes & Patients who presented for cardiac evaluation before kidney transplantation. \\
\hline $\begin{array}{l}\text { Acceptable reference stan- } \\
\text { dard? }\end{array}$ & Yes & Coronary angiography with a reference standard threshold of $\geq 50 \%$ stenosis.
\end{tabular}


Jassal 2007 (Continued)

All tests

Acceptable delay between Unclear Likely to be short delay between tests.
tests?

All tests

Partial verification avoid- Yes ed?

All tests
All participants who underwent the index test also had the reference standard test.

Differential verification $\quad$ Yes $\quad$ Disease status (CAD) diagnosed by coronary angiography.
avoided?
All tests

All tests

Incorporation avoided? Yes Disease status (CAD) diagnosed by coronary angiography.
All tests

Reference standard results Unclear $\quad$ Not reported.
blinded?

blinded?

All tests

\begin{tabular}{|c|c|c|}
\hline $\begin{array}{l}\text { Index test results blinded? } \\
\text { All tests }\end{array}$ & Unclear & Not reported. \\
\hline $\begin{array}{l}\text { Relevant clinical informa- } \\
\text { tion? } \\
\text { All tests }\end{array}$ & Yes & $\begin{array}{l}\text { Relevant clinical information was provided regarding the performance and } \\
\text { analysis of both the index and reference tests. }\end{array}$ \\
\hline
\end{tabular}

Uninterpretable results re- Yes $\quad$ No uninterpretable results were present.
ported?

ported?

\begin{tabular}{ll}
\hline Withdrawals explained? $\quad$ Yes $\quad$ No withdrawals were reported. \\
All tests
\end{tabular}

All tests

\section{Krawczynska 1988}

$\begin{array}{ll}\text { Clinical features and set- } & \text { Clinical features } \\ \text { tings } & \text { - } 305 \text { patients with ESKD undergoing cardiac assessment prior to kidney transplant }\end{array}$

\section{Setting}

- Emory University School of Medicine, Georgia, USA

\begin{tabular}{ll}
\hline Participants & Number: 46 \\
& - DM: percentage not reported \\
& - Angina pectoris: percentage not reported \\
& - Hypertension: percentage not reported \\
& Sex: not reported \\
\hline Study design & Cohort study \\
\hline $\begin{array}{l}\text { Target condition and ref- } \\
\text { erence standard(s) }\end{array}$ & Coronary artery stenosis measured by coronary angiography \\
\hline Cardiac testing for coronary artery disease in potential kidney transplant recipients (Review) \\
Copyright $\odot 2011$ The Cochrane Collaboration. Published by John Wiley \& Sons, Ltd.
\end{tabular}


Krawczynska 1988 (Continued)
Index and comparator
Thalium-201 Cardiac SPECT
tests constituted a positive test.

\begin{tabular}{ll}
\hline Follow-up & Postoperative data available for outcomes of death and adverse cardiac events. \\
\hline Notes & Only available in abstract form (presentation).
\end{tabular}

- Stress was induced in 200 patients via exercise, 105 with dipyridamole. Reversible perfusion deficits

\section{Table of Methodological Quality}

\begin{tabular}{|c|c|c|}
\hline Item & Authors' judgement & Description \\
\hline $\begin{array}{l}\text { Representative spectrum? } \\
\text { All tests }\end{array}$ & Yes & $\begin{array}{l}\text { Prerenal transplant cardiac assessment. } 305 \text { ESKD patients waiting kidney } \\
\text { transplantation. }\end{array}$ \\
\hline $\begin{array}{l}\text { Acceptable reference stan- } \\
\text { dard? } \\
\text { All tests }\end{array}$ & Yes & Coronary angiography with a reference standard threshold $\geq 50 \%$ stenosis. \\
\hline $\begin{array}{l}\text { Acceptable delay between } \\
\text { tests? } \\
\text { All tests }\end{array}$ & Unclear & Likely to be short delay between tests. \\
\hline $\begin{array}{l}\text { Partial verification avoid- } \\
\text { ed? } \\
\text { All tests }\end{array}$ & No & 38 patients received both coronary angiography and stress test. \\
\hline $\begin{array}{l}\text { Differential verification } \\
\text { avoided? } \\
\text { All tests }\end{array}$ & Yes & Disease status (CAD) diagnosed by coronary angiography. \\
\hline $\begin{array}{l}\text { Incorporation avoided? } \\
\text { All tests }\end{array}$ & Yes & Disease status (CAD) diagnosed by coronary angiography. \\
\hline $\begin{array}{l}\text { Reference standard results } \\
\text { blinded? } \\
\text { All tests }\end{array}$ & Unclear & Not stated in abstract. \\
\hline $\begin{array}{l}\text { Index test results blinded? } \\
\text { All tests }\end{array}$ & Unclear & Not stated in abstract. \\
\hline $\begin{array}{l}\text { Relevant clinical informa- } \\
\text { tion? } \\
\text { All tests }\end{array}$ & Unclear & $\begin{array}{l}\text { Insufficient clinical information provided about performance and analysis of } \\
\text { the index and reference tests. }\end{array}$ \\
\hline $\begin{array}{l}\text { Uninterpretable results re- } \\
\text { ported? } \\
\text { All tests }\end{array}$ & Yes & No results were reported to be uninterpretable. \\
\hline $\begin{array}{l}\text { Withdrawals explained? } \\
\text { All tests }\end{array}$ & Yes & All patients missing from the final analysis were accounted for. \\
\hline
\end{tabular}


Marwick 1989

\section{Clinical features and set- tings}

\section{Clinical features}

- ESKD patients undergoing coronary angiography as part of transplant workup over a 2 year period. Patients were selected on the basis of longstanding diabetes history of chest pain or previous $\mathrm{MI}$, or age $>40$.

\section{Setting}

- Cleveland Clinic, Ohio, USA

\begin{tabular}{ll} 
Participants & Number: 86 \\
& - DM: $29 \%$ \\
- Angina pectoris or IHD: $11 \%$ \\
- Hypertension: $36 \%$ \\
\hline
\end{tabular}

Study design Cross sectional study.

\section{Target condition and ref- Coronary artery stenosis measured by coronary angiography} erence standard(s)

- CAD was defined as the presence of $\geq 1$ coronary arteries with $\geq 50 \%$ diameter stenosis

Index and comparator DSF
tests

- Results were classified based on the presence or absence of calcification of the coronary arteries

Follow-up None reported.

\section{Notes}

\section{Table of Methodological Quality}

\begin{tabular}{lll}
\hline Item & Authors' judgement & Description \\
\hline $\begin{array}{l}\text { Representative spectrum? } \\
\text { All tests }\end{array}$ & Yes & ESKD patients undergoing cardiac evaluation as part of transplant workup. \\
\hline $\begin{array}{l}\text { Acceptable reference stan- } \\
\text { dard? }\end{array}$ & Yes & Coronary angiography with a reference standard threshold of $\geq 50 \%$ stenosis. \\
$\begin{array}{l}\text { All tests } \\
\text { Acceptable delay between }\end{array}$ & Yes & \\
$\begin{array}{l}\text { tests? } \\
\text { All tests }\end{array}$ & & Tests performed at the same time. \\
\hline $\begin{array}{l}\text { Partial verification avoid- } \\
\text { ed? }\end{array}$ & Yes & All participants who underwent an index test received the reference standard \\
All tests & & test. \\
\hline
\end{tabular}

Differential verification $\quad$ Yes Disease status (CAD) diagnosed by coronary angiography.
avoided?
All tests

\begin{tabular}{lll}
\hline $\begin{array}{l}\text { Incorporation avoided? } \\
\text { All tests }\end{array}$ & Yes & Disease status (CAD) diagnosed by coronary angiography. \\
\hline $\begin{array}{l}\text { Reference standard results } \\
\text { blinded? }\end{array}$ & Yes & Author correspondence.
\end{tabular}


Marwick 1989 (Continued)

All tests

Index test results blinded? Yes Author correspondence.

All tests

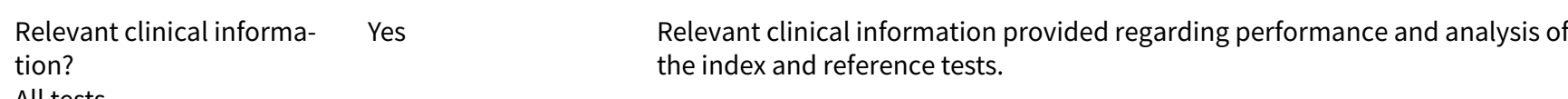

All tests

No results were reported to be uninterpretable.

Uninterpretable results re- Yes ported?

All tests

Withdrawals explained? Yes No withdrawals were reported.
All tests

Marwick 1990

$\begin{array}{ll}\begin{array}{l}\text { Clinical features and set- } \\ \text { tings }\end{array} & \text { Clinical features } \\ & \begin{array}{l}\text { ESKD patients undergoing coronary angiography as part of transplant workup with longstanding di- } \\ \text { abetes, history of chest pain or previous MI, or age }>40\end{array}\end{array}$

\section{Setting}

- Cleveland Clinic, Ohio, USA

\begin{tabular}{ll}
\hline Participants & Number: 45 \\
& - DM: $51 \%$ \\
- Angina pectoris or IHD: $33 \%$ \\
- Hypertension: $81 \%$ \\
Exclusion criteria \\
- Recent angina or MI male \\
\hline Study design & Cohort study
\end{tabular}

\section{Target condition and ref- Coronary artery stenosis measured by coronary angiography} erence standard(s)

- Each angiogram was independently assessed by a reviewer blinded to fluorographic results.

- CAD was defined as presence of $\geq 1$ coronary arteries with $\geq 70 \%$ diameter stenosis.

\section{Index and comparator Dipyridamole SPECT Thallium Imaging}

tests

- Images were displayed using a semi-quantitative system with a segmented colour scale. Scans were interpreted by an experienced observer without knowledge of catheterisation results, and were classified into groups with normal perfusion, fixed defect or reversible defect.

Follow-up Follow up over $25 \pm 14$ months.

\section{Notes}

\section{Table of Methodological Quality}

Item Authors' judgement Description

Cardiac testing for coronary artery disease in potential kidney transplant recipients (Review)

Copyright @ 2011 The Cochrane Collaboration. Published by John Wiley \& Sons, Ltd. 
Marwick 1990 (Continued)

Representative spectrum? Yes ESKD patients undergoing cardiac evaluation as part of transplant workup. All tests

Acceptable reference stan- Yes

Coronary angiography with a reference standard threshold of $\geq 70 \%$ stenosis.

dard?

All tests

Acceptable delay between Yes Thallium scanning was performed within a week of coronary angiography.
tests?

tests?

All tests

$\begin{array}{ll}\begin{array}{l}\text { Partial verification avoid- } \\ \text { ed? }\end{array} & \text { Yes } \\ \text { All tests } & \text { test. }\end{array}$

All tests

Differential verification $\quad$ Yes Disease status (CAD) diagnosed by coronary angiography.
avoided?

All tests

\begin{tabular}{|c|c|c|}
\hline $\begin{array}{l}\text { Incorporation avoided? } \\
\text { All tests }\end{array}$ & Yes & Disease status (CAD) diagnosed by coronary angiography. \\
\hline $\begin{array}{l}\text { Reference standard results } \\
\text { blinded? } \\
\text { All tests }\end{array}$ & Yes & Author correspondence. \\
\hline $\begin{array}{l}\text { Index test results blinded? } \\
\text { All tests }\end{array}$ & Yes & Author correspondence. \\
\hline $\begin{array}{l}\text { Relevant clinical informa- } \\
\text { tion? } \\
\text { All tests }\end{array}$ & Yes & $\begin{array}{l}\text { Relevant clinical information was provided regarding performance and analy- } \\
\text { sis of the index and reference tests. }\end{array}$ \\
\hline $\begin{array}{l}\text { Uninterpretable results re- } \\
\text { ported? } \\
\text { All tests }\end{array}$ & Yes & No results were reported to be uninterpretable. \\
\hline $\begin{array}{l}\text { Withdrawals explained? } \\
\text { All tests }\end{array}$ & Yes & No withdrawals were reported. \\
\hline
\end{tabular}

\section{Modi 2006}

Clinical features and settings

\section{Clinical features}

- ESKD patients with hypertension on maintenance dialysis undergoing pre-transplant coronary angiography as per the institutional protocol if they were aged $>40$ years to rule out CAD as part of transplant workup

\section{Setting}

- Sanjay Gandhi Post Graduate Institute of Medical Sciences, Lucknow, India

\begin{tabular}{ll}
\hline Participants & Number: 105 \\
- DM: $61 / 105(58 \%)$ \\
- Hypertension: all were hypertensive \\
- Sex: $102(97.1 \%)$ male
\end{tabular}

Cardiac testing for coronary artery disease in potential kidney transplant recipients (Review)

Copyright @ 2011 The Cochrane Collaboration. Published by John Wiley \& Sons, Ltd. 
Modi 2006 (Continued)

- Age (mean \pm SD): $51.6 \pm 6.2$ years (range 38 to 64 years)

Study design Cross sectional study.

\section{Target condition and ref- Coronary artery stenosis measured by coronary angiography}

erence standard(s)

- CAD defined as presence of $\geq 1$ coronary arteries with $\geq 50 \%$ diameter stenosis

Index and comparator tests

\section{CIMT measurement}

- CIMT measurement was conducted on USG B mode 7.5 MHZ probe. At least three readings were taken, and the average of three readings was taken for evaluation. IMT on both sides was calculated and averaged. Plaques were defined as focal widening relative to the adjacent segments, with protrusion into the lumen, composed either of only calcified deposits or a combination of calcification and noncalcified material. The site and extent of lesions were not quantified.

- Patients were further divided into two groups according to average CIMT (average IMT >0.75 mm and those with IMT $<0.75 \mathrm{~mm}$ ).

Follow-up None reported.

\section{Notes}

\section{Table of Methodological Quality}

\begin{tabular}{|c|c|c|}
\hline Item & Authors' judgement & Description \\
\hline $\begin{array}{l}\text { Representative spectrum? } \\
\text { All tests }\end{array}$ & Yes & ESKD patients undergoing cardiac evaluation as part of transplant workup. \\
\hline $\begin{array}{l}\text { Acceptable reference stan- } \\
\text { dard? } \\
\text { All tests }\end{array}$ & Yes & $\begin{array}{l}\text { Yes, coronary angiography with a reference standard threshold of } \geq 50 \% \text { steno- } \\
\text { sis. }\end{array}$ \\
\hline $\begin{array}{l}\text { Acceptable delay between } \\
\text { tests? } \\
\text { All tests }\end{array}$ & Unclear & Unclear, but likely to be only short delay between tests. \\
\hline $\begin{array}{l}\text { Partial verification avoid- } \\
\text { ed? } \\
\text { All tests }\end{array}$ & Yes & $\begin{array}{l}\text { All participants who received an index test received the reference standard } \\
\text { test. }\end{array}$ \\
\hline $\begin{array}{l}\text { Differential verification } \\
\text { avoided? } \\
\text { All tests }\end{array}$ & Yes & $\begin{array}{l}\text { This was not an issue in this study. Disease status (CAD) is diagnosed only } \\
\text { through coronary angiography. }\end{array}$ \\
\hline $\begin{array}{l}\text { Incorporation avoided? } \\
\text { All tests }\end{array}$ & Yes & $\begin{array}{l}\text { This was not an issue in this study. Disease status (CAD) is diagnosed only } \\
\text { through coronary angiography. }\end{array}$ \\
\hline $\begin{array}{l}\text { Reference standard results } \\
\text { blinded? } \\
\text { All tests }\end{array}$ & Yes & $\begin{array}{l}\text { Reference standard performed before index test. Therefore it was not influ- } \\
\text { enced by results of index test. }\end{array}$ \\
\hline $\begin{array}{l}\text { Index test results blinded? } \\
\text { All tests }\end{array}$ & Yes & $\begin{array}{l}\text { An operator, who was blinded with respect to the results of the coronary an- } \\
\text { giography, measured CIMT in all patients prior to coronary angiography and } \\
\text { recorded it on videotape. Two independent observers who were blinded to the } \\
\text { result of coronary angiography, measured CIMT offline to validate its predic- } \\
\text { tive accuracy as a noninvasive test in predicting the presence or absence of } \\
\text { CAD. }\end{array}$ \\
\hline
\end{tabular}


Modi 2006 (Continued)

Relevant clinical informa- Yes

tion?

All tests
Relevant clinical information was provided regarding the performance and analysis of both the index and reference tests.

Uninterpretable results re- Yes No results were reported to be uninterpretable. ported?

All tests

Withdrawals explained? Yes No withdrawals were present.

All tests

Reis 1995

$\begin{array}{ll}\begin{array}{ll}\text { Clinical features and set- } \\ \text { tings }\end{array} & \text { Clinical features } \\ & \text { - ESKD patients on dialysis undergoing cardiac evaluation (DSE) as part of transplant workup. Antihy- } \\ & \text { pertensive treatment and aggressive DM control were undertaken as clinically indicated } \\ & \text { Setting } \\ & \text { - University of Michigan, Ann Arbor, Michigan, USA } \\ & \text { - Number: } 97 \text { patients underwent screening; only } 30 \text { patients received both DSE and coronary angiog- } \\ & \text { raphy } \\ \text { Participants } & \text { DM: } 64 \% \\ \text { - Angina pectoris or history of IHD: } 30 \% & \text { - Hypertension: } 96 \% \\ \text { - Sex: } 63 \% \text { male }\end{array}$

Study design Cohort study.

\section{Target condition and ref- Coronary artery stenosis measured by coronary angiography} erence standard(s)

- CAD was defined as presence of $\geq 1$ coronary arteries with $\geq 50 \%$ stenosis.

Index and comparator tests
DSE

- After completing a resting echocardiogram, stepwise infusion of dobutamine starting at $10 \mathrm{pg} / \mathrm{kg} /$ min, and increasing to 20 and a peak of 30 or $40 \mathrm{pg} / \mathrm{kg} / \mathrm{min}$ in 3-minute stages was initiated.

- All DSE studies were reviewed by experienced echocardiographers blinded to angiographic data and classified as:

- normal response: global increase in contractility, with an associated increase in ejection fraction, implying an absence of significant obstructive CAD (no regional wall motion abnormalities were seen at rest or during DSE).

- inducible ischaemia: wall motion abnormalities during DSE in 22 segments in regions that were normal at baseline, implying CAD without prior MI.

- fixed response: wall motion abnormality at baseline and no change during DSE implying prior MI without inducible ischaemia.

- mixed response: new and/or worsening wall motion abnormality in a patient with a wall motion abnormality at rest, implying prior MI with additional inducible ischaemia.
Follow-up
$12 \pm 6$ months.

Notes 
Reis 1995 (Continued)

Table of Methodological Quality

\begin{tabular}{|c|c|c|}
\hline Item & Authors' judgement & Description \\
\hline $\begin{array}{l}\text { Representative spectrum? } \\
\text { All tests }\end{array}$ & Yes & ESKD patients undergoing cardiac evaluation as part of transplant workup. \\
\hline $\begin{array}{l}\text { Acceptable reference stan- } \\
\text { dard? } \\
\text { All tests }\end{array}$ & Yes & Coronary angiography with a reference standard threshold of $\geq 50 \%$ stenosis. \\
\hline $\begin{array}{l}\text { Acceptable delay between } \\
\text { tests? } \\
\text { All tests }\end{array}$ & Yes & Within 4 months. \\
\hline $\begin{array}{l}\text { Partial verification avoid- } \\
\text { ed? } \\
\text { All tests }\end{array}$ & No & Coronary angiography was performed in $30 / 97$ patients. \\
\hline $\begin{array}{l}\text { Differential verification } \\
\text { avoided? } \\
\text { All tests }\end{array}$ & Yes & Disease status (CAD) diagnosed by coronary angiography. \\
\hline $\begin{array}{l}\text { Incorporation avoided? } \\
\text { All tests }\end{array}$ & Yes & Disease status (CAD) diagnosed by coronary angiography. \\
\hline $\begin{array}{l}\text { Reference standard results } \\
\text { blinded? } \\
\text { All tests }\end{array}$ & Unclear & Not reported. \\
\hline $\begin{array}{l}\text { Index test results blinded? } \\
\text { All tests }\end{array}$ & Yes & $\begin{array}{l}\text { All DSE studies were reviewed by experienced echocardiographers blinded to } \\
\text { angiographic data. }\end{array}$ \\
\hline $\begin{array}{l}\text { Relevant clinical informa- } \\
\text { tion? } \\
\text { All tests }\end{array}$ & Yes & $\begin{array}{l}\text { Relevant clinical information was provided regarding the performance and } \\
\text { analysis of both the index and reference tests. }\end{array}$ \\
\hline $\begin{array}{l}\text { Uninterpretable results re- } \\
\text { ported? } \\
\text { All tests }\end{array}$ & Yes & No results were reported to be uninterpretable. \\
\hline $\begin{array}{l}\text { Withdrawals explained? } \\
\text { All tests }\end{array}$ & Yes & All patients missing from the final analysis were accounted for. \\
\hline
\end{tabular}

\section{Rosario 2010}

Clinical features and settings

\section{Clinical features}

- CKD patients in haemodialysis programs referred for kidney coronary angiography as part of a kidney transplant evaluation. The clinical indication for coronary angiography was based on the fact that the patients belonged to the group under high risk for CAD either due to symptoms and/or previous invasive exams that would lead to a suspicion of CVD.

\section{Setting}


Rosario 2010 (Continued)

- Instituto do Coração (InCor) do Hospital das Clínicas da Faculdade de Medicina da Universidade de São Paulo, São Paulo, Brazil.

\begin{tabular}{ll}
\hline Participants & - Number: 97 \\
& - DM: $38 \%$ \\
& - Angina pectoris or IHD: $29 \%$ \\
& - Hypertension: $90 \%$ \\
\hline Study design $65 \%$ male
\end{tabular}

Follow-up Follow-up ongoing.

\section{Notes}

\section{Table of Methodological Quality}

\begin{tabular}{lll}
\hline Item & Authors' judgement & Description \\
\hline $\begin{array}{ll}\text { Representative spectrum? } \\
\text { All tests }\end{array}$ & Yes & $\begin{array}{l}\text { CKD patients already in a haemodialysis program and referred to be submitted } \\
\text { to kidney transplant. }\end{array}$
\end{tabular}

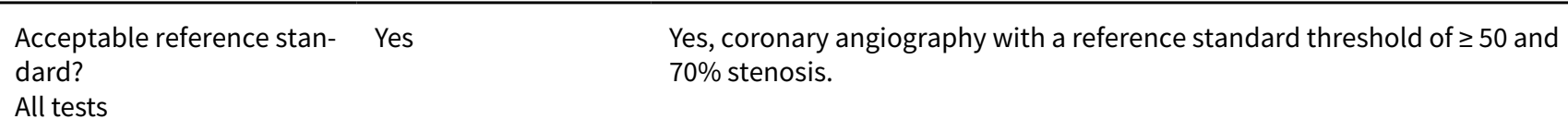

Yes

Acceptable delay between Yes

tests?

All tests
Time elapsed between Multi-detector CT and coronary angiography was on average 99.03 days, SD 87.65 days, and median 79 days. Minimum interval was 2 days, and maximum interval was 380 days. Only 2 cases exceeded 1 year, and 16 cases had an interval over 6 months.

All participants who received an index test received the reference standard test.

Partial verification avoid- Yes $\quad$ test.
ed?

All tests

\begin{tabular}{|c|c|c|}
\hline $\begin{array}{l}\text { Differential verification } \\
\text { avoided? }\end{array}$ & Yes & $\begin{array}{l}\text { This was not an issue in this study. Disease status (CAD) is diagnosed only } \\
\text { through coronary angiography. }\end{array}$ \\
\hline
\end{tabular}

All tests

\begin{tabular}{ll}
\hline Incorporation avoided? Yes & $\begin{array}{l}\text { This was not an issue in this study. Disease status (CAD) is diagnosed only } \\
\text { through coronary angiography. }\end{array}$ \\
All tests & then
\end{tabular}


Rosario 2010 (Continued)

Reference standard results Yes An observer experienced in QCA technique and who did not participate in the blinded? Multi-detector CT analysis - also blind and independent.

All tests

Index test results blinded? Unclear Not reported.
All tests

All tests

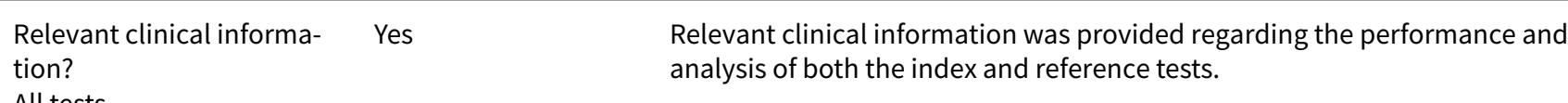

All tests

All tests

Withdrawals explained? Yes No withdrawals were present.

All tests

Sharma 2005

$\begin{array}{ll}\begin{array}{l}\text { Clinical features and set- } \\ \text { tings }\end{array} & \text { Clinical features } \\ & \text { - ESKD patients undergoing cardiac evaluation } \\ & \text { Setting } \\ & \text { - St George's Hospital, London, UK } \\ & \text { - Number: } 128 \\ \text { - Dialysis: } 54 \% \\ \text { Participants } & \text { Principal cause of ESKD: DM (39 patients) } \\ & \text { - Angina pectoris or IHD: } 42 \% \\ & \text { - Hypertension: } 91 \% \\ \text { - Sex: } 64 \% \text { male }\end{array}$

\section{Exclusion criteria}

- Age $<18$ years; severe aortic stenosis; unstable angina; inability to consent.

\begin{tabular}{|c|c|}
\hline Study design & Cohort study \\
\hline $\begin{array}{l}\text { Target condition and ref- } \\
\text { erence standard(s) }\end{array}$ & $\begin{array}{l}\text { Coronary artery stenosis measured by coronary angiography } \\
\text { - CAD defined as the presence of } \geq 1 \text { coronary arteries with } \geq 70 \% \text { diameter stenosis. }\end{array}$ \\
\hline $\begin{array}{l}\text { Index and comparator } \\
\text { tests }\end{array}$ & $\begin{array}{l}\text { - Exercise ECG } \\
\text { * Patients had treadmill exercise testing according to standard Bruce protocol to limiting symptoms. } \\
\text { The } 12 \text { lead ECG was recorded continuously and the following documented: exercise time to lim- } \\
\text { iting symptom, maximal ST segment change, Duke multivariate prognostic score, maximal heart } \\
\text { rate, maximal systolic blood pressure, limiting symptoms. The test was stopped if: limiting symp- } \\
\text { toms (angina, shortness of breath, dizziness, lethargy), ST depression }>3 \mathrm{~mm} \text {, ventricular tachy- } \\
\text { cardia, drop in blood pressure }>30 \mathrm{~mm} \mathrm{Hg} \text {, SBP rise }>230 \mathrm{~mm} \mathrm{Hg} \text { occurred. Patients were given an } \\
\text { angina score: } 0=\text { none, } 1=\text { non-limiting angina, } 2=\text { limiting angina. Duke score was calculated as: } \\
\text { total treadmill time (min)- } 5 \mathrm{X} \text { magnitude of maximal ST depression (mm)- } 4 \mathrm{X} \text { angina index. Hori- } \\
\text { zontal or down sloping ST depression }>1 \mathrm{~mm} \text { measured } 80 \mathrm{~ms} \text { after the J point, and ST elevation }>1 \\
\text { mm measured } 40 \mathrm{~ms} \text { after the J point, were regarded as positive results. The test was described as }\end{array}$ \\
\hline
\end{tabular}


inconclusive if stopped before $85 \%$ predicted heart rate could be achieved with no cardiac symptoms or significant changes at that stage.

- DSE

* An abnormal response was described as the occurrence under stress of hypokinesia, akinesia or dyskinesia in one or more resting normal segments and/or worsening of wall motion in one or more resting hypokinetic segments.

- Echocardiography

\section{- Mitral annular calcification}

* The presence of mitral annular calcification was defined as an echo dense band visualised throughout systole and diastole, distinguishable from the posterior mitral valve leaflet, and located anterior and parallel to the posterior left ventricular wall on M-mode recordings.

- Resting wall motion abnormality

\section{- Resting ECG}

* The ECG was considered abnormal if any of the following criteria were met in any of the standard limb leads or precordial leads, except AVR or V1: pathological Q waves, left ventricular hypertrophy by Sokolow-Lyon criteria or Cornell index, ST depression $\geq 1 \mathrm{~mm}$, ST elevation $\geq 1 \mathrm{~mm}$, T wave inversion or bundle branch block (QRS $\geq 120 \mathrm{~ms}$ ).

Notes

Table of Methodological Quality

\begin{tabular}{lll}
\hline Item & Authors' judgement & Description \\
\hline $\begin{array}{l}\text { Representative spectrum? } \\
\text { All tests }\end{array}$ & Yes & ESKD patients undergoing cardiac evaluation as part of transplant workup. \\
\hline $\begin{array}{l}\text { Acceptable reference stan- } \\
\text { dard? }\end{array}$ & Yes & Coronary angiography with a reference standard threshold of $\geq 70 \%$ stenosis. \\
All tests & & \\
\hline
\end{tabular}

\begin{tabular}{lll}
\hline $\begin{array}{l}\text { Acceptable delay between } \\
\text { tests? }\end{array}$ & Unclear & Likely to be short delay between tests. \\
All tests & \\
\hline $\begin{array}{l}\text { Partial verification avoid- } \\
\text { ed? }\end{array}$ & Yes & $\begin{array}{l}\text { All participants who underwent the index test received the reference standard } \\
\text { test. }\end{array}$ \\
All tests & \\
\hline
\end{tabular}

Differential verification $\quad$ Yes Disease status (CAD) diagnosed by coronary angiography.
avoided?
All tests

Incorporation avoided? Yes Disease status (CAD) diagnosed by coronary angiography.

All tests

\begin{tabular}{lll}
$\begin{array}{l}\text { Reference standard results } \\
\text { blinded? } \\
\text { All tests }\end{array}$ & Yes & $\begin{array}{l}\text { Angiograms were interpreted by two experienced, blinded observers with con } \\
\text { sensus for disagreement. }\end{array}$ \\
\hline $\begin{array}{l}\text { Index test results blinded? } \\
\text { All tests }\end{array}$ & Yes & $\begin{array}{l}\text { All images were reported offline by two experienced observers blinded to the } \\
\text { rest of the study. }\end{array}$ \\
\hline
\end{tabular}

\begin{tabular}{|c|c|c|}
\hline $\begin{array}{l}\text { Relevant clinical informa- } \\
\text { tion? }\end{array}$ & Yes & $\begin{array}{l}\text { Relevant clinical information was provided regarding performance and analy- } \\
\text { sis of both the index and reference tests. }\end{array}$ \\
\hline
\end{tabular}


Sharma 2005 (Continued)

Uninterpretable results re- Yes No results were reported to be uninterpretable. ported?

All tests

Withdrawals explained? Yes No withdrawals were reported.

All tests

\section{Sharma 2009}

Clinical features and settings

\section{Clinical features}

- ESKD patients undergoing cardiac evaluation as part of transplant workup

\section{Setting}

- Ealing Hospital NHS Trust, Middlesex, UK

\begin{tabular}{ll}
\hline Participants & Number: 143 \\
- DM: $38 \%$ \\
- Angina pectoris or IHD: $27 \%$ \\
- Hypertension: $92 \%$ \\
\hline Sex: $64 \%$ male
\end{tabular}

\section{Exclusion criteria}

- <18 years; severe aortic stenosis; unstable angina

Study design Cohort study

\section{Target condition and ref- Coronary artery stenosis measured by coronary angiography}

erence standard(s)

- CAD defined as presence of $\geq 1$ coronary arteries with $\geq 70 \%$ diameter stenosis

Index and comparator tests

\section{DSE}

- Peak systolic velocity measured by tissue Doppler imaging: The percentage of ischaemic myocardium was calculated from tissue Doppler imaging analysis as the number of ischaemic segments divided by the number of visualised segments.

- Conventional visual assessment: Semi-quantitative analysis was performed using a 17-segment model. An abnormal response was described by the occurrence under stress of a new or worsening wall motion abnormality in $\geq 1$ left ventricular segment. The severity of ischaemia was determined by the number of ischaemic segments seen during dobutamine stress and by the peak wall motion score index.

\section{Echocardiography}

- Resting wall motion abnormality

Follow-up Mean follow-up was $2.3 \pm 0.7$ years (range 0.2 to 3.3 years)

Notes

The authors reported that this study population was different from the study results published in 2005. We were able to create $2 \times 2$ tables using tabulated results from the study.

\section{Table of Methodological Quality}

Item Authors' judgement Description


Sharma 2009 (Continued)

Representative spectrum? Yes $\quad$ ESKD patients undergoing cardiac evaluation as part of transplant workup.
All tests

Acceptable reference stan- Yes Coronary angiography with a reference standard threshold of $\geq 70 \%$ stenosis.
dard?
All tests

Acceptable delay between Unclear Unclear, but likely to be only short delay between tests.
tests?
All tests

\begin{tabular}{|c|c|c|}
\hline $\begin{array}{l}\text { Partial verification avoid- } \\
\text { ed? } \\
\text { All tests }\end{array}$ & Yes & $\begin{array}{l}\text { All participants who underwent the index test received the reference standard } \\
\text { test. }\end{array}$ \\
\hline
\end{tabular}

\begin{tabular}{|c|c|c|}
\hline $\begin{array}{l}\text { Differential verification } \\
\text { avoided? } \\
\text { All tests }\end{array}$ & Yes & $\begin{array}{l}\text { This was not an issue in this study. Disease status (CAD) is diagnosed only } \\
\text { through coronary angiography. }\end{array}$ \\
\hline
\end{tabular}

All tests

\begin{tabular}{|c|c|c|}
\hline $\begin{array}{l}\text { Incorporation avoided? } \\
\text { All tests }\end{array}$ & Yes & $\begin{array}{l}\text { This was not an issue in this study. Disease status (CAD) is diagnosed only } \\
\text { through coronary angiography. }\end{array}$ \\
\hline $\begin{array}{l}\text { Reference standard results } \\
\text { blinded? } \\
\text { All tests }\end{array}$ & Yes & $\begin{array}{l}\text { Angiograms were interpreted blindly by two experienced observers and con- } \\
\text { sensus was obtained in discordant cases from a third experienced operator. }\end{array}$ \\
\hline $\begin{array}{l}\text { Index test results blinded? } \\
\text { All tests }\end{array}$ & Yes & $\begin{array}{l}\text { The analysis of conventional and tissue Doppler imaging stress echo data was } \\
\text { performed off-line by two independent, experienced observers blinded to clin- } \\
\text { ical and coronary angiography data. Consensus was obtained in discordant } \\
\text { cases from a third experienced operator. }\end{array}$ \\
\hline $\begin{array}{l}\text { Relevant clinical informa- } \\
\text { tion? } \\
\text { All tests }\end{array}$ & Yes & All patients missing from the final analysis were accounted for. \\
\hline $\begin{array}{l}\text { Uninterpretable results re- } \\
\text { ported? } \\
\text { All tests }\end{array}$ & Yes & No results were reported to be uninterpretable. \\
\hline $\begin{array}{l}\text { Withdrawals explained? } \\
\text { All tests }\end{array}$ & Yes & No withdrawals were reported. \\
\hline
\end{tabular}

\section{Sharples 2004}

\section{Clinical features and set- Clinical features} tings

- ESKD patients referred for coronary angiography as part of cardiac work up before kidney transplantation

\section{Setting}

- Two inner city renal units in Royal London and St Bartholomew's Hospital, London, UK

\begin{tabular}{ll}
\hline Participants & Number: 18 \\
- DM: percentage not reported & Angina pectoris: percentage not reported
\end{tabular}


Sharples 2004 (Continued)

- Hypertension: percentage not reported

- Sex: 50\% male

- Man age: 53.9 years (range 31 to 73 years)

- Mean time on RRT: 27.4 months (range 4 to 111 months)

\begin{tabular}{ll}
\hline Study design & Cross sectional study \\
\hline $\begin{array}{l}\text { Target condition and ref- } \\
\text { erence standard(s) }\end{array}$ & $\begin{array}{l}\text { Coronary artery stenosis measured by coronary angiography } \\
\text { - }\end{array}$ \\
\hline $\begin{array}{l}\text { Index and comparator } \\
\text { tests }\end{array}$ & EBCT defined as presence of $\geq 1$ coronary arteries with at least $50 \%$ stenosis. \\
& $\begin{array}{l}\text { Images were performed with a 100-ms scanning time and a single slice thickness of } 3 \text { mm. } 36 \text { to } 40 \text { to- } \\
\text { mographic slices were obtained for each subject during } 2 \text { breath-holding sessions. The degree of coro- } \\
\text { nary artery calcification was calculated by multiplying the area of each calcified lesion by a weighting } \\
\text { factor corresponding to the peak pixel intensity for each lesion to yield a lesion-specific calcification } \\
\text { score. The proximal segments of the left main stem, left anterior descending, left circumflex and right } \\
\text { coronary arteries were examined. }\end{array}$
\end{tabular}

\begin{tabular}{ll}
\hline Follow-up & None reported. \\
\hline Notes & Results reported per vessel, not per patient. Insufficient data to construct meaningful $2 \times 2$ table. \\
& Therefore, study did not contribute data to the meta-analysis.
\end{tabular}

\section{Table of Methodological Quality}

\begin{tabular}{lll}
\hline Item & Authors' judgement & Description \\
\hline $\begin{array}{l}\text { Representative spectrum? } \\
\text { All tests }\end{array}$ & Yes & ESKD patients assessed for CAD before kidney transplant. \\
\hline $\begin{array}{l}\text { Acceptable reference stan- } \\
\text { dard? }\end{array}$ & Yes & Coronary angiography with a reference standard threshold of $\geq 75 \%$ stenosis. \\
All tests & & \\
\hline
\end{tabular}

\begin{tabular}{|c|c|c|}
\hline $\begin{array}{l}\text { Acceptable delay between } \\
\text { tests? } \\
\text { All tests }\end{array}$ & Unclear & Likely to be short delay between tests. \\
\hline $\begin{array}{l}\text { Partial verification avoid- } \\
\text { ed? } \\
\text { All tests }\end{array}$ & Yes & $\begin{array}{l}\text { All participants who underwent the index test received the reference standard } \\
\text { test. }\end{array}$ \\
\hline
\end{tabular}

Differential verification $\quad$ Yes Disease status (CAD) diagnosed by coronary angiography.
avoided?
All tests

Incorporation avoided? Yes Disease status (CAD) diagnosed by coronary angiography.
All tests

\begin{tabular}{lll}
\hline $\begin{array}{l}\text { Reference standard results } \\
\text { blinded? } \\
\text { All tests }\end{array}$ & Yes & $\begin{array}{l}\text { Analysis of the coronary angiograms was performed using a digital analysis } \\
\text { system operated by a cardiologist blinded to the calcification score. }\end{array}$ \\
\hline $\begin{array}{l}\text { Index test results blinded? } \\
\text { All tests }\end{array}$ & Yes & $\begin{array}{l}\text { The acquired images were scored with the use of Imatron software by a single } \\
\text { radiologist blinded to the clinical or angiographic history of the patient. }\end{array}$
\end{tabular}


Sharples 2004 (Continued)

Relevant clinical informa- Yes

tion?

All tests
Relevant clinical information was provided regarding the performance and analysis of both the index and reference tests.

Uninterpretable results re- Yes There were no uninterpretable results.
ported?

ported?

All tests

Withdrawals explained? Yes There were no withdrawals.

All tests

Vandenberg 1996

Clinical features and set-
tings $\begin{aligned} & \text { Clinical features } \\ & \text { - Patients with kidney disease and DM referred for kidney and/or pancreas transplantation from } 1988 \text { to } \\ & 1993 \text { undergoing cardiac evaluation as part of transplant workup with no history of angina, MI, coro- } \\ & \text { nary artery bypass surgery, or percutaneous transluminal coronary angioplasty; pharmacologic stress } \\ & \text { thallium scintigraphy and/or exercise radionuclide ventriculography performed as part of the evalu- } \\ & \text { ation; and coronary artery angiography performed within } 6 \text { months after the radionuclide evaluation } \\ & \text { (and no cardiac symptoms in the interim period). }\end{aligned}$

\section{Setting}

- Cardiovascular Center, University of lowa College of Medicine, lowa, USA

\begin{tabular}{ll}
\hline Participants & Number: 47 \\
- DM: $100 \%$ & Angina pectoris or IHD: Nil \\
- Hypertension: $74 \% .35 / 74(74 \%)$ \\
$*$ Patients were taking antihypertensive medications, including beta blockers and calcium channel \\
$\quad$ blockers; medications were continued during stress testing \\
- Sex: not reported
\end{tabular}

\section{Target condition and ref- Coronary artery stenosis measured by coronary angiography}

erence standard(s)

- CAD defined as presence of $\geq 1$ coronary arteries with $\geq 75 \%$ diameter stenosis. Separate data available for $50 \%$ stenosis

Index and comparator tests

\section{Pharmacologic stress thallium scintigraphy}

- IV dipyridamole was infused at a rate of $0.142 \mathrm{mg} / \mathrm{kg}$ per min for $4 \mathrm{~min}$. IV adenosine was infused at a rate of $0.14 \mathrm{mg} / \mathrm{kg}$ per min for $6 \mathrm{~min}$. Thallium-201 ( $3 \mathrm{mCi}$ ) was injected IV $5 \mathrm{~min}$ after the completion of the dipyridamole infusion or $4 \mathrm{~min}$ after the beginning of the adenosine infusion. Imaging was performed within 10 min with a gamma-camera. Planar images in anterior and lateral projections were obtained and were followed immediately by single-photon emission CT imaging. Images were interpreted by consensus of two experienced radiologists who were unaware of the angiography results. Test results were considered abnormal if either a fixed or a reversible defect was present.

\section{Exercise radionuclide ventriculography}

- Radionuclide ventriculography was performed in 40 patients using a modified in vivo red blood celllabelling technique with an initial IV injection of $5.1 \mathrm{mg}$ of stannous pyrophosphate, followed by 25 to $30 \mathrm{mCi}$ of technetium-99m pertechnetate. Patients performed semi supine exercise with a bicycle ergometer table during continuous 12-lead ECG monitoring. Exercise was begun at a pedal speed of $50 \mathrm{rpm}$ and a work load of about 50 watts, which was increased by 10 watts every $30 \mathrm{sec}$ to a symp-

Cardiac testing for coronary artery disease in potential kidney transplant recipients (Review)

Copyright @ 2011 The Cochrane Collaboration. Published by John Wiley \& Sons, Ltd. 
tom-limited maximum. Heart rate and blood pressure were recorded at each exercise level. Images were obtained in the left anterior oblique projection at peak exercise and ejection fraction was calculated from this image. Exercise was considered adequate if the peak rate pressure product was > 20,000 or if the rate pressure product at least doubled from baseline to peak exercise.

- A test result was considered abnormal if any of the following were present:

* resting ejection fraction of $<50 \%$

* failure to increase ejection fraction by at least 5 percentage points (in female subjects and in those with a resting ejection fraction of $>60 \%$, the failure to increase ejection fraction was not considered abnormal); or

* a new wall motion abnormality with exercise

\section{Notes}

\section{Table of Methodological Quality}

\begin{tabular}{|c|c|c|}
\hline Item & Authors' judgement & Description \\
\hline $\begin{array}{l}\text { Representative spectrum? } \\
\text { All tests }\end{array}$ & Yes & $\begin{array}{l}\text { Renal failure patients undergoing cardiac evaluation as part of transplant } \\
\text { workup. }\end{array}$ \\
\hline $\begin{array}{l}\text { Acceptable reference stan- } \\
\text { dard? } \\
\text { All tests }\end{array}$ & Yes & $\begin{array}{l}\text { Yes, coronary angiography with a reference standard threshold of } \geq 75 \% \text { steno- } \\
\text { sis. }\end{array}$ \\
\hline $\begin{array}{l}\text { Acceptable delay between } \\
\text { tests? } \\
\text { All tests }\end{array}$ & Yes & $\begin{array}{l}\text { Angiography was performed } 55 \pm 42 \text { days after thallium scintigraphy in } 42 \text { pa- } \\
\text { tients and } 50 \pm 45 \text { days after exercise radionuclide ventriculography in } 40 \text { pa- } \\
\text { tients. }\end{array}$ \\
\hline $\begin{array}{l}\text { Partial verification avoid- } \\
\text { ed? } \\
\text { All tests }\end{array}$ & Yes & $\begin{array}{l}\text { All participants who received an index test received the reference standard } \\
\text { test. }\end{array}$ \\
\hline
\end{tabular}

\begin{tabular}{|c|c|c|}
\hline $\begin{array}{l}\text { Differential verification } \\
\text { avoided? }\end{array}$ & Yes & $\begin{array}{l}\text { This was not an issue in this study. Disease status (CAD) is diagnosed only } \\
\text { through coronary angiography. }\end{array}$ \\
\hline
\end{tabular}

This was not an issue in this study. Disease status (CAD) is diagnosed only through coronary angiography.

\begin{tabular}{|c|c|c|}
\hline $\begin{array}{l}\text { Incorporation avoided? } \\
\text { All tests }\end{array}$ & Yes & $\begin{array}{l}\text { This was not an issue in this study. Disease status (CAD) is diagnosed only } \\
\text { through coronary angiography. }\end{array}$ \\
\hline
\end{tabular}

Reference standard results Yes blinded?

All tests

\begin{tabular}{|c|c|c|}
\hline $\begin{array}{l}\text { Index test results blinded? } \\
\text { All tests }\end{array}$ & Yes & $\begin{array}{l}\text { Images were interpreted by the consensus of two experienced radiologists } \\
\text { who were unaware of the angiography results. }\end{array}$ \\
\hline $\begin{array}{l}\text { Relevant clinical informa- } \\
\text { tion? } \\
\text { All tests }\end{array}$ & Yes & $\begin{array}{l}\text { Relevant clinical information was provided regarding the performance and } \\
\text { analysis of both the index and reference tests. }\end{array}$ \\
\hline $\begin{array}{l}\text { Uninterpretable results re- } \\
\text { ported? } \\
\text { All tests }\end{array}$ & Yes & $\begin{array}{l}\text { Yes. One MPS was technically suboptimal and was therefore not included in } \\
\text { the analysis. Exercise ventriculography was suboptimal in five patients and } \\
\text { they were not included in the analysis. }\end{array}$ \\
\hline $\begin{array}{l}\text { Withdrawals explained? } \\
\text { All tests }\end{array}$ & Yes & All patients missing from the final analysis were accounted for. \\
\hline
\end{tabular}

Cardiac testing for coronary artery disease in potential kidney transplant recipients (Review)

Copyright @ 2011 The Cochrane Collaboration. Published by John Wiley \& Sons, Ltd. 


$\begin{array}{ll}\begin{array}{l}\text { Clinical features and set- } \\ \text { tings }\end{array} & \text { Clinical features } \\ & \text { - Dialysis-dependent renal transplant candidates evaluated between } 1 \text { January } 1993 \text { and } 1 \text { March } 1995 \\ & \text { were screened for cardiac high-risk factors (identified as those with diabetes mellitus, previous MI, } \\ & \text { age } 50 \text { years or more cerebral and/or peripheral vascular disease, CHF, class I or II angina (Canadian } \\ & \text { Cardiovascular Society classification), and dialysis dependency of more than } 5 \text { years). }\end{array}$

\section{Setting}

- Geisinger Medical Center, Danville, Pennsylvannia, USA

\begin{tabular}{ll}
\hline Participants & Number: 33 \\
& - DM: percentage not reported \\
& - Hypertension: percentage not reported \\
& - Sex: not reported \\
\hline Study design & Cohort study
\end{tabular}

\section{Target condition and ref- Coronary artery stenosis measured by coronary angiography} erence standard(s)

- CAD was defined as the presence of one or more coronary arteries with $70 \%$ or greater diameter stenosis, or greater than $50 \%$ in left main coronary artery.

Index and comparator tests

\section{DSE}

- DSE was performed the day after dialysis to avoid hypertensive blood pressure response from volume overload. A standardised DSE protocol was used. DSE findings were graded as negative if normal wall motion was present and positive when:

* CAD: fixed, inducible, or mixed segmental wall motion abnormalities

* Cardiomyopathy: diffuse wall motion abnormalities or

* Primary valvular heart disease: severe aortic stenosis, aortic insufficiency, mitral stenosis, or mitral regurgitation secondary to primary leaflet abnormalities were present

Notes

\section{Table of Methodological Quality}

\begin{tabular}{lll}
\hline Item & Authors' judgement & Description \\
\hline $\begin{array}{l}\text { Representative spectrum? } \\
\text { All tests }\end{array}$ & Yes & ESKD patients undergoing cardiac evaluation as part of transplant workup. \\
\hline $\begin{array}{l}\text { Acceptable reference stan- } \\
\text { dard? } \\
\text { All tests }\end{array}$ & Yes & $\begin{array}{l}\text { Coronary artery stenosis measured by coronary angiography. CAD defined as } \\
\text { the presence of } \geq 1 \text { coronary arteries with } \geq 70 \% \text { diameter stenosis, or }>50 \% \text { in } \\
\text { left main coronary artery. }\end{array}$ \\
\hline $\begin{array}{l}\text { Acceptable delay between } \\
\text { tests? }\end{array}$ & Unclear & Likely to be only delay between tests. \\
$\begin{array}{ll}\text { All tests } & \end{array}$ \\
$\begin{array}{l}\text { Partial verification avoid- } \\
\begin{array}{l}\text { ed? } \\
\text { All tests }\end{array}\end{array}$ & Yes & $\begin{array}{l}\text { All participants who underwent the index test received the reference standard } \\
\text { test. }\end{array}$ \\
\hline
\end{tabular}


West 2000 (Continued)

Differential verification Yes Disease status (CAD) diagnosed by coronary angiography. avoided?

All tests

Incorporation avoided? Yes Disease status (CAD) diagnosed by coronary angiography.
All tests

Reference standard results Unclear Not reported.

blinded?

All tests

Index test results blinded? Unclear Not reported.
All tests

\begin{tabular}{lll}
\hline $\begin{array}{l}\text { Relevant clinical informa- } \\
\text { tion? } \\
\text { All tests }\end{array}$ & $\begin{array}{l}\text { Res } \\
\text { analysis of the index and reference tests. }\end{array}$ \\
\hline $\begin{array}{l}\text { Uninterpretable results re- } \\
\text { ported? } \\
\text { All tests }\end{array}$ & Yes & There were no uninterpretable results. \\
\hline $\begin{array}{l}\text { Withdrawals explained? } \\
\text { All tests }\end{array}$ & Yes & $\begin{array}{l}\text { Nine patients were excluded because of prior coronary angiography (5), class } \\
\text { III } \pm \text { IV angina (3), and refusal to participate in the study (1). }\end{array}$ \\
\hline
\end{tabular}

Worthley 2003

$\begin{array}{ll}\begin{array}{l}\text { Clinical features and set- } \\ \text { tings }\end{array} & \text { Clinical features } \\ & \text { - ESKD patients with multiple risk factors (> 60 years; HTN; DM; history of smoking; family history of } \\ & \text { CAD; hypercholesterolaemia) undergoing cardiac evaluation as part of transplant workup }\end{array}$

\section{Setting}

- North Western Adelaide Health Service, University of Adelaide, Australia

\begin{tabular}{ll}
\hline Participants & Number: 40 \\
- DM: $78 \%$ \\
- Angina pectoris or IHD: $18 \%$ \\
- Hypertension: $98 \%$ \\
- Sex: $48 \%$ male \\
Exclusion criteria \\
- Normal coronary angiography within the preceding 2 years; coronary revascularisation within the last \\
12 months; evidence of previous Q-wave infarction on ECG at rest; class III to IV angina pectoris at \\
study entry \\
\hline Study design \\
\hline
\end{tabular}

\footnotetext{
Target condition and ref- Coronary artery stenosis measured by coronary angiography erence standard(s)

- Angiograms were assessed by 2 cardiologists who were blinded to the perfusion imaging results. A significant coronary stenosis was defined as $>70 \%$
}

\section{Index and comparator Tachycardic-stress perfusion imaging}

tests 
- All patients underwent induction of tachycardiac stress via treadmill exercise or temporary cardiac pacing. Treadmill exercise was performed using the Bruce protocol, on a symptom-limited basis. Exercise was deemed adequate if peak heart rate was $>75 \%$ of the theoretic maximal values, or if exercise was terminated because of angina pectoris. Pacing was performed in patients unable to attain adequate stress on treadmill testing. Pacing was performed at the time of cardiac catheterisation, but before coronary angiography. Myocardial imaging was achieved by IV injection of technetium- $99 \mathrm{~m}$ tetrofosmin (400 MBq) 1 minute before termination of tachycardiac stress. Images were acquired on a triple-headed gamma camera with $180^{\circ}$ single-photon emission CT. The images were assessed by nuclear cardiologists who were blinded to the cardiac catheterisation results.

\begin{tabular}{ll}
\hline Follow-up & Mean follow-up of $28 \pm 10$ months. \\
\hline Notes & Informed consent was obtained before study entry.
\end{tabular}

\section{Table of Methodological Quality}

\begin{tabular}{lll}
\hline Item & Authors' judgement & Description \\
\hline $\begin{array}{l}\text { Representative spectrum? } \\
\text { All tests }\end{array}$ & Yes & ESKD patients undergoing cardiac evaluation as part of transplant workup. \\
\hline $\begin{array}{l}\text { Acceptable reference stan- } \\
\text { dard? }\end{array}$ & Yes & Coronary angiography with a reference standard threshold of $\geq 70 \%$ stenosis. \\
All tests & & \\
\hline
\end{tabular}

\begin{tabular}{|c|c|c|}
\hline $\begin{array}{l}\text { Acceptable delay between } \\
\text { tests? } \\
\text { All tests }\end{array}$ & Yes & Tests were done at the same time (author correspondence). \\
\hline $\begin{array}{l}\text { Partial verification avoid- } \\
\text { ed? } \\
\text { All tests }\end{array}$ & Yes & $\begin{array}{l}\text { All participants who underwent the index test received the reference standard } \\
\text { test. }\end{array}$ \\
\hline
\end{tabular}

Differential verification $\quad$ Yes Disease status (CAD) diagnosed by coronary angiography.
avoided?
All tests

\begin{tabular}{lll}
\hline $\begin{array}{l}\text { Incorporation avoided? } \\
\text { All tests }\end{array}$ & Yes & Disease status (CAD) diagnosed by coronary angiography. \\
\hline $\begin{array}{l}\text { Reference standard results } \\
\text { blinded? }\end{array}$ & Yes & $\begin{array}{l}\text { Angiograms were assessed by } 2 \text { cardiologists who were blinded to the perfu- } \\
\text { sion imaging results. }\end{array}$ \\
All tests & &
\end{tabular}

\begin{tabular}{lll}
\hline $\begin{array}{l}\text { Index test results blinded? } \\
\text { All tests }\end{array}$ & Yes & $\begin{array}{l}\text { Images were assessed by nuclear cardiologists who were blinded to the car- } \\
\text { diac catheterisation results. }\end{array}$ \\
\hline $\begin{array}{l}\text { Relevant clinical informa- } \\
\text { tion? } \\
\text { All tests }\end{array}$ & Yes & $\begin{array}{l}\text { Relevant clinical information was provided regarding the performance and } \\
\text { analysis of the index and reference tests. }\end{array}$ \\
\hline $\begin{array}{l}\text { Uninterpretable results re- } \\
\text { ported? } \\
\begin{array}{l}\text { All tests } \\
\text { Withdrawals explained? }\end{array}\end{array}$ & Yes & There were no uninterpretable test results. \\
\hline $\begin{array}{l}\text { All tests } \\
\end{array}$ & No withdrawals reported. \\
\hline
\end{tabular}


bpm: beats per minute; CAD: coronary artery disease; CF: cardiac failure; CHF: congestive heart failure; CIMT: carotid intimal medial thickness; CKD: chronic kidney disease; CVD: cardiovascular disease; DBP: diastolic blood pressure; DM: diabetes mellitus; DSE: dobutamine stress echocardiogram; DSTS: dipyridamole stress thallium scan; EBCT: electron beam computed tomography; ECG: electrocardiogram; ESKD: end-stage kidney disease; HTN: hypertension; IHD: ischaemic heart disease; IMT: intimal media thickness; IV: intravenous; MI: myocardial infarction; MIBI: methoxyisobutyl isonitrile stress; MPS: myocardial perfusion scintigraphy; QCA: quantitative coronary analysis; RRT: renal replacement therapy; RWM: regional wall motion; SBP: systolic blood pressure; ST: sinus tachycardia; WMA: wall motion abnormality

\section{Characteristics of excluded studies [ordered by study ID]}

\begin{tabular}{|c|c|}
\hline Study & Reason for exclusion \\
\hline Ali 2004 & Coronary angiography not routinely performed on patients in study. \\
\hline Arantes 2010 & $\begin{array}{l}\text { Prognostic study; not enough data available to allow for diagnostic accuracy comparison with } \\
\text { coronary angiography. }\end{array}$ \\
\hline Braun 1984 & No index tests for comparison. \\
\hline Brown 1989 & $\begin{array}{l}\text { Prognostic study; not enough data available to allow for diagnostic accuracy comparison with } \\
\text { coronary angiography. }\end{array}$ \\
\hline Caglar 2006 & $\begin{array}{l}\text { Patient population not consisting of patients who are potential transplant recipients; coronary an- } \\
\text { giography only provided to patients who tested positive to other tests. }\end{array}$ \\
\hline Camp 1990 & Coronary angiography not used as reference standard. \\
\hline Cortigiani 2005 & Coronary angiography not used as reference standard. \\
\hline Cottier 1990 & Coronary angiography not routinely performed on patients in study. \\
\hline Cross 1996 & $\begin{array}{l}\text { Prognostic study; not enough data available to allow for diagnostic accuracy comparison with } \\
\text { coronary angiography. }\end{array}$ \\
\hline Dahan 1995 & $\begin{array}{l}\text { Patient population not entirely consisting of patients who are potential transplant recipients. } \\
\text { Separate data for potential transplant recipients not available. }\end{array}$ \\
\hline Dahan 1998 & $\begin{array}{l}\text { Patient population not entirely consisting of patients who are potential transplant recipients. } \\
\text { Separate data for potential transplant recipients not available. }\end{array}$ \\
\hline Dahan 2002 & $\begin{array}{l}\text { Patient population not entirely consisting of patients who are potential transplant recipients. } \\
\text { Separate data for potential transplant recipients not available. }\end{array}$ \\
\hline De Vriese 2009 & $\begin{array}{l}\text { Patient population not entirely consisting of patients who are potential transplant recipients. } \\
\text { Roughly } 1 / 3 \text { of the patients that were included in the study were being evaluated for kidney trans- } \\
\text { plantation. The others consented to have the evaluation as a screening test, because the authors } \\
\text { explained to them that the majority of patients with CAD on dialysis are asymptomatic (author } \\
\text { communication). Separate data for potential transplant recipients not available. }\end{array}$ \\
\hline Derfler 1991 & Coronary angiography not used as reference standard. \\
\hline Dussol 2004 & $\begin{array}{l}\text { Coronary angiography not routinely performed on patients in study, only performed on patients } \\
\text { who were index test positive. }\end{array}$ \\
\hline Eschertzhuber 2005 & Coronary angiography not routinely performed on patients in study. \\
\hline Feola 2002 & Coronary angiography not used as reference standard. \\
\hline
\end{tabular}




\begin{tabular}{ll}
\hline Study & Reason for exclusion \\
\hline Fossati 2004 & Data insufficient to construct appropriate $2 \times 2$ table. \\
\hline Fujimoto 2006 & $\begin{array}{l}\text { This was a study of diagnostic accuracy but the patient population did not consist entirely of pa- } \\
\text { tients who are potential transplant recipients. Separate data on patients who were potential trans- } \\
\text { plant recipients not available. }\end{array}$
\end{tabular}

\section{Fukui 2005}

This was a study of diagnostic accuracy but the patient population did not consist entirely of patients who are potential transplant recipients. Separate data on patients who were potential transplant recipients not available.

\begin{tabular}{ll}
\hline Fuster 2000 & $\begin{array}{l}\text { Coronary angiography not routinely performed on patients in study, only performed on patients } \\
\text { who were index test positive. }\end{array}$ \\
\hline Holley 1991 & $\begin{array}{l}\text { Coronary angiography not routinely performed on patients in study; data insufficient to construct } \\
\text { appropriate } 2 \times 2 \text { table. }\end{array}$
\end{tabular}

\begin{tabular}{ll}
\hline Iqbal 1991 & Coronary angiography not used as reference standard. \\
\hline Jeloka 2007 & Coronary angiography not used as reference standard. \\
\hline Krotin 2007 & Coronary angiography not used as reference standard. \\
\hline Langford 1997 & Coronary angiography not used as reference standard. \\
\hline Le 1994 & $\begin{array}{l}\text { Prognostic study; not enough data available to allow for diagnostic accuracy comparison with } \\
\text { coronary angiography. }\end{array}$
\end{tabular}

\begin{tabular}{ll}
\hline Leonardi 2009 & Single centre case experience; not a study of diagnostic accuracy. \\
\hline Lewis 2002 & $\begin{array}{l}\text { Prognostic study; not enough data available to allow for diagnostic accuracy comparison with } \\
\text { coronary angiography. }\end{array}$
\end{tabular}

\begin{tabular}{|c|c|}
\hline Lin 2001 & Coronary angiography not used as reference standard. \\
\hline Ma 2006 & Coronary angiography only used in those with high risk scores. \\
\hline Manske 1997 & Data insufficient to construct appropriate $2 \times 2$ table. \\
\hline Mao 2010 & Coronary angiography not used as reference standard. \\
\hline Mistry 1998 & Coronary angiography not used as reference standard. \\
\hline Morrow 1983 & Coronary angiography not used as reference standard. \\
\hline Nguyen 2007 & Coronary angiography not used as reference standard. \\
\hline Nishimura 2004 & $\begin{array}{l}\text { This was a study of diagnostic accuracy but the patient population did not consist entirely of pa- } \\
\text { tients who are potential transplant recipients. Separate data on patients who were potential trans- } \\
\text { plant recipients not available. }\end{array}$ \\
\hline Ohtake 2005 & $\begin{array}{l}\text { This was a study of diagnostic accuracy but the patient population did not consist entirely of pa- } \\
\text { tients who are potential transplant recipients. Separate data on patients who were potential trans- } \\
\text { plant recipients not available. }\end{array}$ \\
\hline
\end{tabular}




\begin{tabular}{|c|c|}
\hline Study & Reason for exclusion \\
\hline Patel 2003 & Coronary angiography not used as reference standard. \\
\hline Patel 2008 & Coronary angiography not routinely performed on patients in study. \\
\hline Philipson 1986 & $\begin{array}{l}\text { Reference standard differentially applied to different treatment groups; unable to construct mean- } \\
\text { ingful } 2 \times 2 \text { table. }\end{array}$ \\
\hline Porter 2003 & Coronary angiography not used as reference standard. \\
\hline Rakhit 2006 & Coronary angiography not used as reference standard. \\
\hline Robinson 2007 & $\begin{array}{l}\text { This was a study of diagnostic accuracy but the patient population did not consist entirely of pa- } \\
\text { tients who are potential transplant recipients. Separate data on patients who were potential trans- } \\
\text { plant recipients not available. }\end{array}$ \\
\hline Russell 1993 & $\begin{array}{l}\text { Prognostic study; not enough data available to enable diagnostic accuracy comparison with coro- } \\
\text { nary angiography. }\end{array}$ \\
\hline Schmidt 2001 & $\begin{array}{l}\text { Patient population not exclusively consisting of patients who are potential transplant recipients; } \\
\text { patients were either those who were on long-term RRT, or who had undergone successful renal } \\
\text { transplantation. Separate data on patients who were potential transplant recipients not available. }\end{array}$ \\
\hline Sharma 2007 & Coronary angiography not used as reference standard. \\
\hline Tita 2008 & Coronary angiography not used as reference standard. \\
\hline Trochu 1991 & Coronary angiography not used as reference standard. \\
\hline Venkataraman 2008 & Coronary angiography not used as reference standard. \\
\hline Weinrauch 1978 & Only coronary angiography studied. No index tests for comparison. \\
\hline Weinrauch 1992 & Coronary angiography not used as reference standard. \\
\hline Witczak 2006 & Only coronary angiography studied. No index tests for comparison. \\
\hline Wong 2008 & Coronary angiography not used as reference standard. \\
\hline
\end{tabular}

\section{A T A}

Presented below are all the data for all of the tests entered into the review.

\section{Table Tests. Data tables by test}

\begin{tabular}{lll}
\hline Test & No. of studies & No. of participants \\
\hline 1 DSE & 13 & 745 \\
\hline 2 MPS & 9 & 582 \\
\hline 3 EST & 2 & 129 \\
\hline
\end{tabular}




\begin{tabular}{|c|c|c|}
\hline Test & No. of studies & No. of participants \\
\hline 4 ЕВCT & 1 & 97 \\
\hline $5 \mathrm{DSF}$ & 1 & 86 \\
\hline $6 \mathrm{EV}$ & 1 & 35 \\
\hline $7 \mathrm{CIMT}$ & 1 & 105 \\
\hline 8 Echo (RWMA) & 2 & 265 \\
\hline 9 Echo (LV) & 1 & 52 \\
\hline 10 Echo (MAC) & 1 & 125 \\
\hline $11 \mathrm{ECG}$ & 3 & 263 \\
\hline
\end{tabular}

Test 1. DSE.

Test 2. MPS.

Test 3. EST.

Test 4. EBCT.

Test 5. DSF.

Test 6. EV.

Test 7. CIMT.

Test 8. Echo (RWMA). 
Test 9. Echo (LV).

Test 10. Echo (MAC).

Test 11. ECG.

ADDITIONAL TABLES

Table 1. Description of index tests

\begin{tabular}{llll}
\hline Test Description Advantages & Disadvantages & Type of result Presence of cut- \\
off values
\end{tabular}

\section{Screening tests}

\begin{tabular}{|c|c|c|c|c|c|}
\hline $\begin{array}{l}\text { MPS } \\
\text { Stress } \\
\text { Exercise } \\
\text { dipyridamole } \\
\text { dobutamine } \\
\text { Radionu- } \\
\frac{\text { cleotide }}{\text { thallium-201 }} \\
\text { or Tc-99m ses- } \\
\text { tamibi ra- } \\
\text { dionucleotide } \\
\text { agents }\end{array}$ & $\begin{array}{l}\text { This compares perfusion of my- } \\
\text { ocardium at rest and after a } \\
\text { 'stress' such as exercise or drugs } \\
\text { (e.g. dipyridamole). } \\
\text { When coronary arteries are nor- } \\
\text { mal, 'stress' results in vasodi- } \\
\text { latation and increased coronary } \\
\text { blood flow. However, diseased } \\
\text { coronary arteries cannot dilate } \\
\text { because they are already max- } \\
\text { imally dilated and there is no } \\
\text { increase in blood flow after a } \\
\text { stress. MPS reveals these areas as } \\
\text { regions of decreased perfusion. } \\
\text { A reversible perfusion defect is a } \\
\text { sign of ischaemia. A fixed defect } \\
\text { (when there is decreased perfu- } \\
\text { sion before, during and after the } \\
\text { stress) is an indicator of infarc- } \\
\text { tion. } \\
\text { Pharmacological agents over- } \\
\text { come limitations of exercise test- } \\
\text { ing in patients with kidney dis- } \\
\text { ease }\end{array}$ & $\begin{array}{l}\text { Non-invasive } \\
\text { Provides infor- } \\
\text { mation regard- } \\
\text { ing functional } \\
\text { status of my- } \\
\text { ocardium under } \\
\text { stress conditions }\end{array}$ & $\begin{array}{l}\text { Neither } 100 \% \text { sensi- } \\
\text { tive nor specific } \\
\text { Radiation dose } \\
\text { Results subject to } \\
\text { interpretation and } \\
\text { reader bias } \\
\text { False positives due } \\
\text { to increase in at- } \\
\text { tenuation artefacts } \\
\text { caused by left ven- } \\
\text { tricular hypertro- } \\
\text { phy } \\
\text { False negatives } \\
\text { due to balanced is- } \\
\text { chaemia (e.g. triple } \\
\text { vessel disease) } \\
\text { More expensive } \\
\text { than exercise ECG }\end{array}$ & $\begin{array}{l}\text { Dichotomous } \\
\text { (i.e. stress } \\
\text { test positive } \\
\text { or stress test } \\
\text { negative) }\end{array}$ & $\begin{array}{l}\text { None. However, } \\
\text { whether a stress } \\
\text { test is interpret- } \\
\text { ed as positive } \\
\text { or negative de- } \\
\text { pends largely on } \\
\text { observer inter- } \\
\text { pretation }\end{array}$ \\
\hline $\begin{array}{l}\text { DSE } \\
\text { Stress } \\
\text { Exercise } \\
\text { dobutamine }\end{array}$ & $\begin{array}{l}\text { Stress echocardiography com- } \\
\text { pares the regional wall motion } \\
\text { and thickness of myocardium } \\
\text { both at rest and after stress. Re- } \\
\text { gional systolic dysfunction is usu- } \\
\text { ally caused by CAD. } \\
\text { Pharmacological stress agent } \\
\text { overcomes limitations of exercise } \\
\text { testing in patients with kidney } \\
\text { disease }\end{array}$ & $\begin{array}{l}\text { Non-invasive } \\
\text { No radiation } \\
\text { dose } \\
\text { Provides infor- } \\
\text { mation regard- } \\
\text { ing functional } \\
\text { status of my- } \\
\text { ocardium under } \\
\text { stress conditions }\end{array}$ & $\begin{array}{l}\text { Neither } 100 \% \text { sensi- } \\
\text { tive nor specific } \\
\text { Results subject to } \\
\text { interpretation and } \\
\text { reader bias } \\
\text { Operator depen- } \\
\text { dent }\end{array}$ & $\begin{array}{l}\text { Dichotomous } \\
\text { (i.e. stress } \\
\text { test positive } \\
\text { or stress test } \\
\text { negative) }\end{array}$ & $\begin{array}{l}\text { None. However, } \\
\text { whether a stress } \\
\text { test is interpret- } \\
\text { ed as positive } \\
\text { or negative de- } \\
\text { pends largely on } \\
\text { observer inter- } \\
\text { pretation }\end{array}$ \\
\hline
\end{tabular}


Table 1. Description of index tests (Continued)

Provides assessment of ventricular size and function
Acoustic windows

not possible in up

to $20 \%$ of subjects

Hypertensive re-

sponse to stress

agent possible

Cardiomyopathies may also show regional variation in function

\begin{tabular}{|c|c|}
\hline Exercise ECG & Patient exercises on a treadmill \\
\hline $\begin{array}{l}\text { Bruce protocol } \\
\text { stress ECG }\end{array}$ & $\begin{array}{l}\text { level of exercise is increased in } \\
\text { progressive stages. The patient's }\end{array}$ \\
\hline & $\begin{array}{l}\text { symptoms and blood pressure re- } \\
\text { sponse are checked repeatedly. } \\
\text { Ischaemic ECG changes or angi- } \\
\text { na symptoms brought on by exer- } \\
\text { cise are highly suggestive of un- } \\
\text { derlying CAD }\end{array}$ \\
\hline
\end{tabular}

\section{Non-invasive}

Provides information regarding functional status of myocardium under stress conditions derlying CAD
Neither $100 \%$ sensitive nor specific

Results subject to interpretation and reader bias

Often limited by the inability of CKD patients to achieve an adequate peak exercise workload, development of exercise-induced hypotension

High proportion have abnormal baseline ECG (left ventricular hypertrophy)

\section{Coronary artery calci- um score}

EBCT

Multidetector computed tomography

\begin{abstract}
Cardiac calcium scoring is a noninvasive test that uses computed tomography to detect the presence of calcium in plaque on the walls of the arteries of the heart (coronary arteries). A calcium score is then derived, calculated as a summation of all calcified lesions in the coronary arteries. The calcium score is then compared with a reference range appropriate to a patient's age and sex. High calcium scores are associated with higher risks of cardiovascular events
\end{abstract}

\begin{tabular}{ll}
\hline $\begin{array}{l}\text { Echocardiog- } \\
\text { raphy }\end{array}$ & $\begin{array}{l}\text { An ultrasound of the heart that } \\
\text { enables assessment of structure } \\
\text { and function. }\end{array}$ \\
$\begin{array}{l}\text { Trans-thoracic } \\
\text { Trans-oe- } \\
\text { sophageal }\end{array}$ & $\begin{array}{l}\text { Impairment in systolic function } \\
\text { can result from pre-existing CAD }\end{array}$
\end{tabular}

$\begin{array}{ll}\text { Dichotomous } & \text { No. However, } \\ \text { (i.e. stress } & \text { whether a stress } \\ \text { test positive } & \text { test is interpret- } \\ \text { or stress test } & \text { ed as positive } \\ \text { negative) } & \text { or negative de- } \\ & \text { pends largely on } \\ & \text { observer inter- } \\ & \text { pretation }\end{array}$

Neither $100 \%$ sensi- Continuous There is no unitive nor specific formly agreed Radiation dose cut-off value at which patients are considered at high risk of CAD. We planned to analyse results by combining data from studies which share identical cut-off values

\begin{tabular}{|c|c|c|}
\hline $\begin{array}{l}\text { Provides infor- } \\
\text { mation regard- } \\
\text { ing myocardial } \\
\text { function and } \\
\text { regional wall } \\
\text { abnormalities, } \\
\text { which may sug- } \\
\text { gest pre-existing } \\
\text { ischaemia or MI }\end{array}$ & $\begin{array}{l}\text { Neither highly sen- } \\
\text { sitive nor specific } \\
\text { Does not provide } \\
\text { any information } \\
\text { of reversible is- } \\
\text { chaemia } \\
\text { Results subject to } \\
\text { interpretation and } \\
\text { reader bias }\end{array}$ & $\begin{array}{l}\text { Dichotomous } \\
\text { (e.g. presence } \\
\text { or absence of } \\
\text { resting wall } \\
\text { motion abnor- } \\
\text { mality) }\end{array}$ \\
\hline
\end{tabular}


Table 1. Description of index tests (Continued)

Enables assess-

ment of struc-

ture

\begin{tabular}{ll}
\hline CT coronary & $\begin{array}{l}\text { Specialised form of CT that en- } \\
\text { angiography }\end{array}$ \\
& $\begin{array}{l}\text { ables imaging of the heart and } \\
\text { computerised reconstruction of } \\
\text { sessment of the lumen and vessel } \\
\text { walls }\end{array}$
\end{tabular}

Non-invasive

Enables diagno-

sis of precise lo-

cation and sever-

ity of each lesion

as opposed to

vascular territo-

ry affected, as is

the case for most

functional tests.

Assesses not

only the lumen

of the vessel

but also the

wall. It can al-

so demonstrate

soft atheroma-

tous plaques,

which cannot be

demonstrated

on conventional

coronary angiog-

raphy
Radiation dose

Contrast nephropa-

thy

Inability to provide opportunity for immediate interven-

tion (as opposed to

coronary angiography)
Dichotomous Yes (i.e. $\geq 50 \%$

(i.e. presence stenosis or $\geq 70 \%$

or absence stenosis)

of significant

CAD)

We planned to manage the issue of different cut points by involving an analysis that included:

- All studies regardless of threshold of CAD on coronary angiography (these will include both studies which have $\geq$ $50 \%$ stenosis and $\geq 70 \%$ stenosis

- Only studies which had $\geq$ $70 \%$ stenosis threshold

$\begin{array}{ll}\text { Cardiac mag- } & \text { MRI of the heart that enables } \\ \text { netic reso- } & \text { evaluation of its structure and } \\ \text { nance imag- } & \text { function } \\ \text { ing } & \end{array}$

\section{Non-invasive \\ No radiation \\ dose}

Enables assess-

ment of struc-

ture of myocardi-

um

High spatial res-

olution means

low inter-observ-

er variability

\begin{tabular}{|c|c|c|c|c|c|}
\hline Resting ECG & $\begin{array}{l}\text { Transthoracic interpretation of } \\
\text { the electrical activity of the heart } \\
\text { over time captured and external- } \\
\text { ly recorded by skin electrodes }\end{array}$ & $\begin{array}{l}\text { Provides infor- } \\
\text { mation regard- } \\
\text { ing the electri- } \\
\text { cal function of } \\
\text { the myocardium, } \\
\text { which may sug- } \\
\text { gest pre-existing } \\
\text { ischaemia, left } \\
\text { ventricular hy- } \\
\text { pertrophy or ar- } \\
\text { rhythmias }\end{array}$ & $\begin{array}{l}\text { Neither sensitive } \\
\text { nor specific } \\
\text { Does not provide } \\
\text { any information } \\
\text { of reversible is- } \\
\text { chaemia }\end{array}$ & $\begin{array}{l}\text { Dichotomous } \\
\text { (i.e. presence } \\
\text { or absence of } \\
\text { certain ECG } \\
\text { features) }\end{array}$ & None \\
\hline CIMT & $\begin{array}{l}\text { Measurement of the thickness of } \\
\text { artery walls, usually by external }\end{array}$ & Non-invasive & $\begin{array}{l}\text { Neither highly sen- } \\
\text { sitive nor specific }\end{array}$ & Continuous & $\begin{array}{l}\text { Yes. } \\
\text { depe }\end{array}$ \\
\hline
\end{tabular}


Table 1. Description of index tests (Continued) ultrasound, to detect both the presence and to track the progression of atherosclerotic disease in humans. Used as a surrogate marker for atherosclerosis
Evaluates both cardiac and pulmonary function. Cardiac function is evaluated in terms of aerobic capacity and respiratory function.

The subject is exercised on a bicycle ergometer or treadmill. The test enables calculation of maximal aerobic capacity and the point during exercise where anaerobic metabolism is used to supplement aerobic metabolism as a source of energy. These can be measured via gas exchange data
Does not provide any information on cardiac function the institution

(e.g. $0.75 \mathrm{~mm}$ )
Non-invasive

measurement of

ventricular func-

tion, respiratory

function and cel-

lular function via

measurement of

gas exchange, as

well as detection

of myocardial is-

chaemia

Excellent

method of evalu-

ating fitness and

operative fitness

Not commonly per-
formed

Dichotomous

(e.g. stress

ECG posi-

tive or stress

ECG negative;

presence or

absence of

cardiac fail-

ure) and

Continuous

(e.g. measurement of the maximum aerobic capacity and anaerobic threshold)
Yes, although these will vary for different variables and for different institutions

\begin{tabular}{|c|c|c|c|c|c|}
\hline DSF & $\begin{array}{l}\text { Used to detect coronary artery } \\
\text { calcification. Digital subtraction } \\
\text { improves resolution of conven- } \\
\text { tional fluoroscopic methods }\end{array}$ & $\begin{array}{l}\text { Non-invasive } \\
\text { Non exercise }\end{array}$ & $\begin{array}{l}\text { Not commonly } \\
\text { used } \\
\text { Radiation dose }\end{array}$ & $\begin{array}{l}\text { Dichotomous } \\
\text { (i.e. presence } \\
\text { or absence of } \\
\text { calcification) }\end{array}$ & None \\
\hline $\begin{array}{l}\text { Exercise } \\
\text { radionu- } \\
\text { cleotide ven- } \\
\text { triculography }\end{array}$ & $\begin{array}{l}\text { Technique for a combined as- } \\
\text { sessment of exercise capacity } \\
\text { and an evaluation of ventricular } \\
\text { size and performance }\end{array}$ & & $\begin{array}{l}\text { Not commonly } \\
\text { used } \\
\text { Radiation dose }\end{array}$ & $\begin{array}{l}\text { Dichotomous } \\
\text { (i.e. stress } \\
\text { test positive } \\
\text { or stress test } \\
\text { negative) }\end{array}$ & $\begin{array}{l}\text { None. However, } \\
\text { whether a stress } \\
\text { test is interpret- } \\
\text { ed as positive } \\
\text { or negative de- } \\
\text { pends largely on } \\
\text { observer inter- } \\
\text { pretation }\end{array}$ \\
\hline
\end{tabular}

\section{Reference standard}

\begin{tabular}{|c|c|c|c|c|c|}
\hline $\begin{array}{l}\text { Coronary an- } \\
\text { giography }\end{array}$ & $\begin{array}{l}\text { Coronary catheterisation is an in- } \\
\text { vasive procedure to access the } \\
\text { coronary circulation and blood } \\
\text { filled chambers of the heart using } \\
\text { a catheter. It can be performed } \\
\text { for both diagnostic and interven- } \\
\text { tional (treatment) purposes. It as- } \\
\text { sesses the diameter of coronary } \\
\text { artery lumens, heart chamber } \\
\text { size and heart muscle contrac- } \\
\text { tion performance }\end{array}$ & $\begin{array}{l}\text { Gold standard } \\
\text { for detecting } \\
\text { CAD. } \\
\text { Enables diagno- } \\
\text { sis of precise lo- } \\
\text { cation and sever- } \\
\text { ity of each lesion } \\
\text { Intervention (PT- } \\
\text { CA) possible dur- } \\
\text { ing procedure }\end{array}$ & $\begin{array}{l}\text { High cost } \\
\text { Lack of sensitivity } \\
\text { to intramural coro- } \\
\text { nary atherosclero- } \\
\text { sis } \\
\text { Risk of complica- } \\
\text { tions } \\
\text { Intravenous con- } \\
\text { trast media may } \\
\text { worsen kidney } \\
\text { function } \\
\text { Little information } \\
\text { on function } \\
\text { Radiation dose }\end{array}$ & $\begin{array}{l}\text { Dichotomous } \\
\text { (i.e. presence } \\
\text { or absence } \\
\text { of significant } \\
\text { CAD) }\end{array}$ & $\begin{array}{l}\text { Yes (i.e. } \geq 50 \% \\
\text { stenosis or } \geq 70 \% \\
\text { stenosis). } \\
\text { We managed the } \\
\text { issue of different } \\
\text { cut points by in- } \\
\text { volving an analy- } \\
\text { sis which includ- } \\
\text { ed: } \\
\text { - All studies re- } \\
\text { gardless of } \\
\text { threshold of } \\
\text { CAD on coro- } \\
\text { nary angiog- } \\
\text { raphy (these } \\
\text { will include } \\
\text { both studies } \\
\text { which have } \geq \\
50 \% \text { stenosis }\end{array}$ \\
\hline
\end{tabular}


Table 1. Description of index tests (Continued)

Results subject to interpretation and reader bias, although to a lesser extent than functional tests and $\geq 70 \%$ stenosis

- Only studies which had $\geq$ $70 \%$ stenosis threshold

CAD: coronary artery disease; CIMT: carotid intimal medial thickness; CT: computed tomography; ECG: electrocardiograph; MPS: myocardial perfusion scintigraphy; MRI: magnetic resonance imaging; PTAC: percutaneous transluminal coronary angioplasty 


\begin{tabular}{|c|c|c|c|c|c|c|c|c|c|c|c|}
\hline Study & Country & $\begin{array}{l}\text { Partici- } \\
\text { pants }\end{array}$ & $\begin{array}{l}\text { Diabetic } \\
\text { patients } \\
(\%)\end{array}$ & $\begin{array}{l}\text { Angina } \\
(\%)\end{array}$ & $\begin{array}{l}\text { Hyper- } \\
\text { tensive } \\
(\%)\end{array}$ & $\begin{array}{l}\text { Male } \\
(\%)\end{array}$ & $\begin{array}{l}\text { Refer- } \\
\text { ence } \\
\text { thresh- } \\
\text { old (\% } \\
\text { steno- } \\
\text { sis) }\end{array}$ & TP & FP & FN & TN \\
\hline \multicolumn{12}{|c|}{ Dobutamine stress echocardiography (DSE) } \\
\hline Bates 1996 & USA & 17 & 100 & NA & 98 & 64 & 50 & 9 & 1 & 1 & 6 \\
\hline Brennan 1997 & USA & 12 & 56 & 21 & 90 & 45 & 50 & 4 & 1 & 2 & 5 \\
\hline Cai 2010 & USA & 38 & 54 & NA & 86 & 64 & 70 & 15 & 2 & 8 & 13 \\
\hline De Lima 2003 & Brazil & 89 & 30 & 25 & 95 & 77 & 70 & 15 & 7 & 19 & 48 \\
\hline Ferreira 2007 & Brazil & 126 & 27 & 12 & NA & 69 & 70 & 24 & 14 & 10 & 78 \\
\hline Gang 2007 & India & 40 & 100 & 5 & 92 & 90 & 70 & 9 & 1 & 10 & 20 \\
\hline Garcia-Canton 1998 & Spain & 27 & NA & NA & NA & 67 & 70 & 11 & 2 & 1 & 13 \\
\hline Herzog 1999 & USA & 50 & 82 & 16 & 94 & 60 & 70 & 12 & 8 & 4 & 26 \\
\hline Jassal 2007 & Canada & 18 & 38 & NA & 77 & 44 & 50 & 0 & 0 & 0 & 18 \\
\hline Reis 1995 & USA & 30 & 64 & 30 & 96 & 63 & 50 & 22 & 1 & 1 & 6 \\
\hline Sharma 2005 & UK & 125 & 39 & 42 & 91 & 64 & 70 & 32 & 5 & 4 & 84 \\
\hline Sharma 2009 & UK & 140 & 38 & 27 & 92 & 64 & 70 & 36 & 5 & 4 & 95 \\
\hline West 2000 & USA & 33 & NA & NA & NA & NA & 70 & 12 & 8 & 1 & 12 \\
\hline \multicolumn{12}{|c|}{ Myocardial perfusion scintigraphy (MPS) } \\
\hline Boudreau 1990 & USA & 80 & 100 & 12.5 & NA & 64 & 70 & 36 & 8 & 6 & 30 \\
\hline De Lima 2003 & Brazil & 65 & 30 & 25 & 95 & 77 & 70 & 8 & 10 & 15 & 32 \\
\hline Garcia-Canton 1998 & Spain & 27 & NA & NA & NA & 67 & 70 & 11 & 3 & 1 & 12 \\
\hline
\end{tabular}

Dobutamine stress echocardiography (DSE)

Myocardial perfusion scintigraphy (MPS) 


\begin{tabular}{|c|c|c|c|c|c|c|c|c|c|c|c|}
\hline Garg 2000 & India & 19 & 100 & NA & 100 & 88 & 50 & 9 & 4 & 2 & 4 \\
\hline Gowdak 2010 & Brazil & 219 & 100 & NA & 92 & 69 & 70 & 85 & 31 & 52 & 51 \\
\hline Krawczynska 1988 & USA & 46 & NA & NA & NA & NA & 50 & 20 & 18 & 0 & 8 \\
\hline Marwick 1990 & USA & 45 & 51 & 33 & 81 & 71 & 70 & 4 & 9 & 10 & 22 \\
\hline Vandenberg 1996 & USA & 41 & 100 & 0 & NA & NA & 75 & 10 & 6 & 6 & 19 \\
\hline Worthley 2003 & Australia & 40 & 78 & 18 & 98 & 48 & 70 & 13 & 3 & 2 & 22 \\
\hline \multicolumn{12}{|c|}{ Stress electrocardiography (EST) } \\
\hline Bennett 1978 & USA & 4 & 100 & NA & 100 & 36 & 70 & 3 & 1 & 0 & 0 \\
\hline Sharma 2005 & UK & 125 & 39 & 42 & 91 & 64 & 70 & 13 & 8 & 23 & 81 \\
\hline \multicolumn{12}{|c|}{ Electron beam computed tomography (EBCT) } \\
\hline Rosario 2010 & Brazil & 97 & 38 & 29 & 90 & 65 & 70 & 16 & 25 & 9 & 47 \\
\hline Sharples 2004 & UK & 18 & NA & NA & NA & 50 & 75 & * & * & * & * \\
\hline \multicolumn{12}{|c|}{ Digital subtraction fluorography (DSF) } \\
\hline Marwick 1989 & USA & 86 & 29 & 11 & 36 & 27 & 70 & 28 & 17 & 8 & 33 \\
\hline \multicolumn{12}{|c|}{ Exercise ventriculography } \\
\hline Vandenberg 1996 & USA & 35 & 100 & 0 & NA & NA & 75 & 7 & 7 & 7 & 14 \\
\hline \multicolumn{12}{|c|}{ Carotid intimal media thickness (CIMT) } \\
\hline Modi 2006 & India & 105 & 58 & 24 & 100 & NA & 97 & 38 & 14 & 4 & 49 \\
\hline \multicolumn{12}{|c|}{ Echocardiography (resting wall motion abnormality) } \\
\hline Sharma 2005 & UK & 125 & 39 & 42 & 91 & 64 & 70 & 11 & 4 & 25 & 85 \\
\hline Sharma 2009 & UK & 140 & 38 & 27 & 92 & 64 & 70 & 13 & 5 & 27 & 95 \\
\hline
\end{tabular}

$\underset{\omega}{\infty}$ 


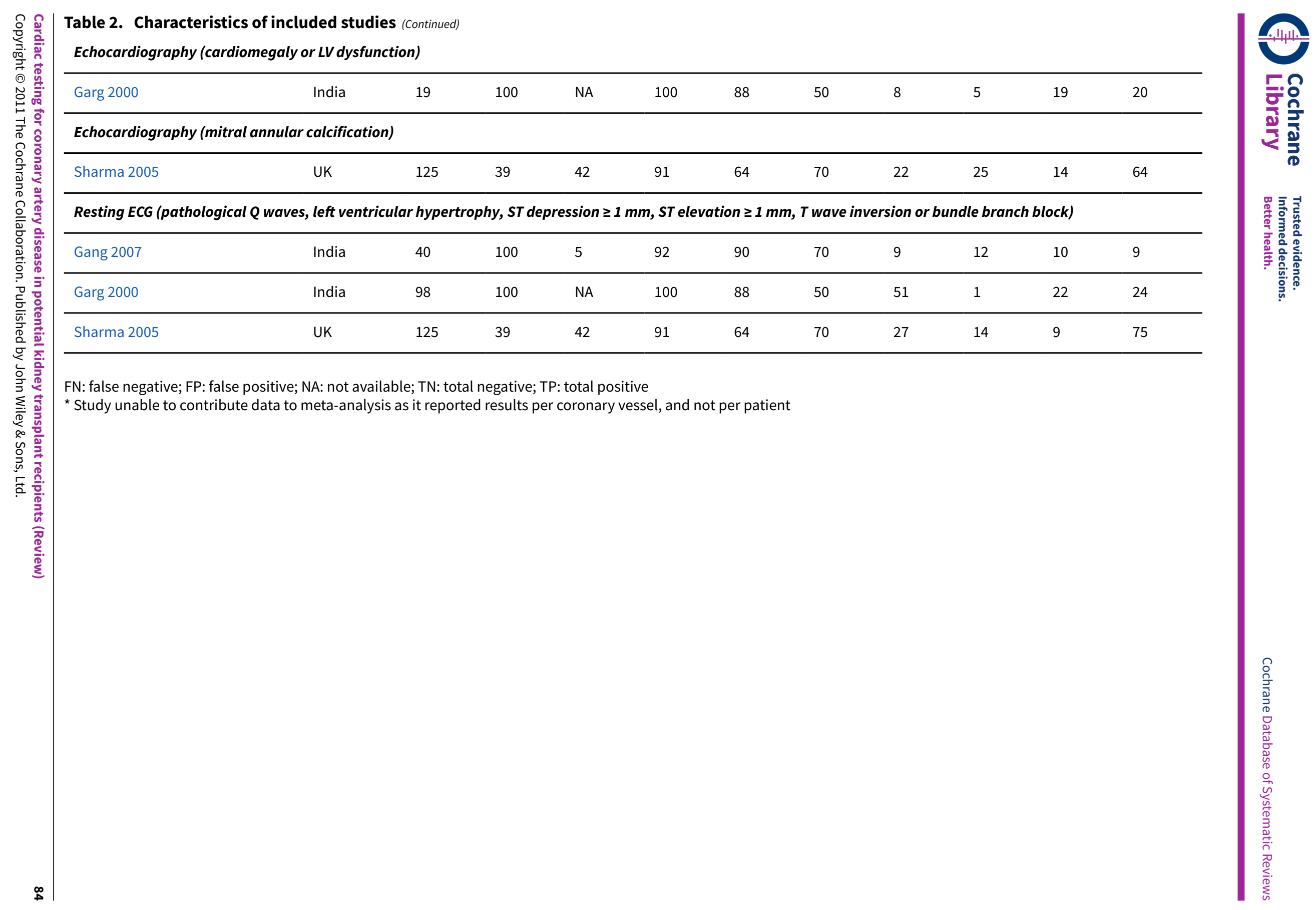


Table 3. Comparison of summary estimates of test performance for dobutamine stress echocardiography (DSE) and myocardial perfusion scintigraphy (MPS)

\begin{tabular}{lllll}
\hline Test Studies (N) & Sensitivity $(95 \% \mathrm{Cl})$ & Specificity $(95 \% \mathrm{Cl})$ & $\begin{array}{l}\text { Diagnostic odds ratio } \\
(95 \% \mathrm{Cl})\end{array}$ & $\begin{array}{l}\text { AUC } \\
\text { P value for } \\
\text { difference } \\
\text { in accura- } \\
\text { cy* }\end{array}$
\end{tabular}

\begin{tabular}{llllll}
\hline \multicolumn{2}{l}{ Overall results: including all studies } \\
\hline MPS & 9 & 0.74 & 0.70 & 6.69 & 0.78 \\
& $(0.54$ to 0.87$)$ & $(0.51$ to 0.84$)$ & $(2.35$ to 19.03$)$ & & \\
\hline DSE & 13 & 0.79 & 0.89 & 29.98 & 0.91 \\
& & $(0.67$ to 0.88$)$ & $(0.81$ to 0.94$)$ & $(12.17$ to 73.89$)$ & \\
\hline
\end{tabular}

Only including studies where reference standard threshold $\geq 70 \%$ coronary artery stenosis on coronary angiography

\begin{tabular}{lllllll}
\hline MPS & 7 & 0.67 & 0.77 & 6.70 & 0.78 & 0.09 \\
& & $(0.48$ to 0.82$)$ & $(0.61$ to 0.88$)$ & $(1.84$ to 24.41) & \\
\hline DSE & 9 & 0.76 & 0.88 & 23.01 & 0.90 \\
& & $(0.60$ to 0.87$)$ & $(0.78$ to 0.94$)$ & $(8.08$ to 65.51$)$ &
\end{tabular}

\begin{tabular}{llllll}
\hline \multicolumn{5}{l}{ Only including studies where partial verification was avoided } \\
\hline MPS & 0.68 & 0.75 & 6.45 & 0.78 \\
& $(0.51$ to 0.81$)$ & $(0.60$ to 0.86$)$ & $(2.12$ to 19.64$)$ & \\
\hline DSE & 9 & 0.80 & 0.89 & 34.28 & 0.92 \\
& & $(0.64$ to 0.90$)$ & $(0.79$ to 0.95$)$ & $(11.10$ to 105.93$)$ &
\end{tabular}

Only including studies which avoided partial verification and had reference standard threshold $\geq 70 \%$ coronary artery stenosis on coronary angiography

\begin{tabular}{lllllll}
\hline MPS & 7 & 0.67 & 0.77 & 6.70 & 0.78 & 0.09 \\
& & $(0.48$ to 0.82$)$ & $(0.61$ to 0.88$)$ & $(1.84$ to 24.41) & \\
\hline DSE & 8 & 0.78 & 0.88 & 25.22 & 0.90 \\
& & $(0.59$ to 0.89$)$ & $(0.76$ to 0.94$)$ & $(7.68$ to 82.80$)$ & \\
\hline
\end{tabular}

AUC: area under the curve; Cl: confidence interval; DSE: dobutamine stress echocardiography; MPS: myocardial perfusion scintigraphy ${ }^{*} P$ values for this variable were calculated using the likelihood ratio test in SAS (PROC NLMIXED), and represented the final P value obtained from a backward elimination approach used to eliminate non-significant terms from the original hierarchical model.

Table 4. Comparison of systematic reviews studying the test performance of myocardial perfusion scintigraphy and dobutamine stress echocardiography

\begin{tabular}{llll}
\hline Review & Population & DSE \\
\hline
\end{tabular}


Table 4. Comparison of systematic reviews studying the test performance of myocardial perfusion scintigraphy and dobutamine stress echocardiography (Continued)

$\begin{aligned} & \text { Sensitivity (95\% } \\ & \text { Cl) }\end{aligned} \begin{array}{lll}\text { Specificity }(95 \% & \text { Sensitivity }(95 \% & \text { Specificity }(95 \% \\ \mathrm{Cl}) & \mathrm{Cl}) & \mathrm{Cl})\end{array}$

\begin{tabular}{llllll}
\hline $\begin{array}{l}\text { Cochrane re- } \\
\text { view }\end{array}$ & $\begin{array}{l}\text { Kidney transplant candi- } \\
\text { dates only }\end{array}$ & $0.79(0.67$ to 0.88$)$ & $0.89(0.81$ to 0.94$)$ & 0.74 (0.54 to 0.87$)$ & 0.70 (0.51 to 0.84$)$ \\
\hline $\begin{array}{l}\text { Fleischmann } \\
1998\end{array}$ & General population & $0.85(0.83$ to 0.87$)$ & $0.77(0.74$ to 0.80$)$ & 0.87 (0.86 to 0.88$)$ & 0.64 (0.60 to 0.68$)$ \\
\hline Schinkel 2003 & General population & 0.80 (NS) & 0.86 (NS) & 0.84 (NS) & 0.77 (NS) \\
\hline
\end{tabular}

DSE: dobutamine stress echocardiography; MPS; myocardial perfusion scintigraphy; NS - not stated

\section{APPENDICES}

\section{Appendix 1. Electronic search strategies}

\begin{tabular}{|c|c|}
\hline Database & Search terms \\
\hline MEDLINE & $\begin{array}{l}\text { 1. Kidney Transplantation/ } \\
\text { 2. Pancreas Transplantation/ } \\
\text { 3. (kidney and pancreas and (transplant\$ or graft\$)).tw. } \\
\text { 4. Kidney Failure/ } \\
\text { 5. Kidney Failure, Chronic/ } \\
\text { 6. (chronic kidney or chronic renal).tw. } \\
\text { 7. (endstage kidney or endstage renal).tw. } \\
\text { 8. (end stage kidney or end stage renal).tw. } \\
\text { 9. (ESRD or ESKD or ESRF or ESKF).tw. } \\
\text { 10.exp Renal Dialysis/ } \\
\text { 11.dialysis.tw. } \\
\text { 12.(hemodialysis or haemodialysis).tw. } \\
\text { 13.(hemodiafilt\$ or haemodiafilt\$).tw. } \\
\text { 14.(hemofilt\$ or haemofilt\$).tw. } \\
\text { 15.(PD or CAPD or CCPD or APD).tw. } \\
\text { 16.or/1-15 } \\
\text { 17.Coronary Disease/ } \\
\text { 18.Coronary Artery Disease/ } \\
\text { 19.Coronary Stenosis/ } \\
\text { 20.(coronary arter\$ and stenos\$).tw. } \\
\text { 21.coronary stenos\$.tw. } \\
\text { 22.coronary atheroscleros\$.tw. } \\
\text { 23.coronary arterioscleros\$.tw. } \\
\text { 24.(coronary adj5 disease).tw. } \\
\text { 25.CAD.tw. } \\
\text { 26.or/17-25 } \\
\text { 27.and/16,26 } \\
\text { 28.exp Echocardiography/ } \\
\text { 29.echocardiogr } \$ . t w . ~\end{array}$ \\
\hline
\end{tabular}


30.echo.tw

31.Dipyridamole/du [Diagnostic Use]

32.Dobutamine/du [Diagnostic Use]

33.Adenosine/du [Diagnostic Use]

34.Imaging, Three Dimensional/

35.exp Tomography, Emission-Computed/

36.exp Tomography, X-ray Computed/

37.SPECT.tw.

38. Thallium Radioisotopes/du [Diagnostic Use]

39. Nucleosides/

40.Technetium Tc 99m Sestamibi/du [Diagnostic Use]

41.((sestamibi or cardiolite or dipyridamole or persantin) adj3 (scan\$ or stud\$)).tw.

42.(thallium adj3 (scan\$ or stud\$)).tw.

43.electron beam tomograph\$.tw.

44.EBT.tw.

45.(comput\$ adj2 tomograph\$).tw.

46.ct scan\$.tw.

47.cat scan\$.tw.

48. Magnetic Resonance Imaging/

49. Magnetic Resonance Angiography/

50.Diffusion Magnetic Resonance Imaging/

51.Echo-Planar Imaging/

52.(echo-planar or echoplanar).tw.

53. Coronary Angiography/

54.Angiography/

55.MRI.tw.

56. magnetic resonance.tw.

57.MRA.tw.

58.angiogr\$.tw.

59.coronary catheteri?ation.tw.

60. (CA or CC).tw.

61.(Fluoroscopy/ or fluoroscopy.tw.) and (Angiography, Digital Subtraction/ or Subtraction Technique/ or digital subtraction.tw.)

62.exp Troponin/du [Diagnostic Use]

63.calcium scor\$.tw.

64.Clinical Enzyme Tests/

65.cardiac enzyme\$.tw.

66.exp Perfusion Imaging/

67.perfusion imaging.tw.

68. perfusion stud\$.tw.

69.perfusion scintigra\$.tw.

70.Exercise Test/

71.Radionuclide Ventriculography/

72.Physical Exertion/

73.stress test $\$$.tw.

74.exercise.tw.

75.ventriculogra\$.tw.

76.treadmill.tw.

77.bicycle.tw.

78.Risk Assessment/

79.risk stratification.tw. 


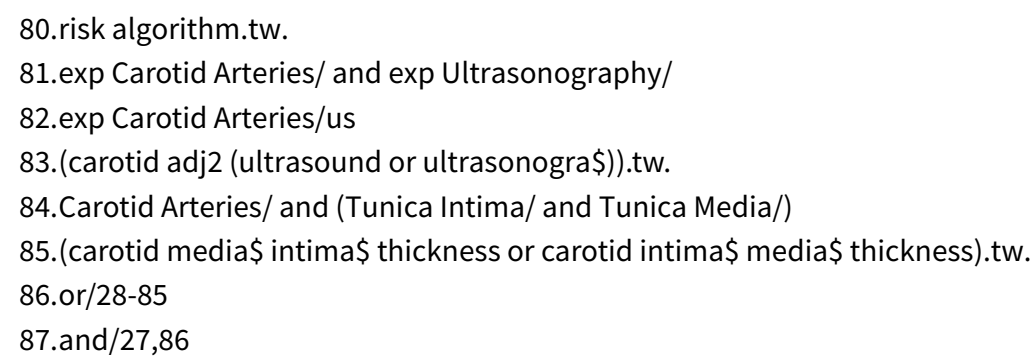

\section{EMBASE}

1. exp Kidney Transplantation/

2. Kidney Failure/

3. Chronic Kidney Failure/

4. Chronic Kidney Disease/

5. (kidney and pancreas and (transplant $\$$ or graft $\$)) . t w$.

6. (chronic kidney or chronic renal).tw.

7. (endstage kidney or endstage renal).tw.

8. (end stage kidney or end stage renal).tw.

9. (ESRD or ESKD or ESRF or ESKF).tw.

10.exp Renal Replacement Therapy/

11.dialysis.tw.

12.(hemodialysis or haemodialysis).tw.

13. (hemofilt\$ or haemofilt\$).tw.

14.(hemodiafilt\$ or haemodiafilt).tw.

15.(PD or CAPD or CCPD or APD).tw.

16.or/1-15

17. Heart Disease/

18.Cardiovascular Disease/

19.Coronary Artery Disease/

20.Coronary Artery Atherosclerosis/

21.Coronary Artery Obstruction/

22.(coronary arter\$ adj5 stenosis).tw.

23.coronary atheroscleros $\$ . t w$.

24.coronary arterioscleros\$.tw.

25.(coronary adj5 disease).tw.

26.CAD.tw.

27.or/17-26

28.Angiography/

29.exp Cardiography/

30.exp Computer Assisted Tomography/

31.Arteriography/

32.exp Heart Function Test/

33.Xeroradiography/

34.Tomography/

35.exp Emission Tomography/

36. Magnetic Resonance Angiography/

37.Nuclear Magnetic Resonance Imaging/

38. Radiography/

39. Contrast Radiography/

40.Radioisotope Diagnosis/

41.(Fluoroscopy/ or fluoroscopy.tw.) and (Digital Subtraction Angiography/ or digital subtraction.tw.)

42.exp Heart Scintiscanning/ 


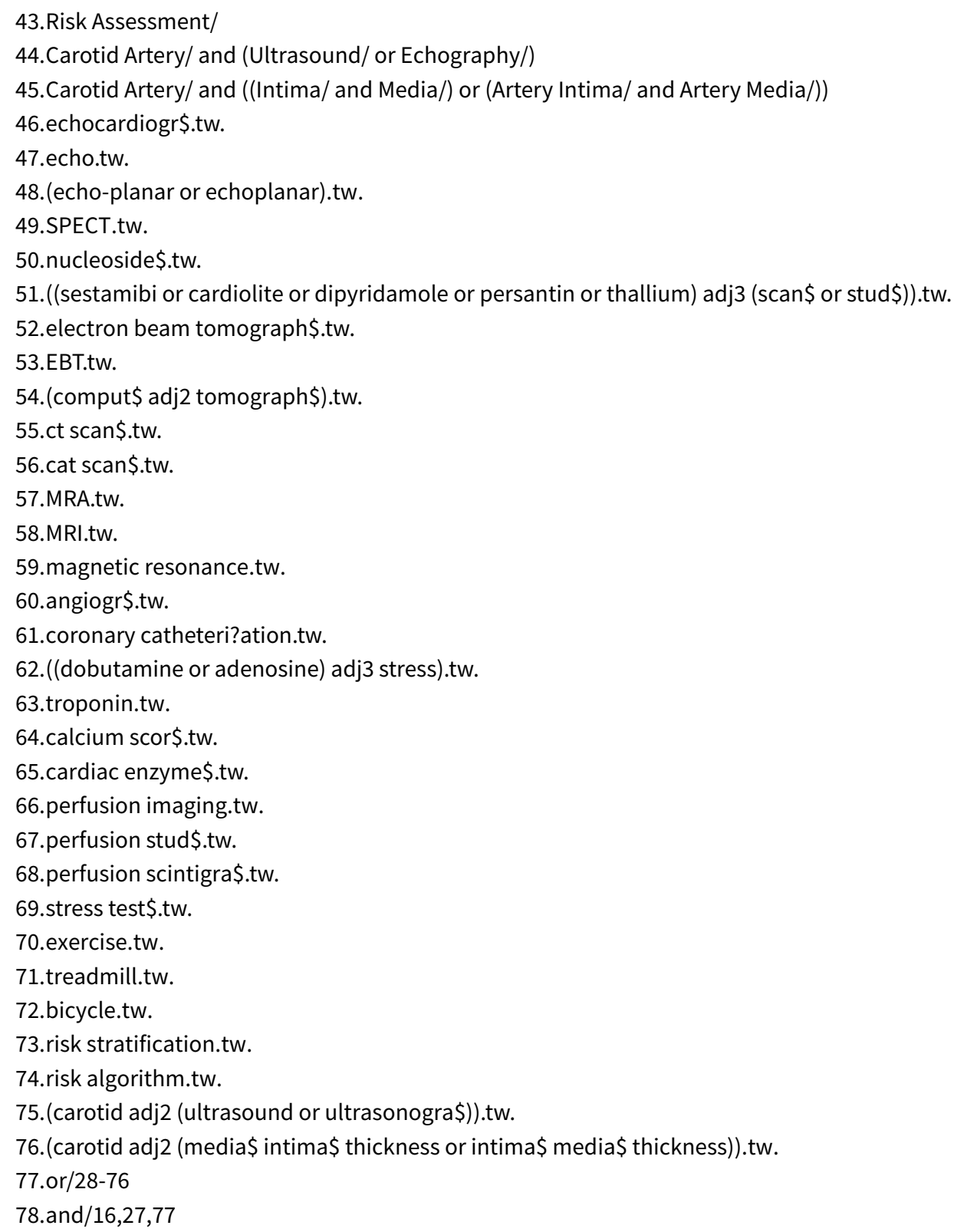

\section{Appendix 2. QUADAS methodological items and operational definitions}

\begin{tabular}{ll}
\hline Methodological variable & Operational definition/information required from each study \\
\hline $\begin{array}{l}\text { 1. Representative spectrum } \\
\text { (spectrum bias) }\end{array}$ & $\begin{array}{l}\text { When included patients did not represent the intended targeted population, this may have led to } \\
\text { an under- or overestimation of diagnostic accuracy depending on the difference between the tar- } \\
\text { geted and included populations. The target spectrum in our review was patients with renal failure } \\
\text { who were candidates for kidney transplantation. This was scored 'yes' if study participants includ- } \\
\text { ed only patients with kidney disease who were considered to be candidates for kidney transplanta- } \\
\text { tion }\end{array}$
\end{tabular}


(Continued)
2. Acceptable reference stan- dard
An imperfect reference standard may have resulted in misclassification of disease positives and disease negatives. For the purpose of this review, studies had an acceptable reference standard if they used coronary angiography as the reference standard

\begin{abstract}
3. Acceptable delay between tests (disease progression bias)
\end{abstract}

Disease may have progressed to a more advanced stage (i.e. greater degree of coronary artery stenosis) if a significant time interval between index and reference tests was observed, thereby leading to disease progression bias. This was scored as 'yes' if the delay between test was short (i.e. less than three months)
Partial verification bias usually leads to an overestimation of sensitivity, although its effect on specificity varies. This item was scored 'yes' if all patients who received the index test were also evaluated by the reference standard
4. Partial verification avoided (verification bias)
This was scored 'yes' if no patients were verified with a second or third reference standard

\section{Differential verification avoided}

6. Incorporation avoided (incorporation bias)
This bias usually leads to an overestimation of diagnostic test accuracy. Incorporation bias was deemed to have existed if the index test was incorporated in a composite reference standard. Studies were scored 'yes' if their classification of disease status did not directly involve the results of the index test

\section{Reference standard results blinded (information bias)}

When the reference standard was interpreted knowing the index test results, this may have led to the overestimation of diagnostic test accuracy. Studies were scored 'yes' if blinding of the reference standard was explicitly stated in the article or if this was acknowledged by authors in subsequent personal communication. Otherwise, the studies were marked 'unclear', unless blinding was explicitly stated to be absent

\section{Index test results blinded (information bias)}

When the index test results were interpreted without the knowledge of results of the reference standard, or with more information than in practice, this may have resulted in bias, usually leading to an overestimation of diagnostic accuracy. This item was scored 'yes' if blinding of the index test was explicitly stated in the article or if this was acknowledged by authors in subsequent personal communication. Otherwise, the studies were marked 'unclear', unless blinding was explicitly stated to be absent
The availability of clinical data during interpretation of test results may have affected estimates of test performance. This item was scored 'yes' if the data available during the study of diagnostic test accuracy was the same as that which would have been available in normal clinical practice

\section{Relevant clinical informa- tion (information bias)}

10. Uninterpretable results explained
This item was scored 'yes' if uninterpretable results were explained or if there were no uninterpretable results present. This item was scored 'no' if uninterpretable results were found but not explained

11. Withdrawals explained

Excluding patients from the study may have led to an overestimation of diagnostic accuracy. This item was scored 'yes' if withdrawals were explained or if there were no withdrawals from the study. This item was scored 'no' if there were withdrawals from the study, but these were unexplained

\section{CONTRIBUTIONS OFAUTHORS}

- Louis W Wang: Designed and co-ordinated the review, collected data, undertook searches, screened search results, organised study retrieval, screened retrieved studies against inclusion criteria, appraised study quality, extracted data, corresponded with study authors to obtain additional information, data management, entry, analysis and interpretation, review writing.

- Angela C Webster: Designed and co-ordinated the review, corresponded with study authors to obtain additional information, analysed and interpreted data, review writing, provided general advice on the review, performed previous work that was the foundation of the current study, provided methodological and clinical perspectives (transplant physician).

- Magid A Fahim: Data collection, undertook searches, screened search results, screened retrieved studies against inclusion criteria, appraised study quality, data extraction.

- Ruth Mitchell: Designed search strategies, undertook searches. 
- Andrew Hayen: Designed the statistical methodology, analysed and interpreted data.

- Laura Baines: Performed previous research that formed the foundation of the current review, provided a clinical perspective (nephrology).

- Stephen Lord: Performed previous research that formed the foundation of the current review, provided a clinical perspective (cardiology).

- Jonathan C Craig: Provided methodological and clinical perspectives, and general advice on the review.

\section{DECLARATIONS OF INTEREST}

- Laura Baines: None known

- Jonathan C Craig: None known

- Magid A Fahim: None known

- Andrew Hayen: None known

- Stephen Lord: None Known

- Ruth L Mitchell: During the time I have been an author on this review my salary has been supported through a grant from the Cochrane Collaboration for work on the Cochrane register of diagnostic test accuracy studies.

- Louis W Wang: None known.

- Angela C Webster: None known

\section{SOURCES OF SUPPORT}

\section{Internal sources}

- No sources of support supplied

\section{External sources}

- Jacquot Research Establishment Award, administered by the Royal Australasian College of Physicians and the Australian and New Zealand Society of Nephrology, Australia.

- Australian National Health and Medical Research Council Program (Grant Number 402764), Australia.

\section{DIFFERENCES BETWEEN PROTOCOL AND REVIEW}

Sparsity of data, both in terms of numbers of studies and participants, meant that we were unable to perform meaningful subgroup analyses of the effect of DM or prevalence of angina and symptomatic ischaemic heart disease on diagnostic test performance.

\section{NOTES}

An earlier version of this review was published in the American Journal of Kidney Diseases (Wang 2011).

\section{INDEX TERMS}

\section{Medical Subject Headings (MeSH)}

*Kidney Transplantation; Coronary Angiography [ ${ }^{\star}$ standards]; Coronary Artery Disease [ ${ }^{\star}$ diagnosis] [etiology]; Heart Function Tests [*methods] [standards]; Kidney Failure, Chronic [ ${ }^{\star}$ complications]; Pancreas Transplantation; Reference Standards

\section{MeSH check words}

Humans 